\title{
A Study of Nikolai Kapustin's Sonata No. 12, Op. 102: A Contemporary Jazz Sonata In Two Movements
}

\author{
Mark Peters
}

Follow this and additional works at: https://researchrepository.wvu.edu/etd

\section{Recommended Citation}

Peters, Mark, "A Study of Nikolai Kapustin's Sonata No. 12, Op. 102: A Contemporary Jazz Sonata In Two Movements" (2017). Graduate Theses, Dissertations, and Problem Reports. 7117.

https://researchrepository.wvu.edu/etd/7117

This Dissertation is protected by copyright and/or related rights. It has been brought to you by the The Research Repository @ WVU with permission from the rights-holder(s). You are free to use this Dissertation in any way that is permitted by the copyright and related rights legislation that applies to your use. For other uses you must obtain permission from the rights-holder(s) directly, unless additional rights are indicated by a Creative Commons license in the record and/ or on the work itself. This Dissertation has been accepted for inclusion in WVU Graduate Theses, Dissertations, and Problem Reports collection by an authorized administrator of The Research Repository @ WVU.

For more information, please contact researchrepository@mail.wvu.edu. 
A Study of Nikolai Kapustin's Sonata No. 12, Op. 102:

A Contemporary Jazz Sonata In Two Movements

\author{
Mark Peters
}

\title{
A Doctoral Research Project submitted to the College of Creative Arts at West Virginia University
}

in partial fulfillment of the requirements for the degree of

\author{
Doctoral of Musical Arts in \\ Piano Performance
}

\author{
James Miltenberger, D.M.A., Committee Chair, Research Advisor \\ Peter Amstutz, D.M.A. \\ William Haller, D.M.A. \\ Keith Jackson, D.M.A. \\ Thomas Sloane, Ph.D.
}

School of Music

Morgantown, West Virginia 2017

Keywords: Nikolai Kapustin, Piano Sonata, twentieth century piano, jazz piano Copyright 2017 Mark Peters 


\begin{abstract}
A Study of Nikolai Kapustin's Sonata No. 12, Op. 102:

A Contemporary Jazz Sonata in Two Movements
\end{abstract}

Mark Peters

Nikolai Girshevich Kapustin emerged as a musical figure during the latter part of the $20^{\text {th }}$ century. Kapustin's virtuosic piano ability (trained in the traditional Russian school of technique) and fascination for American jazz music equally contributed to his unique compositional style. Despite an early interest in jazz, he continued his traditional studies as a concert pianist. In the face of resistance from the Russian government, jazz continued to gain traction throughout the middle of the twentieth century.

Inspired by the styles and harmonic colors that defined jazz, Kapustin decided to merge his knowledge of Classical piano with his admiration for this new musical language. His style predominantly focuses on melding classical forms with jazz stylistic and harmonic languages. Aside from his traditional classical inspirations, jazz legends such as Art Tatum, Oscar Peterson, as well as Bill Evans are among Kapustin's strongest influences.

His popularity has grown quite substantially during the early $21^{\text {st }}$ Century and his output of work is quite prolific. His works include compositional forms such as prelude and etude, as well as twenty piano sonatas and a number of concerto-style works that sound nearly identical to Big Band music.

The purpose of this dissertation is to analyze the use of Sonata form within a contemporary setting. Performance practice suggestions, as well as pedagogical concerns, regarding Sonata No. 12 will be provided to aid aspiring artists and students with methods to navigate the work effectively.

New research surfaces each year concerning the life and music of Nikolai Girshevich Kapustin. Hopefully this document will inspire new students to both attempt and master the challenging music of this great composer. 


\section{Acknowledgments}

I would like to thank my piano teachers who believed in my abilities through each challenge along the way. Dr. Julie Bees and Dr. Andrew Trechak of Wichita State University helped facilitate my early technique and musical direction, while Dr. Peter Amstutz of West Virginia University recognized my abilities and connected me with Dr. James Miltenberger.

The entirety of this degree would not have been possible without Dr. James Miltenberger, my piano professor, head of my Doctoral committee, as well as research advisor. Between technical piano knowledge and an amazing proficiency of piano literature, Miltenberger always provided suggestions or advice for any musical situation. Thanks Doc!

My Doctoral committee members have been very supportive as well throughout this process. Dr. Amstutz, Dr. Haller, Dr. Jackson, and Dr. Sloane- I would like to thank each of you for your patience, guidance, and flexibility during this degree.

Additionally I would like to thank Yana Tyulkova and her brother Kirill. Yana, a friend of Nikolai Kapustin, clarified many concepts concerning the music and history of Kapustin, while her brother Kirill has assisted me in recording a number of my Doctoral recitals. Thank you both for being so helpful!

No youngest-brother would be complete without the role-models of his siblings. Scott, Todd, Brent- thank each of you for helping me believe in my abilities and supporting my efforts throughout the years.

I would especially like to thank my parents, Dr. Thomas and Elaine Peters, for all of the support and love they provided me throughout this endeavor. Though my mother is unable to see me finish this chapter in life, her confidence and unending dedication continue to be the greatest factors to my success. 


\section{Table of Contents}

Acknowledgments $\ldots \ldots \ldots \ldots \ldots \ldots \ldots \ldots \ldots \ldots \ldots \ldots \ldots \ldots \ldots \ldots \ldots \ldots \ldots \ldots \ldots$

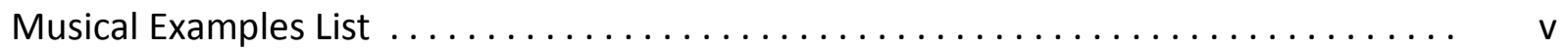

Charts List $\ldots \ldots \ldots \ldots \ldots \ldots \ldots \ldots \ldots \ldots \ldots \ldots \ldots \ldots \ldots \ldots \ldots \ldots \ldots \ldots \ldots \ldots$

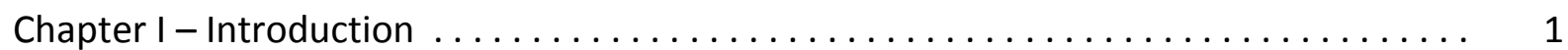

Chapter II - Review of Literature / Biography $\ldots \ldots \ldots \ldots \ldots \ldots \ldots \ldots \ldots \ldots \ldots$

Chapter III - Analysis of Piano Sonata No. 12, Opus $102 \ldots \ldots \ldots \ldots \ldots \ldots \ldots \ldots$

Chapter IV - Stylistic and Pedagogical Observances $\ldots \ldots \ldots \ldots \ldots \ldots \ldots \ldots \ldots \ldots$

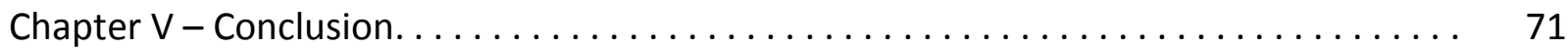

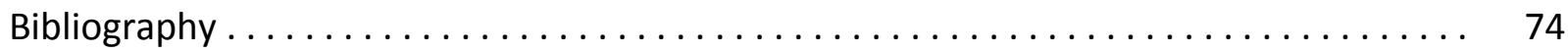

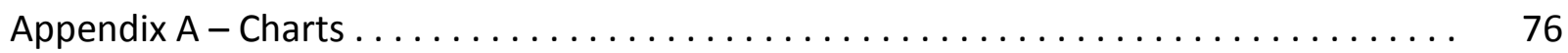

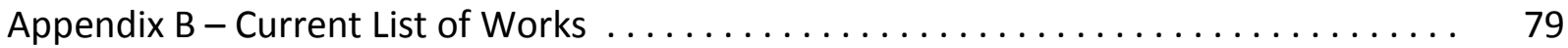




\section{Musical Examples Reference List}

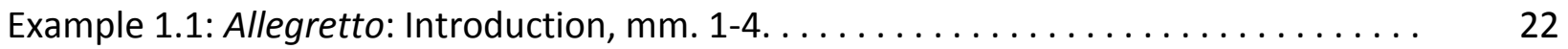

Example 1.2: Allegretto, Introduction - 'blues motive' first appearance, (mm 5-6) . . . . 23

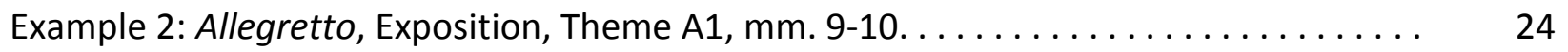

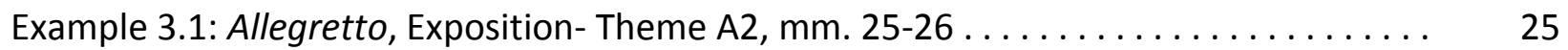

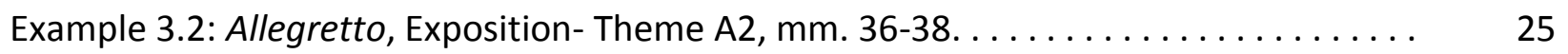

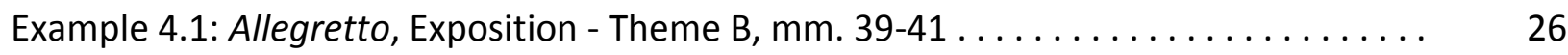

Example 4.2: Allegretto, Exposition- Theme B, 'blues motive'- inverted, mm. 63-66 . . . 27

Example 5.1: Allegretto, Development- Theme B into Development, mm. 68-78 . . . . 28

Example 5.2: Allegretto, Development - Theme A1 in soprano, mm. 81-82 . . . . . 28

Example 5.3: Development, Rhythmically varied Theme B, mm. 105-106 . . . . . . 29

Example 6: Allegretto, Recapitulation, Theme A1, Golden section, mm. 111-116 . . . . 30

Example 7: Allegretto, Recapitulation, Theme B, presented in tonic, mm. 137-139 . . . . 31

Example 8: Allegretto, Coda, Theme A1, mm. 169-176 ............... 33

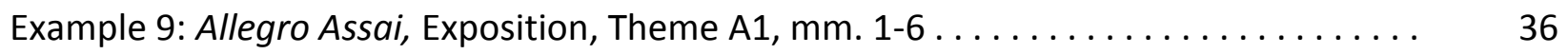

Example 10: Allegro Assai, Exposition- Theme A2, 12-note 'bass motive,' mm. 19-24 . . . 37

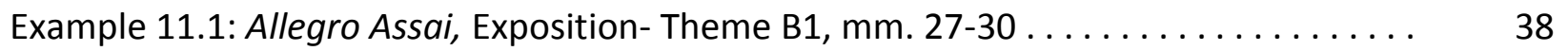

Example 11.2: "Together (Wherever We Go)," melodic comparison with Theme B1 . . . 38

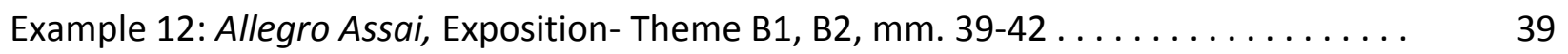

Example 13.1: Allegro Assai, Exposition- B2, Closing Theme, mm. 56-66 . . . . . . . 40

Example 13.2: Allegro Assai, Exposition- Closing Theme, Development, mm. 82-87 . . . 42

Example 14.1: Allegro Assai, Development, walking bass, mm. 91-96 . . . . . . . . 43 
Example 14.2: Allegro Assai, Development Theme B1, A1, mm. 103-108 . . . . . . 43

Example 15: Allegro Assai, Development, Theme B1, Golden section, mm. 121-130 . . . 45

Example 16: Allegro Assai, Recapitulation, Theme A, mm. 135-140 . . . . . . . . 46

Example 17: Allegro Assai, Recapitulation, Theme B1, mm. 162-169. . . . . . . . . 48

Example 18: Allegro Assai, Recapitulation, Closing Theme, mm. 196-201. . . . . . . 49

Example 19.1: Allegro Assai, Coda, new thematic component, mm. 206-207. . . . . . 50

Example 19.2: Allegro Assai, Coda, Theme A1/B1, mm. 217-219 . . . . . . . . . . 50

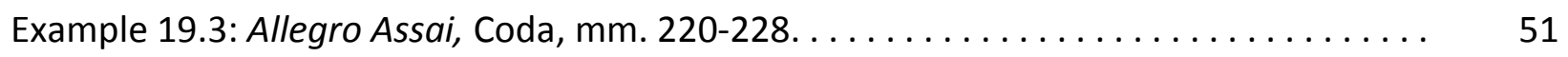

Example 20: Allegretto, Exposition, Theme A1, straight and swung 'blues motive' .... 54

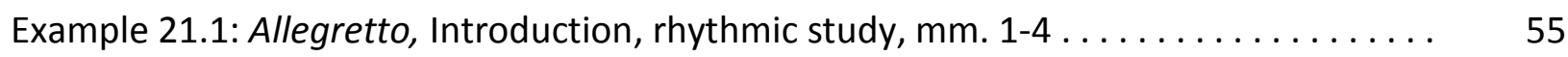

Example 21.2: Allegretto, Exposition, Theme B, rhythmic study, mm. 39-41 ...... 56

Example 21.3: Allegro Assai, Exposition, advanced syncopation, mm. $23-25 \ldots \ldots \ldots$

Example 21.4: Allegro Assai, Recapitulation, advanced syncopation, mm. 135-142 _... 57

Example 22.1: Allegretto, Introduction, pedal as tie, $\mathrm{mm} .3-4 \ldots \ldots \ldots \ldots \ldots$

Example 22.2: Allegretto, Introduction, pedal as tie in both hands, mm. 17-18 ..... 59

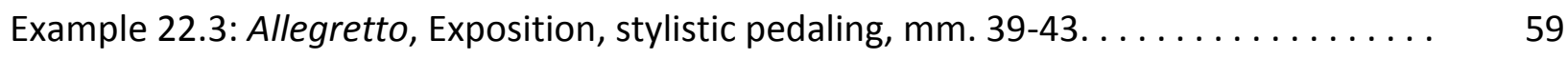

Example 22.4: Allegro Assai, Exposition, pedaling with motives, mm. 15-16 . . . . . 60

Example 22.5: Allegro Assai, Exposition, pedaling with accents, mm. 64-66 ....... 61

Example 23: Allegretto, Introduction/Recapitulation, chord voicings, mm. 4, $142 \ldots \ldots 62$

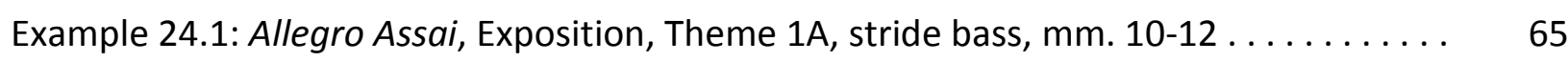

Example 24.2: Allegro Assai, Exposition, left-hand fingering, $\mathrm{mm} .64 \ldots \ldots \ldots \ldots$

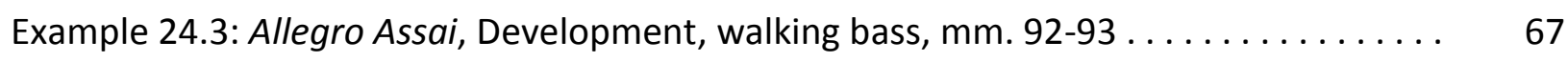




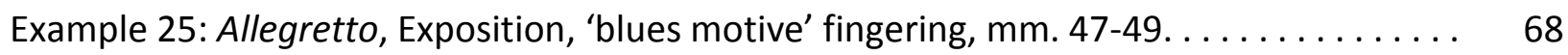

Example 26.1: Allegro Assai, Development, published error, mm. 117. . . . . . . . 69

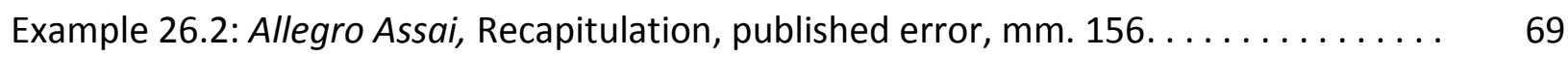

Example 26.3: Allegro Assai, Recapitulation, published error, mm. 203. . . . . . . . 70 


\section{Charts List}

Chart 1: Sonata form- I. Allegretto, Opus 102- Thematic Outline $\ldots \ldots \ldots \ldots \ldots \ldots \ldots$

Chart 2: Sonata form- II. Allegro Assai, Opus 102- Thematic Outline . . . . . . . . . . 34, 77

Chart 3: Root-less Dominant Chord voicing in all keys $\ldots \ldots \ldots \ldots \ldots \ldots \ldots \ldots$. 78 


\section{Chapter One}

\section{Introduction}

Nikolai Girshevich Kapustin emerged as a musical figure during the latter part of the $20^{\text {th }}$ century. Kapustin's virtuosic piano ability (trained in the traditional Russian school of technique) and fascination for American jazz music equally contributed to his unique compositional style. Despite an early interest in jazz, he continued his traditional studies as a concert pianist. In the face of resistance from the Russian government, jazz continued to gain traction throughout the middle of the twentieth century. Inspired by the styles and harmonic colors that defined jazz, Kapustin decided to merge his knowledge of classical piano with his admiration for this new musical language. His style predominantly focuses on melding classical forms with jazz stylistic and harmonic languages. Aside from his traditional classical inspirations, jazz legends such as Art Tatum, Oscar Peterson, as well as Bill Evans are among Kapustin's strongest influences. His prolific output of music (over 150 works) gained significant popularity during the early $21^{\text {st }}$ century. His works include classical forms such as sonata, prelude, and etude in addition to several concerto-style works that sound nearly identical to Big Band music. The purpose of this dissertation is to analyze the use of sonata form within a contemporary style while providing aspiring pianists with stylistically focused performance practice and pedagogical suggestions for Nikolai Kapustin's Sonata No. 12, Opus 102.

Chapter two of this document will discuss some available resources as well as biographical information regarding the life of Nikolai Kapustin. Twenty years ago, this information remained elusive to those in the United States and much of Europe; however 
Kapustin's popularity continues to grow as more musicians discover his music, resulting in more of his musical output being published.

Chapter three presents an analysis regarding the use of Sonata form throughout Opus 102. Kapustin's intricate use of jazz rhythms, harmonies, and styles superimposed onto largescale classical structures combine to create the composer's unique aesthetic, producing a very convincing fusion of the two worlds- Opus 102 is no exception. The formal analysis will focus on the use of sonata form in each movement as well as discuss the use of cyclic elements as a unifying factor. Since neither movement is inherently tonal, harmonic analysis is less effective and therefore a look at Kapustin's brief use of tonal centers will provide additional clues regarding the structure of each movement.

Chapter four presents some of the idiomatic jazz language throughout the work. Through identifying common trends, a classically trained pianist can gain a stronger stylistic understanding of the work becoming more adept with sudden style changes as well gaining perspective on how to approach the work aurally. For instance, Kapustin's rhythm is often scored very specifically; however the question whether to swing notes, or not, is often left up to the performer (Kapustin chooses not to specify in most cases). Additionally, this chapter will present pedagogical concerns as well as performance suggestions for both movements of Opus 102. The paper concludes with Chapter five, reviewing the most important ideas about Kapustin and Piano Sonata No. 12, Opus 102.

Though Opus 102 is approximately twelve to fifteen minutes in duration and spans only two movements, the published score is 40 pages long. Kapustin has a particular fondness for 
this sonata and remains one of his favorites. ${ }^{1}$ After working extensively on the work, it is apparent why he has grown to adore Opus 102. The unity of the work is quite profound when one considers that the lyricism of the first movement presents such great contrast to the aggressive nature of the second movement, yet somehow retains a strong underlying thematic cohesiveness. It is the hope of the author that this paper will help others to decipher and appreciate the complex music of Nikolai Kapustin!

\footnotetext{
${ }^{1}$ Tyulkova, Yana, "Classical and Jazz Influences in the Music of Nikolai Kapustin: Piano Sonata No. 3, Op. 55." (D.M.A diss., West Virginia University, 2015), 34.
} 


\section{Chapter Two}

\section{Review of Current Literature and Biography}

\section{REVIEW OF LITERATURE}

The following information is a basic review of the majority of literature concerning Kapustin currently available in English. There are additional sources available, though some are in Russian and not necessarily easily translated via online translators. Thankfully, after Kapustin's journey to London in the early 2000's, a few interviews via translator were conducted and the English speaking population began to get a glimpse at the life and music of Nikolai Kapustin.

\section{Online Sources}

Grove Music Online provides a few articles surrounding the topic of Kapustin, Sonata, as well as "Third Stream." 2 This online resource provides a basic historical perspective concerning the composer, as well as an understanding of the topics relevant to his style of composition, a jazz-classical union.

Pianosociety.com hosts an article by Chris Breemer and represents an early source containing just a few paragraphs about the music and life of Kapustin as of 2007. Breemer also has uploaded a number of recordings as performed by himself and other artists. Though the recordings are mostly smaller works such as concert etudes, there is also a recording of the second movement of Kapustin's Sixth Piano Sonata, Opus 62. The site contains a forum section where Kapustin's music is gaining popularity as well.

\footnotetext{
2 "Third Stream" is a term used to describe the mixture of classical and jazz musical elements.(Oxford Music Online)
} 
The Wikipedia article on Kapustin (en.wikipedia.org/wiki/Nikolai_Kapustin) provides similar, yet more extensive historical information about Kapustin than the above listed article from pianosociety.com. Additionally, a list of compositions can be found following a link at the bottom of the Kapustin Wikipedia page.

Nikolai-kapustin.info provides one of the closest access points for the general public to Nikolai Kapustin. Moderated by a man named Wim de Haan of the Netherlands, the site is authorized by Kapustin and has his full support. The historical info is the most up to date of the three websites listed here and also has musical manuscript scores for sale. The score used for examples during this research project comes from manuscript obtained from this website. There are audio recordings from each of his released CDs (not available worldwide) in addition to LPs and video recordings. The most appealing factor about several of these recordings is that Kapustin himself is shown on video, playing his music. The sheer output of recordings and scores makes this site the best online resource currently available for direct access to his music.

\section{Dissertations/Theses}

Jiwon Choi's dissertation on Kapustin, entitled An Eclectic Combination of Classical and Jazz Idioms: Nikolai Kapustin's Piano Works was published in 2015 and contains a research document divided into three main areas: biographical information, Kapustin's unique style and influences, and an analysis of how Kapustin blends classical and jazz styles found within his set of 24 Preludes, Opus 53 (complete with performance suggestions). The second section contains a discussion of idiomatic and stylistic jazz figures for the piano, including stride bass, quartal 
harmony, as well as dense textures. Each stylistic feature is paired with examples of which jazz pianists utilized and developed such techniques (Art Tatum, Oscar Peterson -Stride Bass and dense textures, Bill Evans, McCoy Tyner - Quartal Harmony). The final section guides the reader through the use of such techniques throughout Opus 53, ending with performance tips. The document as a whole is invaluable to this study as it clearly depicts each style and its major influences.

Jonathan Edward Mann, son of American musicologist Alfred Mann, published a paper in 2007 entitled Red, White and Blue Notes: The Symbiotic Music of Nikolai Kapustin. This represents one of the earliest dissertations dealing with Kapustin published in the West. Although Mann was unable to access much of Kapustin's music at the time, the author provides an early insight into the style exemplified by Kapustin's music. Being one of the pioneers, Mann attempts to identify Kapustin's music as classical, jazz, or crossover (Third Stream). The opening provides historical information as well as discusses elements that could help identify this music as third stream. Although Kapustin's music avoids improvisation entirely, the harmonic language and use of syncopation and notated swing rhythms provide the effect that many jazz styles produce. He then states that Kapustin's music has a driving quality (like that of the toccata), and swing is often either notated in triplets, or written in text. He claims that some passages could sound great swung but the tempo dictated is too fast for swing to have a proper sound. This is also the case in Sonata No. 12, Opus 102. There are a few moments where swing is utilized (through rhythmic notation) or can be utilized by the performer for style purposes. Alternatively, there are places in the music that would sound interesting stylistically to have 
swing, but the tempo is much too fast for the style to sound correct, specifically the fast blues sections that occur during the second movement.

Mann also discusses major influences upon Kapustin's style being most notably Oscar Peterson (as well as Art Tatum), with a quote from Kapustin stating, "He's No. 1 for me."3

Finally, Mann provides three different types of analysis of Kapustin's works: a look at classical form and jazz harmony in Sonatina, Op. 100; a harmonic anaylsis of Prelude No. 9 in E Major, Op. 53; and a formal analysis of Fugue No. 1 in C Major, Op. 82.

Jonathan E. Roberts Classical Jazz: The Life and Musical Innovations of Nikolai Kapustin, published in 2013, presents a Doctoral study in three parts. It begins with a historical overview of classical-jazz fusion and how Kapustin's music differs from traditional "third stream." Second, Roberts presents a fairly current historical document concerning the life and musical growth of Kapustin. The document concludes with an analysis of the classical and jazz elements in two of Kapustin's works - Sonata No. 2, Op. 54 and Prelude and Fugue Op 82, No. 10. Most notably concerning "crossover" works, Roberts, via emails with Kapustin, states that Kapustin does not like the term "crossover" since it implies that a composer willingly blended two styles (most commonly jazz/classical). Kapustin cannot see his style existing without both elements being interdependent. He remains "equally grounded in both worlds."

The analysis of Sonata No. 2, Op. 54 focuses on the blending of classical and jazz styles. Sonata No. 2, Op. 54 combines a fairly clear sonata structure with jazz idiomatic language such

\footnotetext{
3 Harriet Smith, “Bridging the Divide: The Russian Composer Nikolai Kapustin," International Piano Quarterly 4, no.13 (Autumn 2000): 55.

4 Jonathan E. Roberts, "Classical Jazz: The Life and Musical Innovations of Nikolai Kapustin." University of Alabama, Ann Arbor, 2013, 10.
} 
as altered dominant harmonies, highly syncopated rhythms, as well as an interchangeable major/minor third (blues note). All of these elements are also present in Sonata No. 12, Op. 102.

Yana Tyulkova's Classical and Jazz Influences in the Music of Nikolai Kapustin: Piano Sonata No. 3, Op. 55, published in 2015 , is one of the more recent dissertations concerning the music of Nikolai Kapustin. Similar to other dissertations, the work begins with historical and biographical information regarding the life of Kapustin, continues with a segment on stylistic influences, and concludes with an analysis of one of his works (Sonata No. 3, Op. 55). However, since Tyulkova also speaks Russian, she was able to correspond directly with Kapustin on several occasions. Her perspective remains invaluable due to her first-hand knowledge of Kapustin. Of notable importance to this study, Tyulkova's discussion of the twenty sonatas provides a broad overview of this large output of works. Finally, her analysis of Sonata No. 3, Op. 55, provides insight into how Kapustin's larger scale works fit into the classical mold of sonata form.

\section{Periodicals}

Martin Anderson's “Nikolai Kapustin, Russian Composer of Classical Jazz," from Fanfare: The Magazine for Serious Record Collectors, published in September of 2000, presents one of the first English articles discussing the life of Nikolai Kapustin. The interview was conducted via translator in London. Kapustin had traveled in 2000 to Blackheath Concert Halls in London to hear his Piano Sonata No. 2, Opus 54 performed by Marc-André Hamelin. The interview details Kapustin's upbringing in the Ukraine and his travels to Moscow Conservatory to study when he 
was a young teenager. By his early twenties, Kapustin, now a virtuoso pianist, felt the need to study and play jazz, which would grow to become core to his very musical identity. Performing in big band settings, such as the Oleg Lundström Jazz Orchestra, provided Kapustin with an outlet to perform his early large-scale band pieces (Piano Concerto No.1, Op. 2), though he admitted that due to its length, the orchestra only performed it a total of five times. It is also in this article that Kapustin admits that since his music was not improvisatory, he eluded much of the controversy throughout the Soviet Union during the latter part of the $20^{\text {th }}$ century.

Bayley Lynn René's “Fusion: Music for a New Age," presents a CD review from Fanfare: The Magazine for Serious Record Collectors, in which the author simply states, "(Richard) Steinbach also does a very nice job with two of Nikolai Kapustin's Preludes in Jazz Style."5 Though not much is written about Kapustin directly, the recording contains music of Kapustin and music of Chick Corea, The author then gives Corea's Children's Songs a less than formidable review, stating they do not sound very youthful. He also states they are not in the jazz style of Corea, but rather in a Neoclassical style (with a hint of Minimalism). Regardless, seeing these two different styles scored together on a single recording not only speaks of Kapustin's growing popularity, but also that performers are not afraid to score it alongside some of the more experimental jazz artists of today. The article is quite recent, published last year in 2016.

Alan Becker's "24 Preludes in Jazz Style" from American Record Guide (January/February 2011), provides a favorable review of the "24 Preludes in Jazz Style." Alan Becker gives a brief history of the composer and the work- written in the 1980s and just recently exposed to the

\footnotetext{
${ }^{5}$ Lynn René Bayley, "FUSION: Music for a New Age," Fanfare: The Magazine for Serious Record Collectors 39, no. 3 (January/February 2016): 527-528.
} 
West. The recording he refers to is Boheme 7149 and was originally recorded on the record label Russian Melodiya in 1989.

Jonathan Bellman's, "Guide to Records: KAPUSTIN," provides a review of Stephen Osborne's Hyperion label 67159, entitled Kapustin: Piano Pieces. The recording includes the first two piano sonatas as well as thirteen of the "24 Preludes in Jazz Style." Bellman provides a brief history of Kapustin and his music while praising Osborne's interpretations and his mastery of idiomatic jazz elements throughout the recording. Bellman considers Kapustin to be a descendent in style to Gershwin and Bernstein, however he feels Kapustin's command of styles such as blues show more influence from jazz and the likes of Oscar Peterson.

An online publication MusicWeb International published an article by Leslie De'Ath, entitled "Nikolai Kapustin- a Performer's Perspective" in June 2002. This article provides historical information, as well as description of the virtuosic blend of classical and jazz that exemplifies Kapustin's style. She cites two of the earliest periodicals dealing with Kapustin, both of which are listed here (Martin Anderson's “Nikolai Kapustin, Russian Composer of Classical Jazz," in Fanfare, as well as Harriet Smith's, "Bridging the Divide: The Russian Composer Nikolai Kapustin" from International Piano Quarterly.

Harriet Smith, via translator, provides one of the first accounts of the life of Kapustin in English in her article "Bridging the Divide: The Russian Composer Nikolai Kapustin," appearing in International Piano Quarterly in Autumn of 2000. Smith describes Kapustin as reserved and somewhat shy, which is complemented by the fact that he really possesses no desire to achieve formidable fame. He composes in his unique style to develop his craft and share his music with the world; fame has never been the focus. The article continues by discussing the classical 
influences of Chopin (preludes), Bach (preludes and fugues), as well as his major jazz influences of Oscar Peterson and Art Tatum. It is from this article that many dissertations quote Kapustin's greatest jazz influence being Oscar Peterson - "He's No. 1 for me." ${ }^{\prime 6}$ The correlation between Peterson and Tatum has been widely accepted for years, so stating that both directly influenced Kapustin is the only natural conclusion.

\section{Biography}

Nikolai Grigorievich Kapustin was born on the $22^{\text {nd }}$ of November, 1937, to parents Grigory Efimovich Kapustin and Klavdia Nikolaevna Kapustina, in Gorvolka, Ukraine. Fira Kapustin, Nikolai's older sister, was born six years earlier in 1931. Their parents, without any musical knowledge or training, desired both of their children to become aspiring musicians. Fira studied the violin, though ultimately became a chemist, while Kapustin desired to master the piano. ${ }^{7}$ In fact, when Nikolai was just seven years old, it was Fira's violin teacher Piotr Ivanovich Vinnichenko who discovered Nikolai's aptitude for the piano, noting that he could play two of Clementi's Op. 36 Sonatinas. Without any formal training, armed with some basic theory training from his mother and sister, Nikolai displayed a strong talent for piano. Vinnichenko decided to help nurture this young talent and began to teach young Nikolai as well. ${ }^{8} \mathrm{Just}$ a few years later, in 1949, Vinnichenko, primarily trained as a violinist, decided to take Nikolai to the St. Petersburg Conservatory to meet Lubov' Frantsuzova, his first "real" piano teacher.

Frantsuzova was a graduate of St Petersburg Conservatory and pupil of the well-known Russian

\footnotetext{
${ }^{6}$ Smith, 54.

${ }^{7}$ Roberts, 15.

${ }^{8}$ Roberts, 15.
} 
educator, Samuel Maykapar. ${ }^{9}$ At this point, Kapustin began to experiment with composition at the piano and decided he wanted to commit himself to music. "I was always fond of learning everything myself (for instance, composing)... but playing piano turned out too hard for selfeducation..."10 Apparently, to Kapustin, composition seemed more achievable without formal guidance than learning the technique of the piano.

The standard process for music education in Ukraine and Russia consists of three major stages: seven years of study at Music School, four years of study at Music College, and five years of study at a Music Conservatory. Through training with Ivannovich, but mostly due to the assistance of Frantsuzova, Kapustin bypassed a number of years required at the Music School stage. Instead, Kapustin was prepped directly for the entrance exam to the Academic Moscow College under the Moscow State Tchaikovsky Conservatory. ${ }^{11}$ Kapustin notes that Frantsuzova's lessons focused less on technique and more on musicality. ${ }^{12}$

After only three years preparation with a serious piano teacher, Kapustin worked on pieces such as Beethoven's Rondo in C Major and "Pathétique" Sonata, Mozart's C Major Sonata (K. 545), as well as Grieg's Op. 3, Poetic Tone-Pictures. It was also during this time that Kapustin wrote his first piano sonata, in "traditional Russian-Ukrainian style." ${ }^{13}$ When Kapustin finally auditioned for the Music College in 1952, he travelled to Moscow with his first teacher Ivannovich, performing such works as: J. S. Bach's Prelude and Fugue in B-flat Major (Book I),

\footnotetext{
9 Jonathan Mann, "Red, White and Blue Notes: The Symbiotic Music of Nikolai Kapustin," University of Cincinnati, 2007, 28.

10 Roberts, 16.

11 Yana Tyulkova, "Classical and Jazz Influences in the Music of Nikolai Kapustin: Piano Sonata No. 3, Op. 55." West Virginia University, Morgantown, 2015, 11.

12 Roberts, 16.

13 Ibid, 16.
} 
Mendelssohn's G Minor Piano Concerto and Rondo Capriccioso, as well as Rachmaninoff's Csharp Minor Prelude and Rimsky Korsakov's “Flight of the Bumblebee." He was immediately accepted into the class of Avrelian Grigoryevich Rubakh, a mentor that Kapustin regarded as one of his greatest early influences. ${ }^{14}$

Rubakh studied with Felix Blumenfield, teacher of Vladimir Horowitz, Simone Barere, and Alexander Tsfasman. Tsfasman would prove to be a prominent jazz pianist in Russia during the 1940 's. Interestingly enough, all four of these pianists were born in Ukraine. ${ }^{15}$ At the time of Kapustin's entry to Rubakh's tutelage, Rubakh was not as impressed by Kapustin's pianism, but rather his ability to compose and improvise. Thus, Rubakh supported Kapustin's later interests in jazz. The years Kapustin spent with Rubakh were the most prolific years of Kapustin's student life. He admits that, "He [Rubakh] taught me how to play the piano."16

When Joseph Vissarionovich Stalin died on March $5^{\text {th }}, 1953$, many of the restrictions imposed by his desire to conform and control the nation slowly subsided. In the early 1950's, prior to Stalin's death, nearly everything that represented capitalism was prohibited, including jazz music. Even the music of Rachmaninoff and the writings of Dostoyevsky were also prohibited. The music of conformists such as Shostakovich, though not restricted, was labeled "terrible" music. ${ }^{17}$ Although jazz remained prohibited, a growing interest in jazz as a symbol of freedom had been instilled in the people of Russia.

\footnotetext{
14 Tyulkova, 11-12.

15 lbid, 11.

16 Ibid, 13.

${ }^{17}$ Mann, 28.
} 
During this time, Kapustin's interest in jazz would begin to develop, though his studies would draw his focus toward classical music. While attending college, Kapustin befriended Andrei Mikhalkov-Konchalovsky, son of Sergei Mikhalkov, famous poet, author, and dramatist. ${ }^{18}$ Nikolai and Andrei studied music together at Music College, and Kapustin would ultimately be invited to stay with Andrei's family due to poor living conditions at the college. Kapustin initially stayed at a hostel with an allowance from his parents. After arriving as a guest at the Mikhalkov's home, Kapustin was exposed to some of the most prominent artists from Moscow. Here in the Mikhalkov's home, Kapustin first heard and developed an appetite for jazz. Kapustin states, "I was living in their house for a few years like an adopted son. That's how we first started to become interested in jazz music, listening at night to the radio station "Voice of America."'"19

Kapustin reminisces, "At first my friends and I could hear jazz only on the radio. I do not remember which jazz artist I heard first. It could be Glenn Miller or Louis Armstrong." 20 Kapustin felt an urge to integrate jazz music into his musical composition. He states, “I didn't like performing; composition was more interesting... And as soon as I started playing jazz I understood it was something for me. I understood that I had to combine the two musics-I had that idea from my youth." ${ }^{21}$ Kapustin's initial training in jazz existed through recordings he made of American jazz broadcasts from "Voice of America."

\footnotetext{
18 Tyulkova, 13.

19 Ibid,

${ }^{20}$ Mann, 28.

21 Martin, Anderson, "Nikolai Kapustin, Russian Composer of Classical Jazz," Fanfare: The Magazine for Serious Record Collectors 24 (September 2000): 94.
} 
During the four years that Kapustin studied with Rubakh, Kapustin claimed to have studied so intensely that he was nearly as strong a player as his mentor: "For four years I studied so hard that I feel I was at the same level [as Rubakh], so these four years were critical for me. It was he who took me to Goldenweiser. I played him the Liszt "Don Giovanni Fantasy"; he liked how I played and asked Rubakh, 'Where did you find such a pianist'?"22

Kapustin's audition for Alexander Goldenweiser took place in 1956, and Kapustin was immediately granted entry to the school, under guidance of Goldenweiser. Despite Goldenweiser's prominent pedigree, Kapustin stated that he offered very little as a piano teacher at age 81; however, he had studied alongside some of the great composers of the $20^{\text {th }}$ century, such as Sergei Rachmaninoff, Alexander Scriabin and Nikolai Medtner. Kapustin recalls, "Yes, I felt like they were alive, as if they were here. He told me what they said, how things happened-things you will never read in books about these composers. That was the main interest." ${ }^{23}$ Goldenweiser, a legendary pianist in his own right, was considered one of the greatest pedagogues of the USSR and possibly even the world. He studied with a cousin of Rachmaninoff, Alexander Ziloti, as well as Paul Pabst, Arensky, Ippolitov-Ivanov, and Taneyev. He also taught Feinburg, Ginzburg, and Kabalevsky ${ }^{24}$

The post-Stalin thaw brought about new cultural trends, including the incorporation of jazz as a form of popular musical expression. In 1957, the Russian government included jazz in the Sixth World Youth Festival in Moscow in an attempt to restore relations following the political turmoil created by Stalin. Over 30,000 youth and young adults traveled to Moscow to

\footnotetext{
22 Anderson, 94.

23 Ibid.

${ }^{24}$ Smith, 54.
} 
compete and perform. Juri Saulsky was ordered by the government to bring together Russia's best jazz musicians to perform traditional Soviet songs as well as selections by Stan Kenton and Duke Ellington. ${ }^{25}$ The band, with Kapustin as pianist, won first prize, but were criticized by the government for promoting shameful morals, which clearly displayed their hesitance following Stalin's reign.

Two noteworthy developments occurred during this event. Kapustin began writing for the band (orchestra) in his unique style. In fact, during the festival his Concertino for Piano and Orchestra, Op. 1, was performed by the band. ${ }^{26}$ This work, as with many of his early chamber works, resembles a very bright sounding big band style. Kapustin describes the work as "a very jazzy piece." ${ }^{27}$ In addition to performing his own work with Saulsky's band, Kapustin formed a jazz quintet with a few other members of the band who improvised quite proficiently.

Eventually this band would be recorded at the restaurant 'National' by a member of the American Embassy. This recording would eventually be broadcast during Willis Conover's "Voice of America." Kapustin humbly admits, "It was nice to hear our names announced by W Conover himself." 28

Despite difficulties while attempting to learn jazz alongside his classical studies, Kapustin graduated from Moscow Conservatory in 1961. Due to his fascination with composition and jazz, he chose not follow the path of concert pianist. During his time in the Mikhalkov home, Kapustin met a man named Oleg Lundström. While studying at the conservatory, Lundström

\footnotetext{
${ }^{25}$ Mann, 31.

${ }^{26} \mathrm{lbid}$.

${ }^{27}$ Smith, 54.

${ }^{28}$ Mann, 31.
} 
allowed Kapustin to work as the pianist in the orchestra. After graduating, Kapustin decided to join Lundström's Big Band. Kapustin's role in the ensemble often included orchestrating the pieces they would be performing, thus giving him the perfect outlet to learn and develop his skill in orchestration and part writing. For eleven years, 1961-1972, Kapustin considered his time with the band as his "Second Conservatory." ${ }^{29}$ Using recordings, Kapustin transcribed each part while orchestrating them for the band.

While touring with Lundström in the late 1960's, Nikolai met his wife-to-be at a café in Novokuznetsk, Siberia, and invited her to his performance. In 1969, he married Anna Baranovskaya. Early in the 1970's she gave birth to their two sons, Anton and Pavel. Faced with the decision to tour with the Lundström band or help his wife raise their two boys, Kapustin decided to leave Lundström's band in $1972 .{ }^{30}$ From this point, Kapustin joined the Boris Karamishev "Blue Screen" Orchestra, following advice from his musician friends. The Moscow ensemble primarily focused on live broadcast through television or radio; however, they also toured and recorded a considerable amount of Soviet composers' works, including Kapustin's. Soon after, Kapustin worked for the State Symphonic Orchestra of Cinematography from 1977 to 1984 , where he recorded cinema music, predominantly as a means of producing a steady wage. $^{31}$

In 1983, the first published work of Kapustin, Toccatina, Op. 36, was distributed by publisher Music Publishing House. From the year 1984 until 2007, Kapustin recorded solo albums, but generally avoided public performance as composition remained his primary focus.

\footnotetext{
29 Tyulkova, 17.

30 Ibid, 18.

${ }^{31}$ Tyulkova, 19.
} 
He admits, "I don't like to play on stage, but I do like to record." ${ }^{32}$ Through recording, publishing, and compositional commissions, along with the aid of two Ministries of Culture, Kapustin has supported himself financially, allowing him to focus primarily on his composition. ${ }^{33}$ As Kapustin gained confidence in his compositional craft, he gravitated toward the large-scale solo piano works. He composed ten of his twenty sonatas from 1984 to 1999 as his focus drifted away from piano-focused ensemble works. ${ }^{34}$

In May of the year 2000, Kapustin and his wife Alla journeyed by train to hear the Western premier of his Piano Sonata No. 2, Op. 54 by modern virtuoso, Marc-André Hamelin. The work received excellent reviews as Hamelin produced a masterful performance. Kapustin also met with "Kapustin's Piano Society" while in England, an avid group of supporters organized by Jan Hoare. Ultimately, the weekend culminated in interviews between Kapustin and a few journalists, including Martin Anderson of Fanfare and Harriet Smith of International Piano Quarterly. From these interviews, the history of Nikolai Kapustin's life finally became available in English and accessible to the West. Following his trip to England, Kapustin wrote Piano Sonata No. 11, Op. 101, dedicating it to London with the name "Twickenham," a borough in south-west London. ${ }^{35}$ Piano Sonata No. 12, Op 102, was composed in 2001, also following Kapustin's venture to London. ${ }^{36}$

The last fifteen years have seen quite prolific compositional output. Kapustin composed another ten sonatas after returning from London (beginning with Sonata No. 11), with a total of

\footnotetext{
${ }^{32}$ Anderson, 97.

33 Roberts, 23.

34 Tyulkova, 19.

35 Ibid, 20.

36 Ibid, 34.
} 
twenty in all. Though much of his later output is solo piano, he has composed many chamber and orchestral works as well. His piano and chamber music were both well received at his $70^{\text {th }}$ birthday recital at Gnesina College in Moscow in December of 2007. The works performed included Elegy for Cello and Piano, Op. 96, as well as Trio for Flute, Cello, and Piano, Op. 86. The second half of the concert contained orchestral works including Concerto No. 2 for Cello and String Orchestra, Op. 103. All of the cello parts were performed by Alexander Zagorinsky, a cellist Kapustin collaborated with previously in $2002 .^{37}$

Currently living in a flat in Moscow with his wife Alla, Kapustin continues to compose. Only leaving Moscow to travel to their summer home during the warmer months, Kapustin has no desire to cease writing music. His self-isolating lifestyle has provided the perfect workshop to tune his craft. Although he admits writing grows more difficult with age, Kapustin admits he has no intention to stop composing music. ${ }^{38}$

$37 \mathrm{Ibid}, 20$.

${ }^{38} \mathrm{Ibid}, 21$. 


\section{Chapter Three}

\section{Analysis of Piano Sonata No. 12, Opus 102}

The sonata genre represents a crucial portion of pianists' repertoire. Whether one studies the sonatas of Domenico Scarlatti, Ludwig van Beethoven, or Alexander Scriabin, formal structures exist throughout each sonata that help to define the work while simultaneously representing the form or genre. As the sonata evolves through concepts such as thematic transformation and cyclic unity, composers frequently revisit this genre throughout the twentieth century, expanding the concept of form and genre while adapting to fresh harmonic colors. Nikolai Kapustin's sonatas prove representative of the modern sonata, exhibiting strong coordination of formal sonata structures. Kapustin's fascination with jazz styles and harmonies present a complex synthesis of the two musical worlds. His sonatas are quite complex, yet highly unified, as can be seen in Sonata No. 12, Op. 102. This chapter will guide the reader through a formal analysis of Opus 102.

The elements of sonata style appear at first in isolation. It is easy to attach too much importance to these isolated appearances. An articulated recapitulation has none of the meaning it will have for sonata style when it has not been preceded by an articulated exposition that demands resolution. ${ }^{39}$

Though the above quote from Charles Rosen's Sonata Forms deals with earlier appearances of sonata form, the concept remains relevant to Kapustin's Piano Sonata No. 12. Opus 102 presents a highly unified sonata form in two movements. Not only are the major components of sonata form present (Exposition, Development, Recapitulation), but the use of

${ }^{39}$ Charles Rosen, Sonata Forms, (New York: W.W. Norton, 1980), 131. 
pentatonic scales from which much of the thematic material is derived, also occurs in both movements. This is the only sonata of Kapustin's twenty that contains only two movements. ${ }^{40}$

Sonata Form within Opus 102, I. Allegretto

\begin{tabular}{|c|c|c|c|}
\hline Section & Measures & $\begin{array}{l}\text { Number of } \\
\text { Measures }\end{array}$ & Key Area/Root \\
\hline Exposition & $1-72$ & 72 & \\
\hline Introduction & $1-8$ & 8 & A-Minor \\
\hline Theme A1 & $9-24$ & 16 & A-Minor \\
\hline Theme A2 & $25-38$ & 14 & C-Major/G \\
\hline Theme B & $39-72$ & 34 & C-Major/Dominant \\
\hline Development & 73-110 & 38 & \\
\hline Recapitulation & 111-168 & 58 & \\
\hline Theme A1 & $111-123$ & 11 & A-Major \\
\hline Theme A2 & 124-136 & 13 & G-Major/D \\
\hline Theme B & $137-168$ & 32 & A-Minor \\
\hline Coda (Theme A1) & $169-180$ & 12 & A-Minor \\
\hline
\end{tabular}

Chart 1: Note that the key areas listed above are the harmonic area in which each section begins. The music of Kapustin is often highly chromatic with moments of harmonic clarity.

Kapustin's Piano Sonata No. 12, Opus 102, is twelve to fifteen minutes in length, presented in two movements. The first movement, an Allegretto, is in the style of an

\footnotetext{
${ }^{40}$ Tyulkova, 34.
} 
improvisatory fantasy. It exemplifies Kapustin's mature style, exhibiting mastery of the jazz harmonic language, while clearly adhering to the modern sonata form.

The Introduction contains three distinct components outlining the thematic content for the first theme group of the movement. The opening motive is broken into two halves during the first four measures, ascending and descending an A-minor pentatonic scale $(A, C, D, E, G)$, beginning on the note $E$, in call-and-response style (Example 1.1). ${ }^{41}$ The call motive is presented predominantly in straight eighth-notes, while the response motive is swung in triplets.

Additionally, measures five and six contain a blues-style version of this theme, unbroken, that is expressed in many different variations throughout the movement(referred to later as 'blues motive'). This thematic component ('blues motive') unifies the entire movement, appearing in nearly every thematic group. The first presentation occurs as eighth notes ( $\mathrm{mm}$. 5-6). If one ignores the final resolution note, the motive is exactly twelve notes. Since the motive resolves differently at times, the twelve-note motive is an association that Kapustin very well intended.

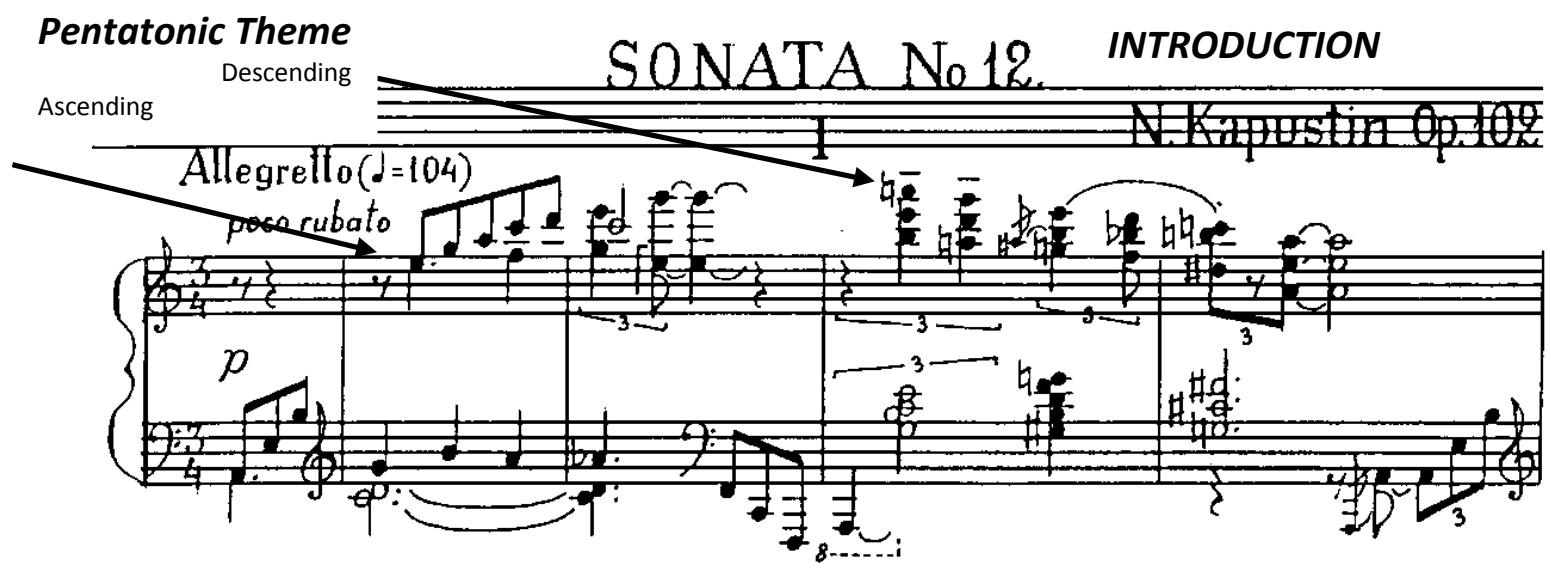

Example 1.1: Allegretto: Introduction, $\mathrm{mm}$. 1-4

\footnotetext{
${ }^{41}$ Score Examples, unless otherwise noted, are from the manuscript edition of Sonata No. 12 Op. 102.
} 
The descending portion of the introductory pentatonic idea becomes Theme A1 of the Exposition, continuing the use of triplets in a swing style. The ascending scale, mostly presented in straight eighths, sets up the harmonic atmosphere (call), while the descending pattern (response) presented in swung triplets, represents the first major theme that will be manipulated and altered throughout Theme A1. The 'blues motive' begins similarly to measure one, but is unbroken at the top, returning downward immediately and utilizing the Eb bluesnote during the triplet (Example 1.2).

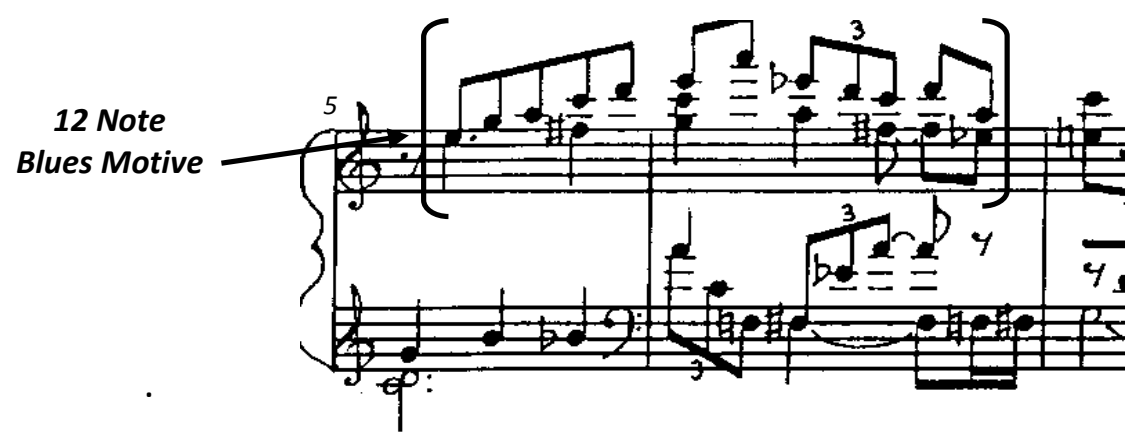

Example 1.2: Allegretto, Introduction - 'blues motive' first appearance, (mm. 5-6)

The opening theme returns in the Exposition, beginning with the descending A-minor pentatonic theme (m. 9). The harmonic language is complex, using quartal and altereddominant harmonies (Example 2). This type of harmonic language presents a mixture of styles, including Bill Evans' quartally harmonized melodies, as well as Alexander Scriabin's use of dominant sonorities presented as stable entities - like the 'mystic' chord).

Theme A1 (mm. 9-24) evolves directly from the introductory thematic components. Rather than begin the first theme group with the ascending motive (call), Kapustin cleverly uses the descending swing component of the Introduction ( $\mathrm{mm} .3-4)$ to open the main body of the work. The descending component occurs four times during Theme A1 before a pivotal Eb 
altered-dominant chord (m. 16) propels the music towards a thinner texture for the rest of Theme A1.
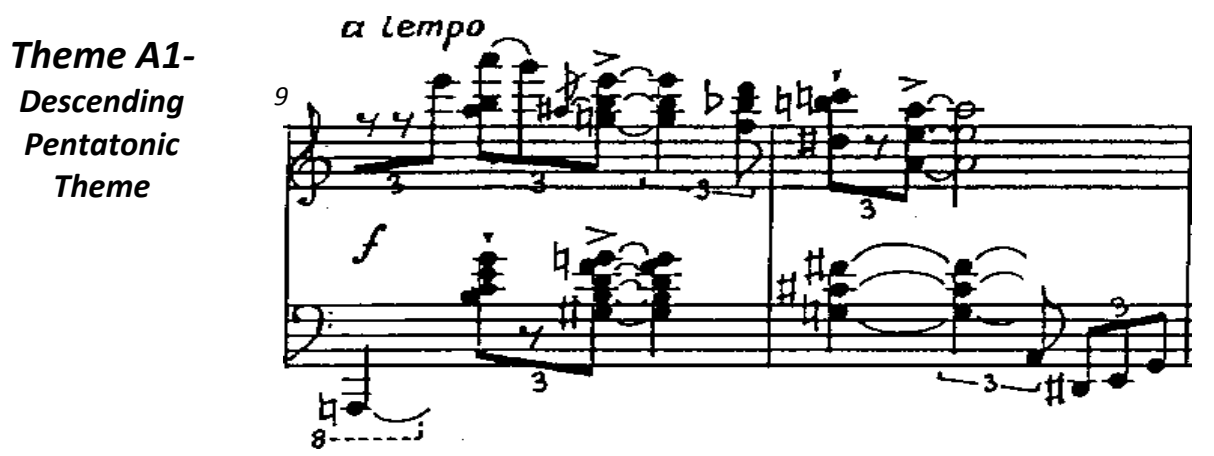

Example 2: Allegretto, Exposition, Theme A1 - from descending portion of the Introduction, mm. 9-10

From this point (mm. 16-24), Kapustin utilizes the first three components of the Introduction in a more lyrical fashion, before pressing on towards Theme A2 (m. 25). The "blues motive' appears both in Theme $\mathrm{A} 1$ and Theme $\mathrm{A} 2$, first in measures $21-23$, and again in measures 29-30, appearing as sixteenth notes for the first time (diminution). Unlike the introduction, both of these motives occur in E-Minor.

The ii-V-I harmonic progression is the foundation of traditional jazz harmonic language. As jazz became more complex, the alteration of the dominant chord became crucial to the exotic sounds musicians expressed. Beginning in measure seventeen, Kapustin introduces Theme A2, which initially appears and sounds like the key of C Major over a G pedal, a tonic 6/4 chord or potentially Mixolydian (Example 3.1). Harmonically, Theme A2 quickly devolves, utilizing a series of ii-V-I chord progressions in multiple keys, directing the listener towards a final ii-V half cadence in C Major (Example 3.2). This half cadence moves the sonata toward the key of Theme B, C Major. It is important to note that Kapustin's transition into Theme B truly elides with the end of Theme A2, and therefore will not be separated in this analysis. Kapustin 
uses an F\# to $\mathrm{G}$ resolution (part of the ii-V half cadence) in order to generate the content for his next thematic group (mm. 36-38).

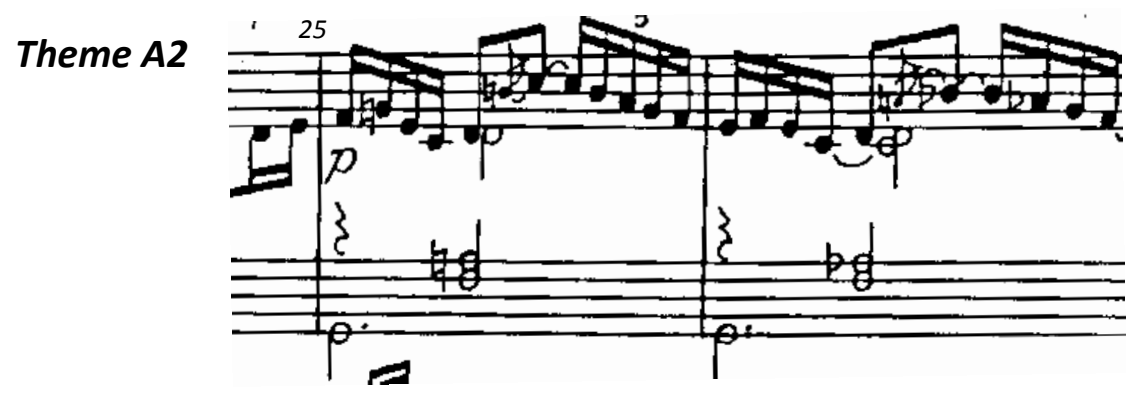

Example 3.1: Allegretto, Exposition- Theme A2 (C-Major / G), mm. 25-26

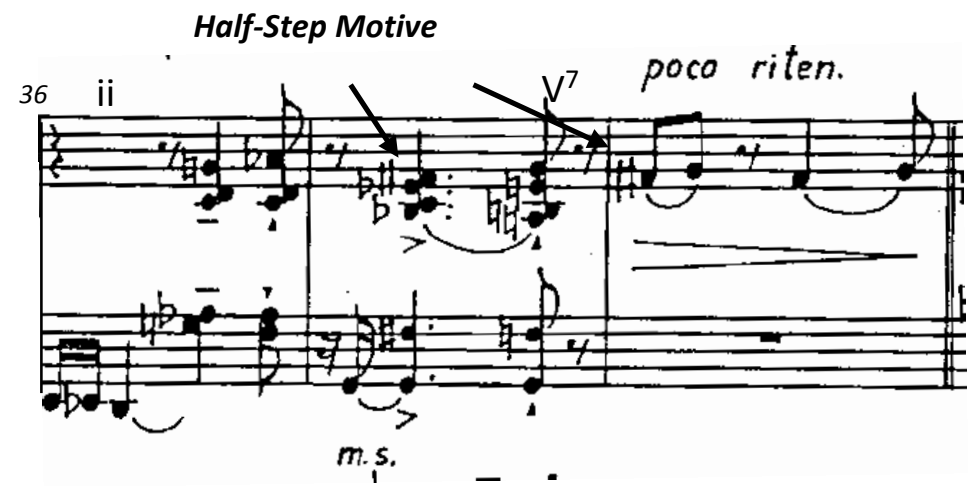

Example 3.2: Allegretto, Exposition- Theme A2 - half cadence in C; half-step motive established, mm. 36-38

Theme B (measures 39-72) blends multiple styles to create a strong polarity from the lyrical opening. The entire theme presents heavy use of pentatonic scales, the 'blue note,' altered dominants, and chromatic harmonic voice-leading. The style sounds like a mix between blues and a jazz waltz with interludes of jazz-style blues solo licks. The theme centers with a C dominant chord as can be seen in the example below (m. 39). The half step that Kapustin had previously accentuated at the end of Theme A2 now becomes the focal point of Theme $B$. In terms of rhythm, Kapustin uses a triplet followed by two successive upbeats (Example 4.1). The organization of rhythm, combined with irregular articulation, produces a very unique sense of rhythmic movement. Thematically speaking, the entire section is presented in order to 
showcase the 'blues motive' from the introduction. The 'blues motive' is most clear during measures 47-48, but Kapustin continues with the style of that motive $k$ to create measures 4954. Unlike the Introduction, the 'blues motive' is now presented only in E Minor, while an appearance in the tonic of A-Minor will not occur again until the Recapitulation.

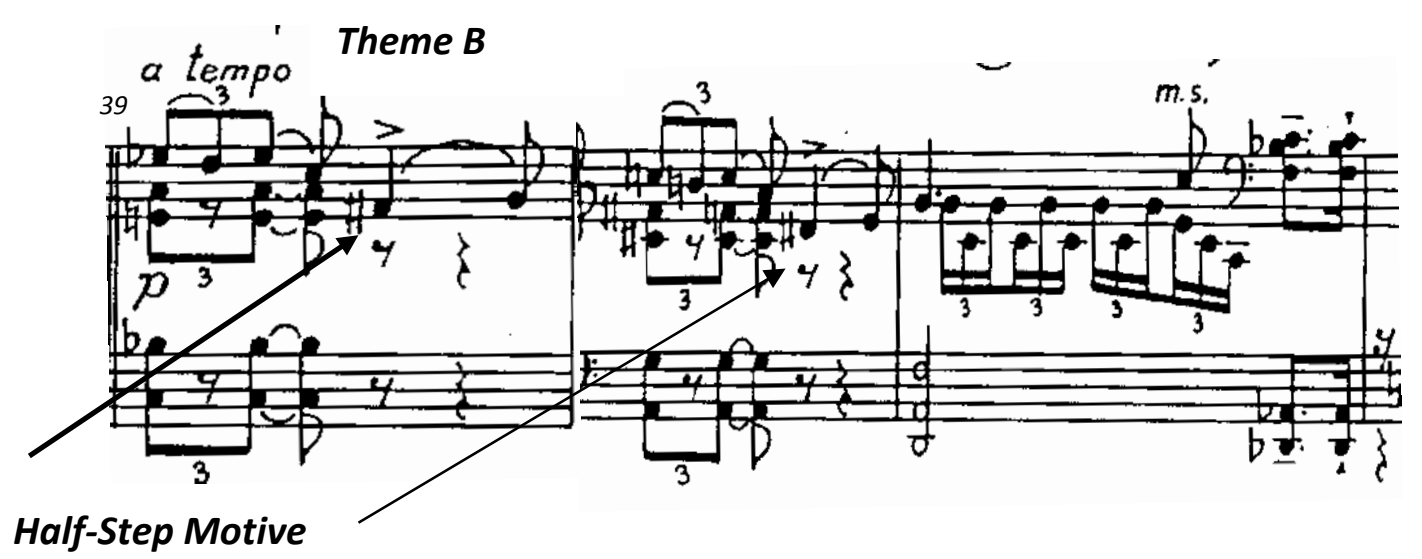

Example 4.1: Allegretto, Exposition - Theme B, mm. 39-41

Measures 54-55 and measures 59-60 present a blues-style solo improvisation replacing the repeat of the opening motive from Theme $\mathrm{B}$. The largest clue to the performer that the thematic material has not shifted is the use of the successive upbeats to end every second measure, mirroring Kapustin's treatment of this motive at the entrance of Theme B. At measure 63 , the first inversion of the 'blues motive' is used to help close out the section. The inversion is played high on the keyboard and is appears in G Major- the relative major to Theme $1 A^{\prime} s$ version (Example 4.2). Immediately after, Kapustin presents the original version of the 'blues motive' in the key of E-minor, very low on the piano. This juxtaposition of original motive and its inversion will appear in both the Exposition as well as the Recapitulation but will always be associated with Theme B. Measures 68-72 utilize the half-step relation Kapustin has drawn so 
much attention to already in this sonata in order to move the work forward into the Development without introducing any completely new thematic ideas.

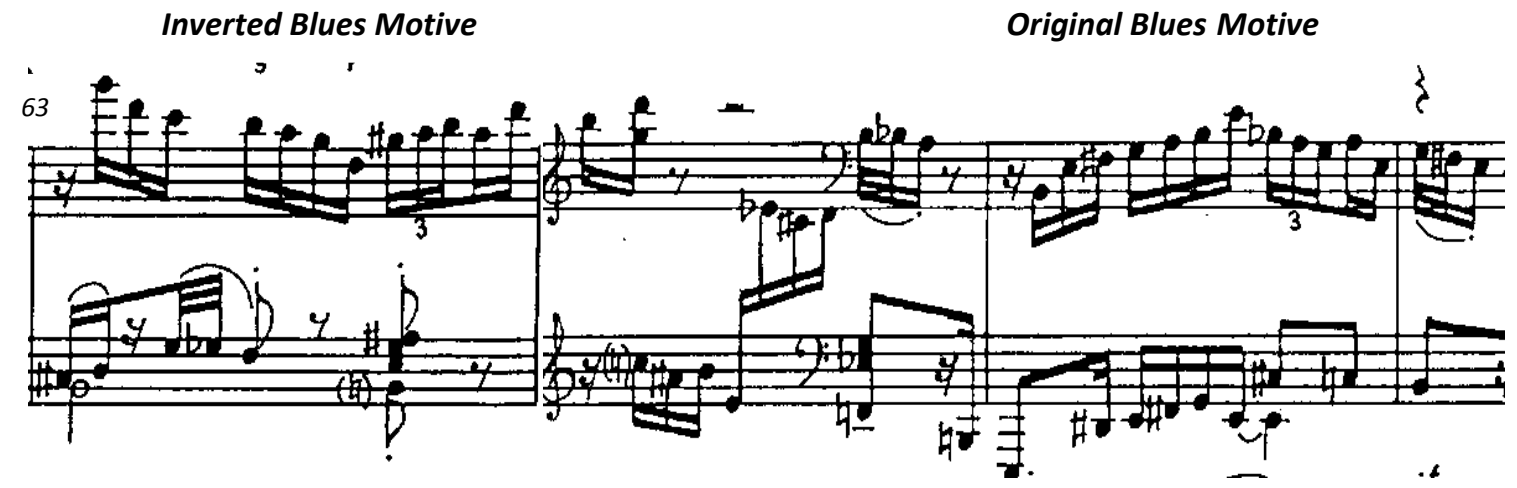

Example 4.2: Allegretto, Exposition- Theme B, 'blues motive'- inverted then original motive, mm 63-66

The Development (mm. 73-110) represents an introspective style of Kapustin. The harmonic language is quite dark, centering around A flat as a root for the first few measures (mm. 73-75). The A-flat is resolved down to $G$ through a series of dense, chromatically voiced chords. The effect is quite dark and solemn. The half-step motive from the Theme B continues until measure 79 (Example 5.1), where a quick, highly chromatic, chord progression moves the piece back to the key of A-minor through an E Dominant $7^{\text {th }}$ chord (m. 80). 
Half-Step Motive

DEVELOPMENT

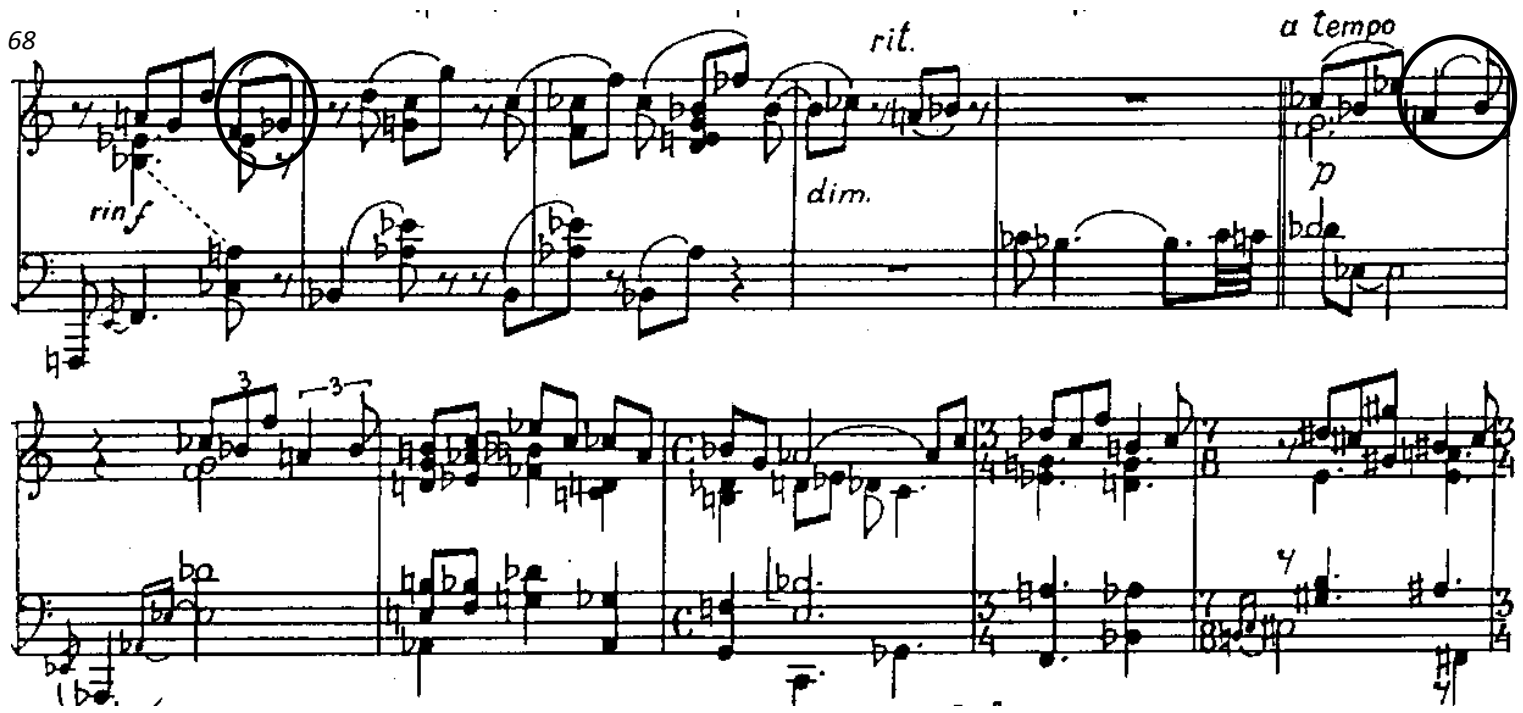

Example 5.1: Allegretto, Development- Theme B into Development, mm. 68-78

From measure 81 until 88, Kapustin focuses on an A Minor sonority with altered upper extensions. Theme A1's descending pentatonic component is placed above in the soprano voice during this section (Example 5.2) The first major eruption of energy during the Development occurs during measures 90-96, where Opus 102 has seemingly unrelated material presented in the Development. However, the style and demeanor of this brief outburst resemble some of the aggressive elements found in Theme $B$. The progressive nature of the bass line $(A b->B b)$ produces the effect of forward movement, while the harmony briefly returns to blues-oriented sonorities.

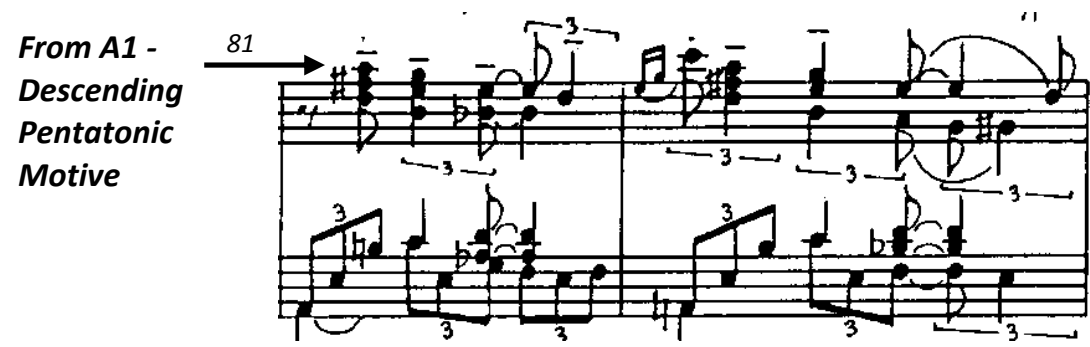

Example 5.2: Allegretto, Development - Theme A1 in soprano, mm. 81-82 
The serenity of the Development returns abruptly with a subito piano in measure 97, returning to the material from the opening of the Development. The importance of the thematic half-step resolution becomes strikingly apparent again, especially following such an awkward boisterous outburst. A variation of Theme B returns (Example 5.3) to drive the movement towards the Recapitulation.

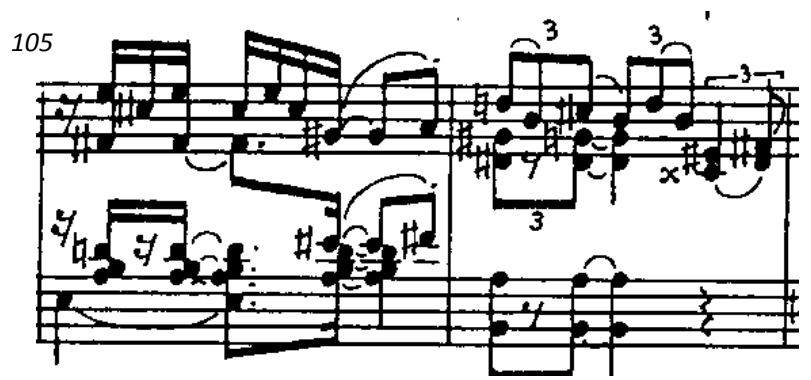

Example 5.3: Development- Rhythmically varied Theme B, mm. 105-106

The Recapitulation ( $\mathrm{mm} .111-180$ ) begins with Theme A1, in a dramatic fortissimo, complete with repetition for each chord in both hands ( $\mathrm{mm} .111-112)$. Instead of quartal harmonies as previously used in Theme A1, Kapustin heightens the sense of climax by using major chords in the right hand and dominant chords in the left, in a parallel fashion. The pentatonic theme in the soprano is still present (Example 6).

Kapustin discusses the use of a Golden section in his works as the point of climax. In an email interview with Yana Tyulkova, he states: "The Golden section is very important moment in my works. Usually, I am trying to watch out for it and carefully control it." 42 The beginning of the Recapitulation until Theme $A 2$ returns represents the Golden section in the first movement of Opus 102 (mm. 111-123). It is important to note that the lyrical presentation of Theme A1, as

\footnotetext{
42 Tyulkova, 60.
} 
seen in measures 19-24 in the Exposition, is not mirrored in the Recapitulation but nearly

entirely omitted. A slight hint of the lyrical portion of Theme A1 helps transition into Theme A2 to complete the Golden section during measures 122-123. The sudden outburst of lyricism emerging through such a powerful musical landscape produces an effect simliar to the calmness after a storm. Kapustin then drives forward into Theme A2 immediately following the decending chordal pattern (mm. 124-136). The energy of the Golden section helps propel this transition rather elegantly.

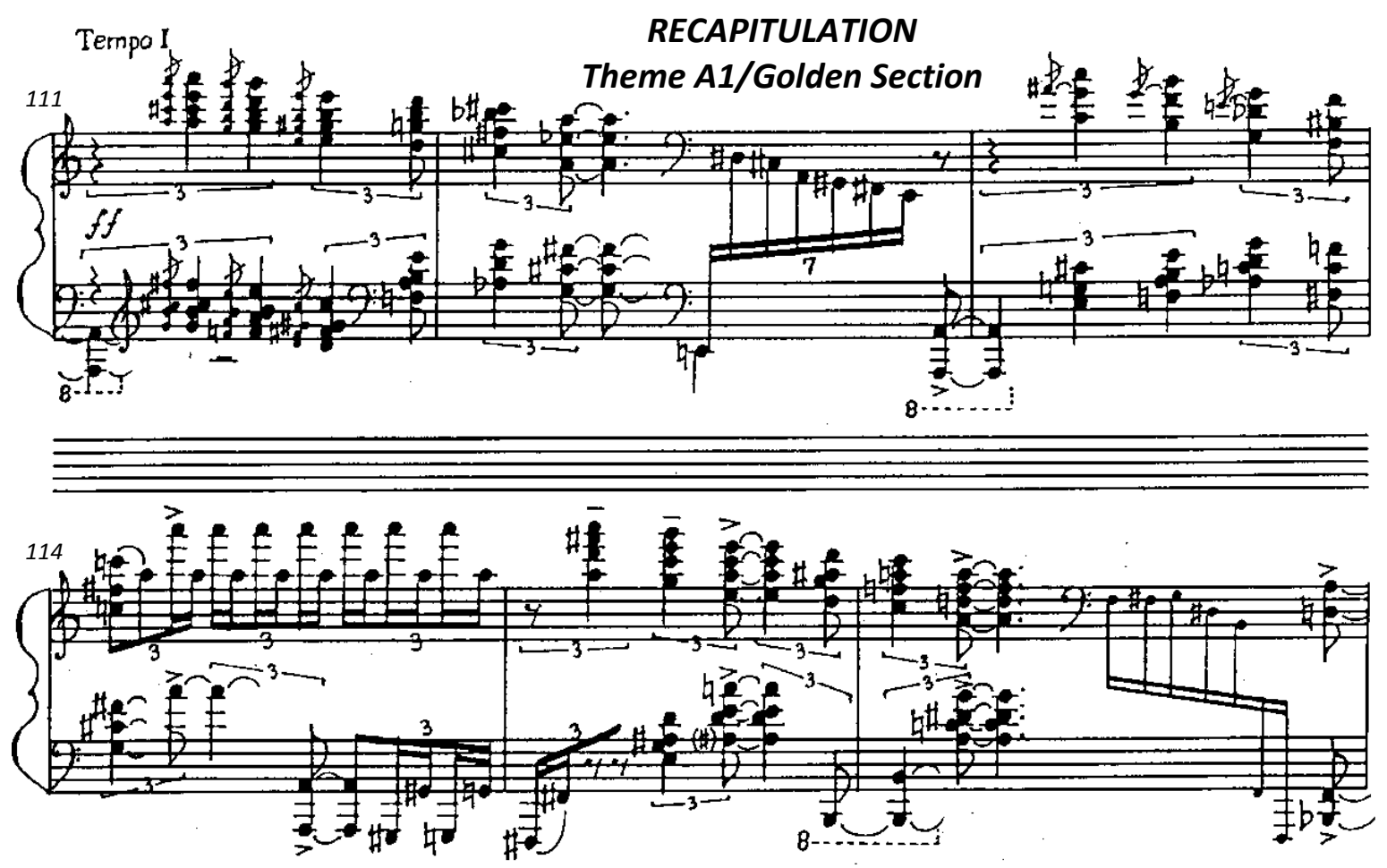

Example 6: Allegretto, Recapitulation- Theme A1, Golden section, mm. 111-116

When Theme A2 returns following the Golden section, the lyrical harmony from the Exposition accompanies it. Though the material begins nearly identically to the Exposition's counterpart, the perspective has shifted due to the material that has just preceded it. Following a lyrical presentation of the main theme, Theme A2 seems like an obvious extension of the previous material. During the Recapitulation, the feeling is quite different, almost soothing the 
listener after a very dramatic presentation of Theme A1. Theme A2 begins as G-major over D but quickly evolves as it had in the Exposition (mm. 124-136). Theme A2 continues to serve as a transitional thematic idea that moves the Sonata toward the presentation of Theme B (mm.137-168).

Theme Group B functions much in the same way as it had in the Exposition. The theme represents a bluesy fantasy complete with virtuosic jazz licks that separate the presentation of thematic ideas. Again the focus is on dominant sonorities, but now in the key of an altered A

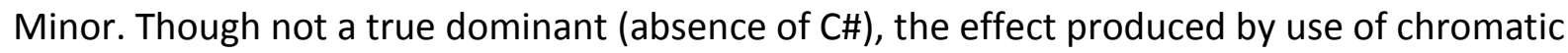
extensions gives the sense of the same type of harmony used when presented in C during the Exposition. The rhythm is nearly identical to its counterpart in the Exposition- a triplet followed by successive upbeats (Example 7). The entire return of Theme B is weighted toward the second half of the theme. Though the first eight measures seem like a mirror of their counterpart in the Exposition, the appearance of the inverted 'blues motive' in measure 145 arrives prematurely in the Recapitulation to be an identical thematic parallel. By measure 152, the texture of the melody becomes harmonic in function and the theme has taken a fairly dramatic shift away from its former character.

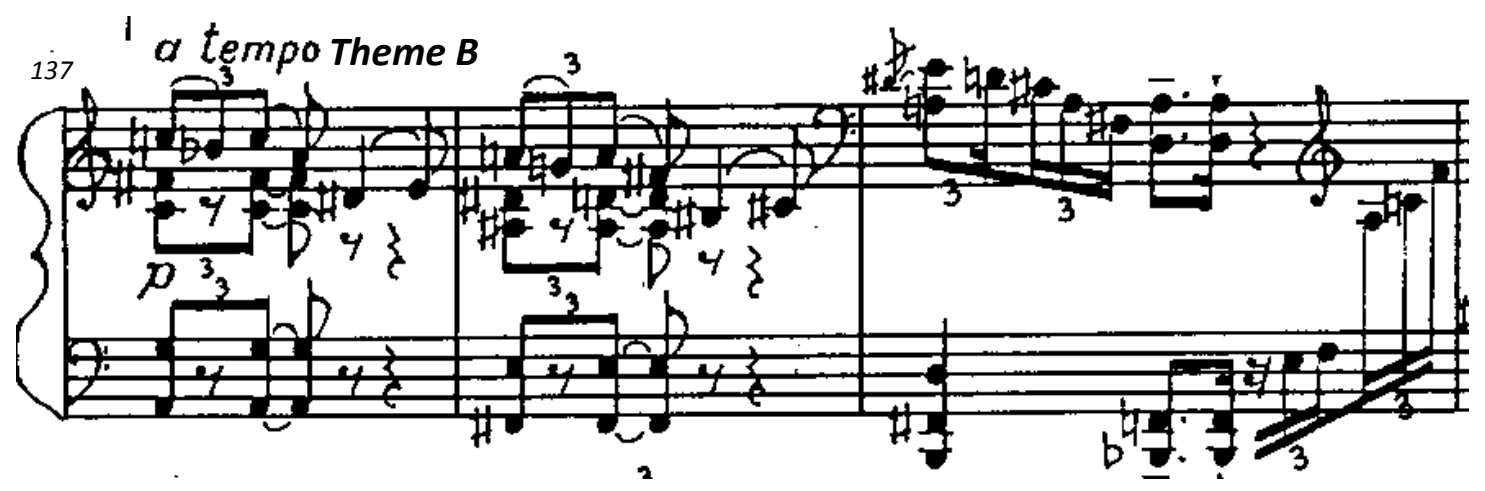

Example 7: Allegretto, Recapitulation - Theme B, presented in tonic, mm. 137-139 
The 'blues motive' occurs multiple times leading up to the Coda during Theme B. It appears inverted in measures 145 (C\# Major) and 163 (A Major) and in original form in measures 147 (A Minor) and 161 (C\# Minor). A fragment of the original form appears again in measure 162 but quickly transitions toward the coda through a series of Theme B motives ( $\mathrm{mm}$. 165-168). Every example of the 'blues motive' in Theme B is presented as a diminution.

The Coda arrives somewhat abruptly at measure 169. Theme A1's descending pentatonic theme returns; however the bass line has changed. The ascending open $5^{\text {th }}$ s are still within the A-Minor pentatonic scale; however, the root is now the note $\mathrm{G}$ (Example 8). This series of open $5^{\text {th }}$ s serves both as a new bass line for the Coda of the Allegretto movement, but also as foreshadowing for the opening of Allegro Assai movement as well. Continuing in measure 171 and 173 , Kapustin expands the open $5^{\text {th }} \mathrm{s}$ to include not only the octave but in some cases the $9^{\text {th }}$ of the chord as well. A series of three varied iterations of the theme occur followed by a thickly-voiced cadence. The final cadence travels to the final key of A Lydian through a B-flat Lydian harmony. The final arpeggio is presented in pianissimo, in sharp contrast to the movement that follows. 


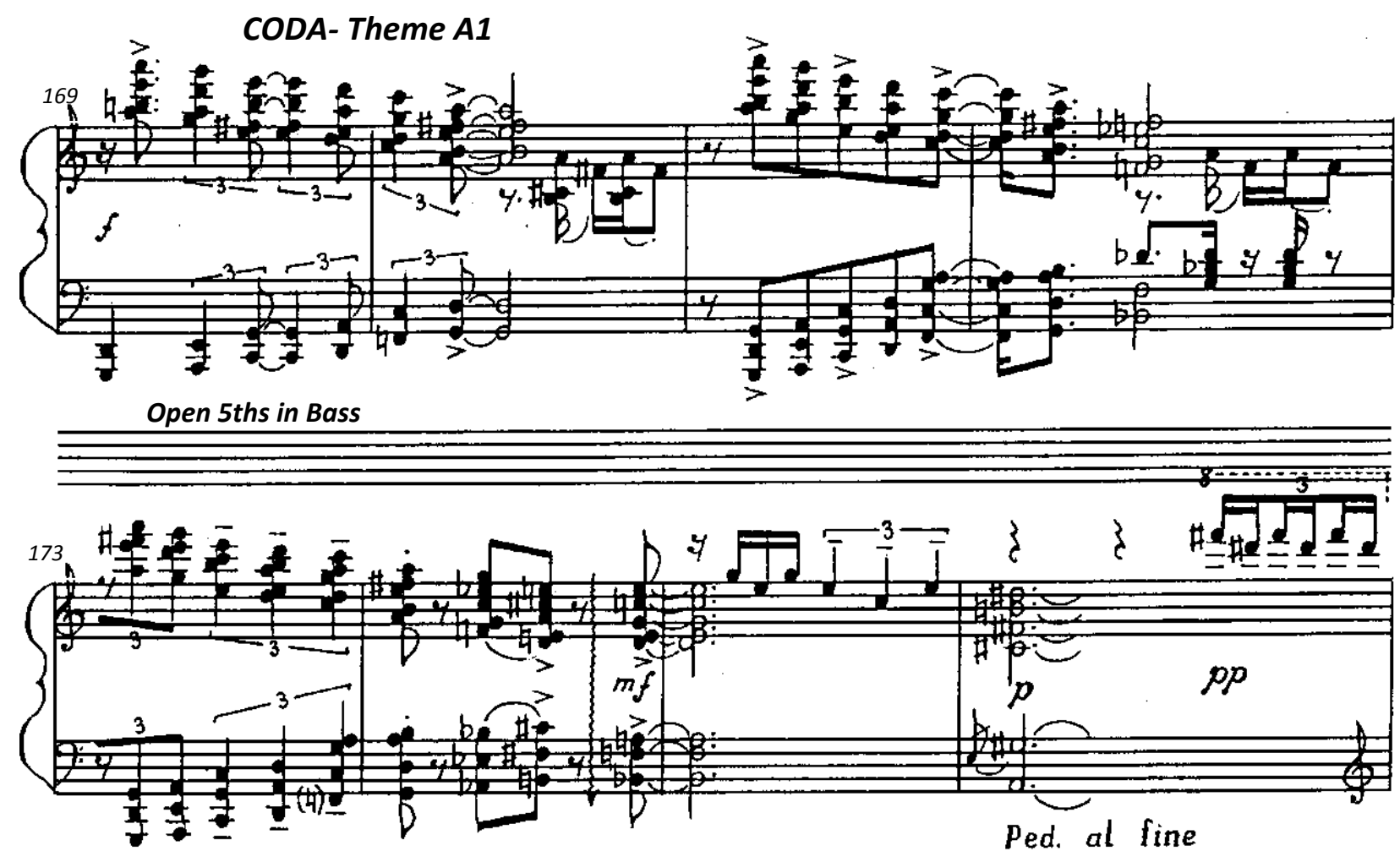

Example 8: Allegretto, Coda- Theme A1, mm. 169-176 
Sonata Form within Opus 102, II. Allegro Assai

\begin{tabular}{|c|c|c|c|}
\hline Section & Measures & \# of Measures & Harmony \\
\hline Exposition & $1-85$ & 85 & \\
\hline $\begin{array}{l}\text { Theme A1 } \\
\text { Theme A2 }\end{array}$ & $\begin{array}{c}1-18 \\
19-26\end{array}$ & $\begin{array}{c}18 \\
8\end{array}$ & A Aeolian \\
\hline Theme B1 & $27-40$ & 14 & E flat $>$ A flat Dominant, sus $4 / 2$ \\
\hline Theme $B 2$ & $41-55$ & 15 & A minor sus 4 (no $3^{\text {rd }}$ ) \\
\hline Transition & $56-61$ & 6 & \\
\hline Closing Theme & $62-85$ & 24 & $\mathrm{C}$ blues \\
\hline Development & $86-134$ & 49 & \\
\hline Recapitulation & $135-205$ & 71 & \\
\hline Theme A1 & $135-152$ & 18 & $\begin{array}{c}\text { A (Both Major/Minor by } m \text {. } \\
\text { 139) }\end{array}$ \\
\hline Theme A2 & $153-164$ & 12 & A Dorian \\
\hline Theme B1 & $165-172$ & 8 & C Dominant- $7^{\text {th }}$ sus $4 / 2$ \\
\hline Theme B2 & $173-194$ & 22 & F Major \\
\hline Cadenza/Transition & 195 & 1 & F Minor \\
\hline Closing Theme & $196-205$ & 10 & A Blues \\
\hline Coda & $206-228$ & 23 & A \\
\hline
\end{tabular}

Chart 2: harmonies listed above are often brief and distorted by chromaticism, similar to the Allegretto. 
The second movement of Nikolai Kapustin's Piano Sonata No. 12 is an Allegro Assai movement in the style of a toccata aggressively fused with jazz, rock, and blues rhythms and harmonies. The harmonic language is similar to the first movement in that much of the language is complex with intricate voice leading resulting in extreme chromaticism. Advanced syncopations exist throughout a majority of the thematic content of this movement.

As noted above, the material for the beginning of the Exposition is derived from the lefthand part of the Coda from the first movement. The notes are identical, but the rhythms have been altered (Example 9). The left hand plays very strong eighth notes in $5^{\text {th }} s$ while the right hand comes in just before beat three with an introductory motive (mm. 1-4). The left-hand notes, as discussed previously, are derived from the fifth mode of the C Major pentatonic scale $(G, A, C, D, E)$, roughly outlining Mixolydian mode. After two iterations of this (four measures in total), the melodic theme begins in the right hand during the upbeat leading to measure five. The entire Theme 1A proves quite complex as it shifts melodic ideas nearly every two measures until theme 1B arrives at measure 19.

Complex syncopated rhythms combined with ties often obscure any sense of quarternote pulse. Kapustin further unifies the sonata by using the descending pentatonic theme from the first movement as the soprano voice beginning (m. 5). This pentatonic (descending E-minor pentatonic- $E, D, B, A, E$ ) is slightly different from the left hand's pentatonic scale but still contains all white keys, allowing the two scales to remain relatively compatible. Together, the scales combine to make an A-Aeolian scale (Missing F Natural). Another interesting factor in this movement is the fascination with syncopations derived from using patterns of three sixteenth notes per grouping. When paired with ties, this produces a type of syncopation that is 
increasingly challenging. Additionally, Kapustin must have been aware that grouping three sixteenth notes innately produces twelve-note patterns when combined with the common $4 / 4$ time, as the lowest common denominator of three and four is twelve.
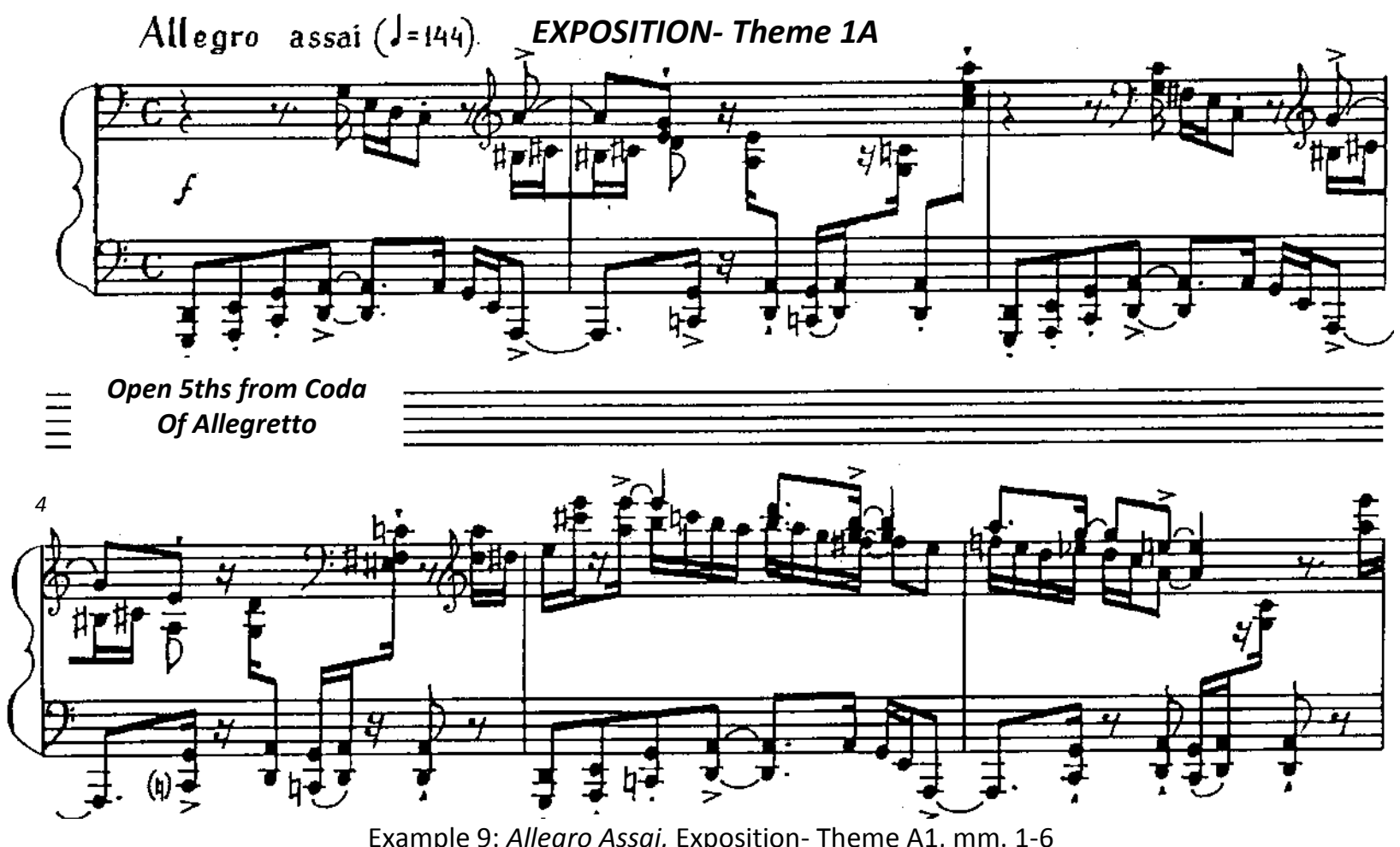

Theme A2 begins abruptly in measure 19 following a series of two measure-long arpeggios in measures $17-18$. This thematic component of Theme A becomes very crucial throughout the movement as it begins with an identifiable 'bass motive' (Example 10). The motive, derived from the syncopated pattern of Theme A1, is a twelve-note pattern divided into four sets of three notes, the root of which is B-natural. Rather than write twelve sixteenth notes, Kapustin combines the final two notes by use of grace note to provide a jarring syncopated feel. Kapustin's 'bass motive' is repeated three times before the fourth repetition leads the music to the end of Theme A2. Measures 23-25 continue the use of twelve-note patterns in the left hand, divided into four sets of three sixteenth notes; however, the right 
hand presents a series of chords with complex syncopation. To add to the confusion of pulse, Kapustin begins the third iteration of this passage one sixteenth note early, displacing the pattern and adding another level of complexity. The entirety of Theme A2 serves as a transitional theme to the more lyrical Theme $B$, arriving following the double bar line at the end of measure 26 .

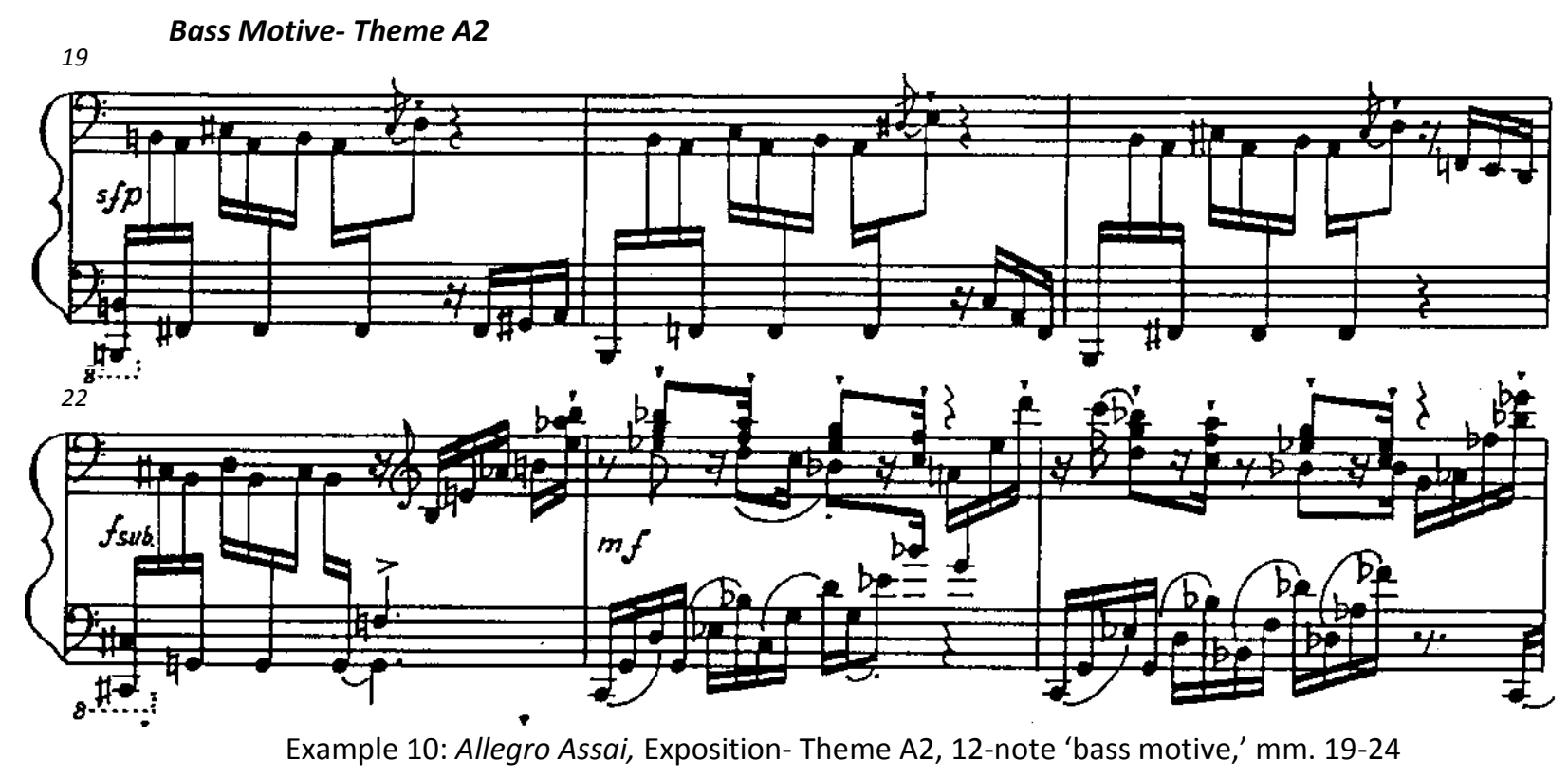

The lyrical quality of Theme B1 and Theme B2 represent harmonic clarity unlike the perpetually shifting rhythmic textures of Theme A. Though still fairly syncopated, the syncopations remain rooted at the eighth-note rhythmic value and less focus is directed at the use of the sixteenth note. As before, Kapustin develops the entire section of Theme B from a simple syncopated eighth-note figure first appearing in measures 27-28 (Example 11.1). This thematic component will prove quite important throughout the entire movement. In fact, this motive has a strong resemblance to a quotation of another song that Kapustin very likely unknowingly quoted. The motive is nearly identical to the main melody from the musical 
theater show Gypsy's “Together Wherever We Go” (Example 11.1, 11.2). Though somewhat chromatic, the melody proves quite serene considering the previous toccata-style section. The harmonic foundation of this entire section rests on where this motive resolves. The use of an Aflat dominant $7^{\text {th }}$ chord appears on the downbeat of measure 28 . The voicing is very typical of Kapustin for this sonata, as it is voiced as a G-flat Major chord over the root of A-flat. The following measure he moves the whole harmonic pattern up a whole-step to A-flat Major over B-flat. This voicing instantly produces a suspended sound, as the $3^{\text {rd }}$ and $5^{\text {th }}$ of the chord are replaced by the $2^{\text {nd }}$ and $4^{\text {th }}$. This innately produces a sense of movement harmonically and can be seen not only in this movement but during the Development of the Allegretto movement as well. Again we see rhythmic groupings of twelve notes at measure 36 when Kapustin changes the texture slightly of the lyrical Theme B by accompanying the melody with triplets in the left hand.

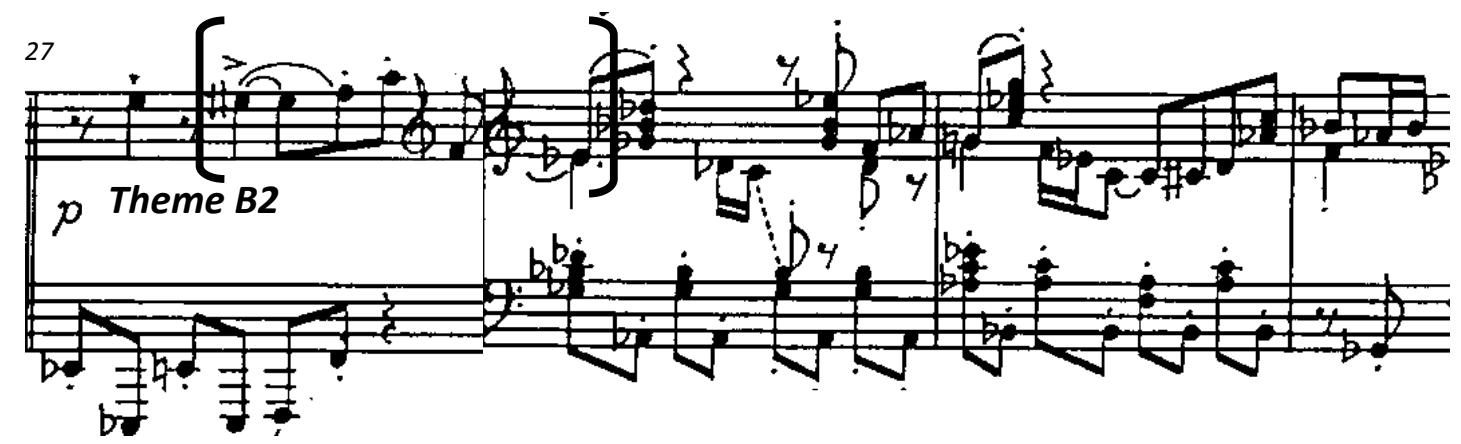

Example 11.1: Allegro Assai, Exposition- Theme B1, mm. 27-30; resembles "Together (Wherever We Go)," from the American musical Gypsy (1959), by Jule Stein, Stephen Sondheim, and Aurthur Laurents

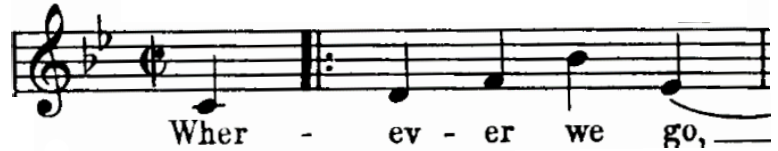

Example 11.2: "Together (Wherever We Go)" - Same contour and nearly identical interval relationship to Theme B1. ${ }^{43}$

\footnotetext{
${ }^{43}$ Laurents, Sondheim, Stein, "Together (Wherever We Go)," Gyspy (1959).
} 
A tempo shift occurs at measure 41 ; however, as the pulse increases, the values of notes remain equivalent with respect to actual duration. This metric modulation is preceded and followed by very clever passage-work allowing Kapustin to make the music generate energy without propelling the tempo to uncontrollable expectations. Kapustin's use of triplets at the end of Theme B1 into eighth-notes during Theme B2, combined with the increase in tempo of 50\% (from 144 per quarter-note to 108 per half-note), allows the actual duration of each notevalue to remain the same. The speed of the triplets matches that of the eighth-notes in the upcoming section. The only rhythmic component that changes is the pulse (Example 12). Harmonically this section is also more lyrical than Theme Group A, though the chromaticism during measures 43-47 implies that the lyrical quality may be ending. However, it returns again from measure 47 until the end of Theme B2 at measure 55.

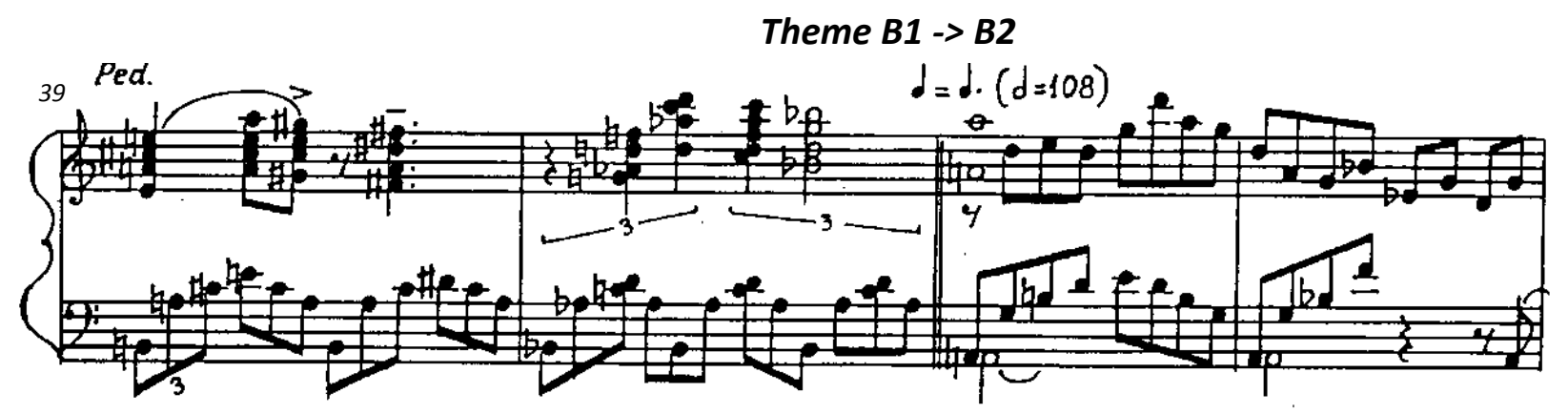

Example 12: Allegro Assai, Exposition- Theme B1 metric modulation into Theme B2, mm. 39-42

The brief transition into the Closing Theme occurs around measure 56, though a case could certainly be made that the transition begins promptly at the double bar line following measure 59. In either case, the transition is either two or six measures long whose function is to return the movement's texture back to the opening style of the driving toccata. A prominent $\mathrm{C}$ dominant $7^{\text {th }}$ followed by $D$ dominant $7^{\text {th }}$ chord shell can be seen at the beginning of the 
transition, though the falling chromatic line makes actual harmony nearly imperceptible. A series of altered dominants presented chromatically in the left $(\mathrm{mm} .59-60)$ provide a sense of harmonic progression. During the transition from Theme B to the Closing theme, the tempo returns to $A$ Tempo, while Kapustin uses eighth-notes temporally shifting into triplets at measure 60. Kapustin begins to beam the eighth notes in sets of three (foreshadowing the upcoming triplets) prior to the tempo shift forcing a seamless transition to the Closing Theme. The sixteenth-note texture returns by measure 61, however the Closing Theme proves quite different than its opening counterpart (Example 13.1).
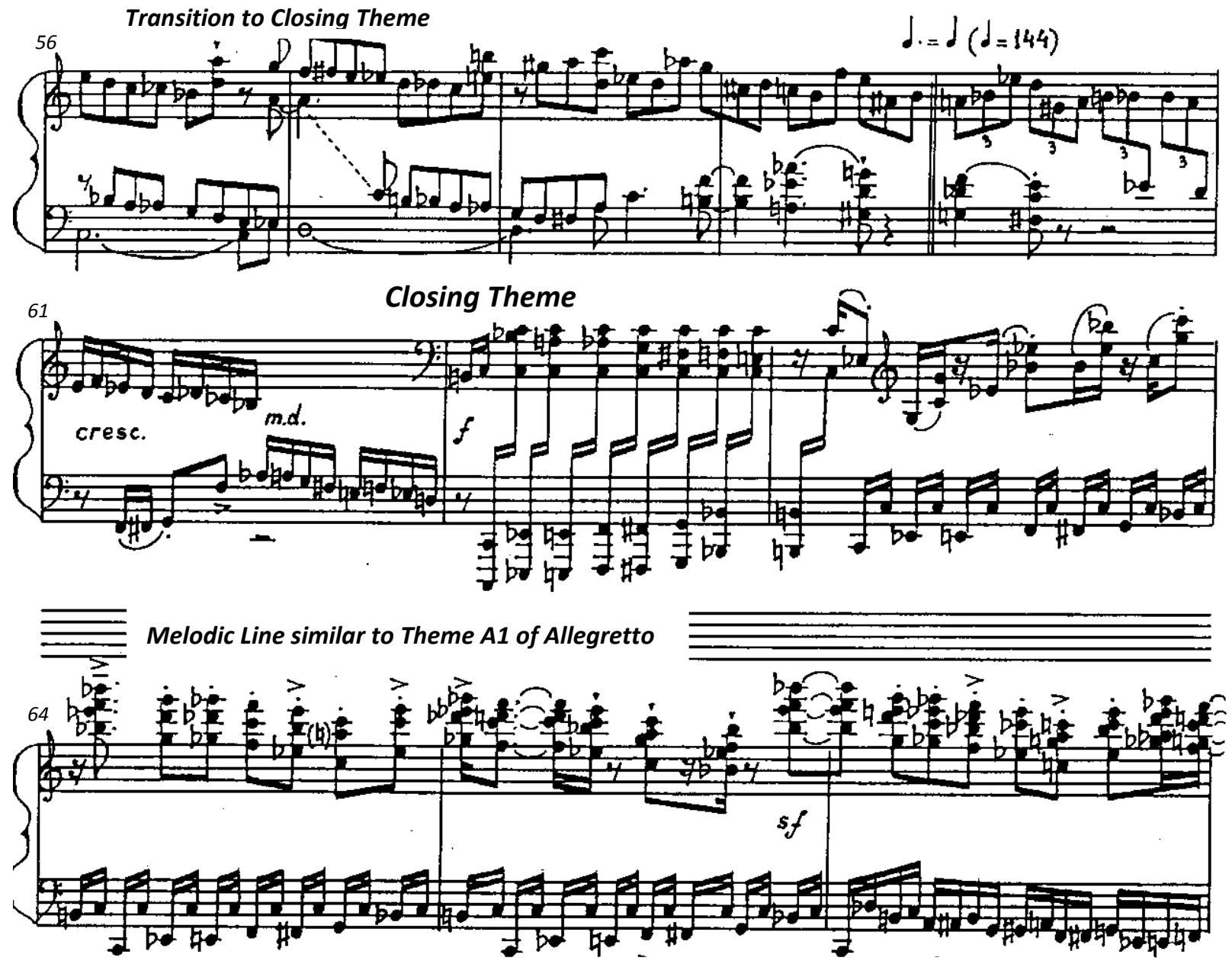

Example 13.1: Allegro Assai, Exposition- Transition from B2 to Closing Theme; Beginning of Closing Theme, mm. 56-66 
The Closing Theme begins with a two-measure bass introduction before the thematic idea enters in the right hand (mm. 64). Syncopation exists throughout this section, but the level of rhythmic complexity is not quite as challenging as the opening theme group. The tonality of this section begins in ' $C$.' The left-hand part is a common blues-style walking bass line reserved for faster tempi; however, Kapustin starts the pattern with a B-natural on the downbeat instead of the more likely $\mathrm{C}$. The right hand plays melody in octaves, harmonized on every melodic note. The use of harmonized octaves seems to represent that of the brass section of a big band, and likely depict a throwback to Kapustin's earlier days of composition.

Though the section appears to follow that of the standard blues at its start (four measures of tonic, one measure of sub-dominant), the harmonic path quickly shifts from the typical as it soon travels to $\mathrm{Bb}, \mathrm{Db}$, eventually leading back to $\mathrm{C}$. The Closing Theme enters again (m. 72), following the same pattern initially, from C to F; however, departs from any standard blues form just after the F chord as it had the first time. When the movement initiates movement toward the Development, the bass line diverts from its rapid blues pattern and becomes highly chromatic and syncopated. Melodic movement is cast in stasis as Kapustin uses a vamp style motive focusing on a low 'F.' A surprising subito fortissimo on a B-diminished chord (F/B) at measure 85, arriving on the second sixteenth note of beat one, leads the movement into the Development (Example 13.2). 

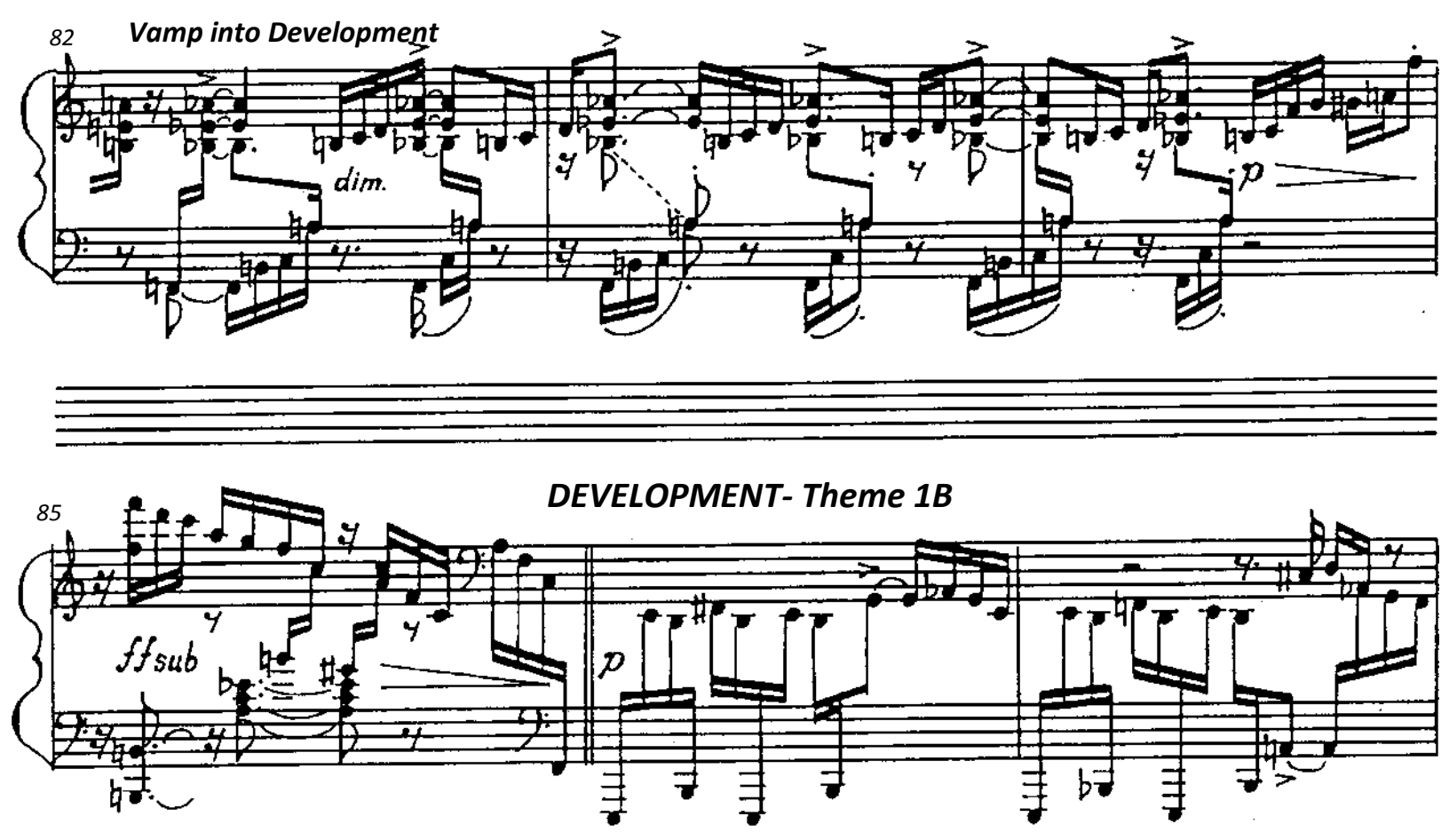

Example 13.2: Allegro Assai, Exposition- Closing Theme into Development, mm. 82-87

The Development (mm. 86-136) spans 51 measures and represents the most chromatic section of the entire piece. Theme $A 2$ begins promptly at measure 86 with the recognizable 'bass motive' as seen in measure 19 of the Exposition. The 'bass motive' develops into a walking bass line as an exciting bebop solo erupts ( $\mathrm{mm}$. 92-99). This section contains elements of both Theme $\mathrm{A} 1$ and $\mathrm{A} 2$ (Example 14.1). These eight measures are highly chromatic, but follow a series of circle progressions over the ii-V-I jazz harmonic series. The chromaticism of both the melody and the walking bass line, along with tritone substitutions $(V=b \mid l)$, contribute greatly to any confusion of tonal center. The arrival of a recognizable Theme A1 occurs very briefly (mm. 100-101) before a strong presentation of Theme B1 arrives at measures 102-105 (Example 14.2). By measure 109, Kapustin revisits the 'bass motive,' though this repetition is much darker in harmonic nature. The chromaticism of this section provides Kapustin with a new motive to return to the end of Thematic Group A (mm.109-115). 

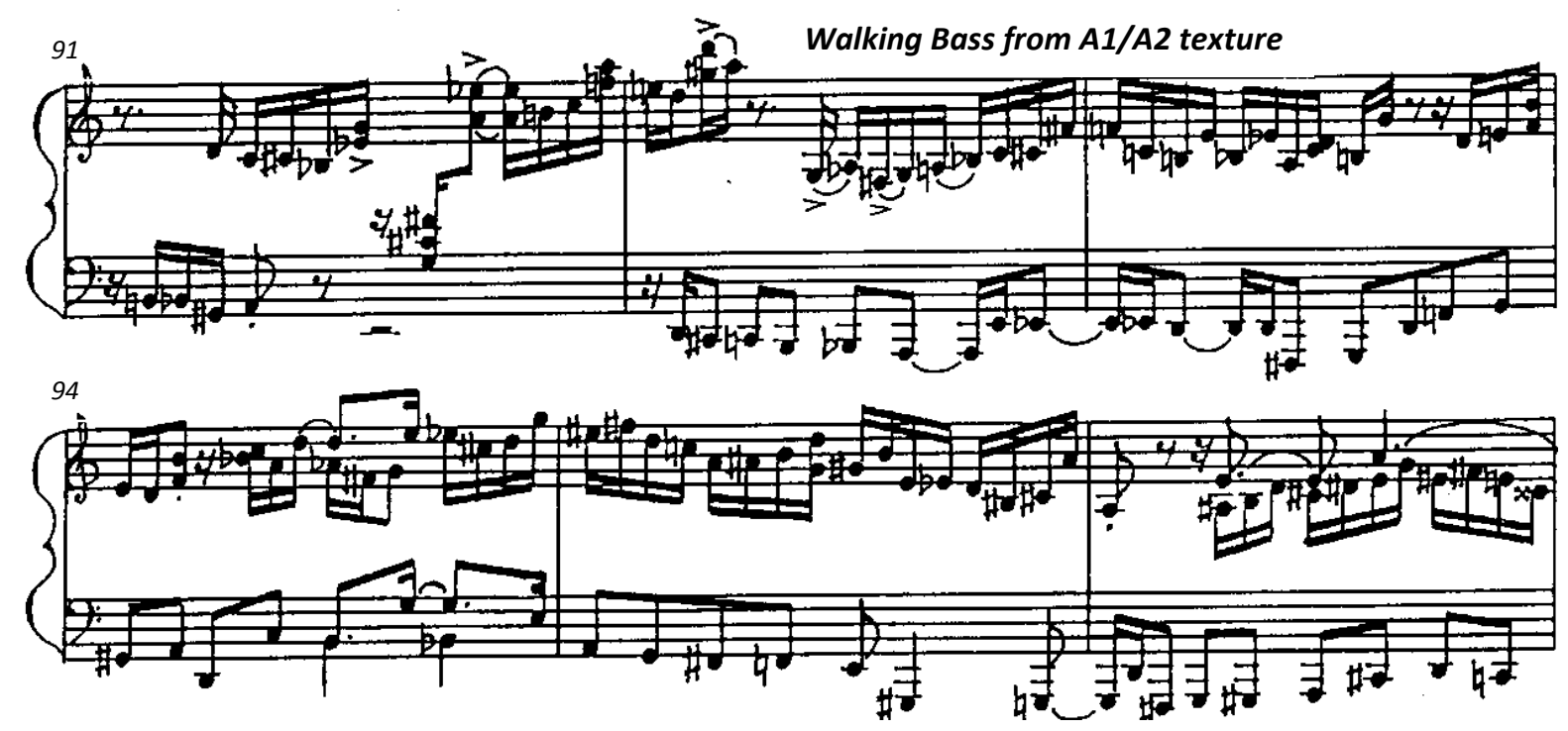

Example 14.1: Allegro Assai, Development - Walking Bass - Theme A1/A2 Textures, mm. 91-96
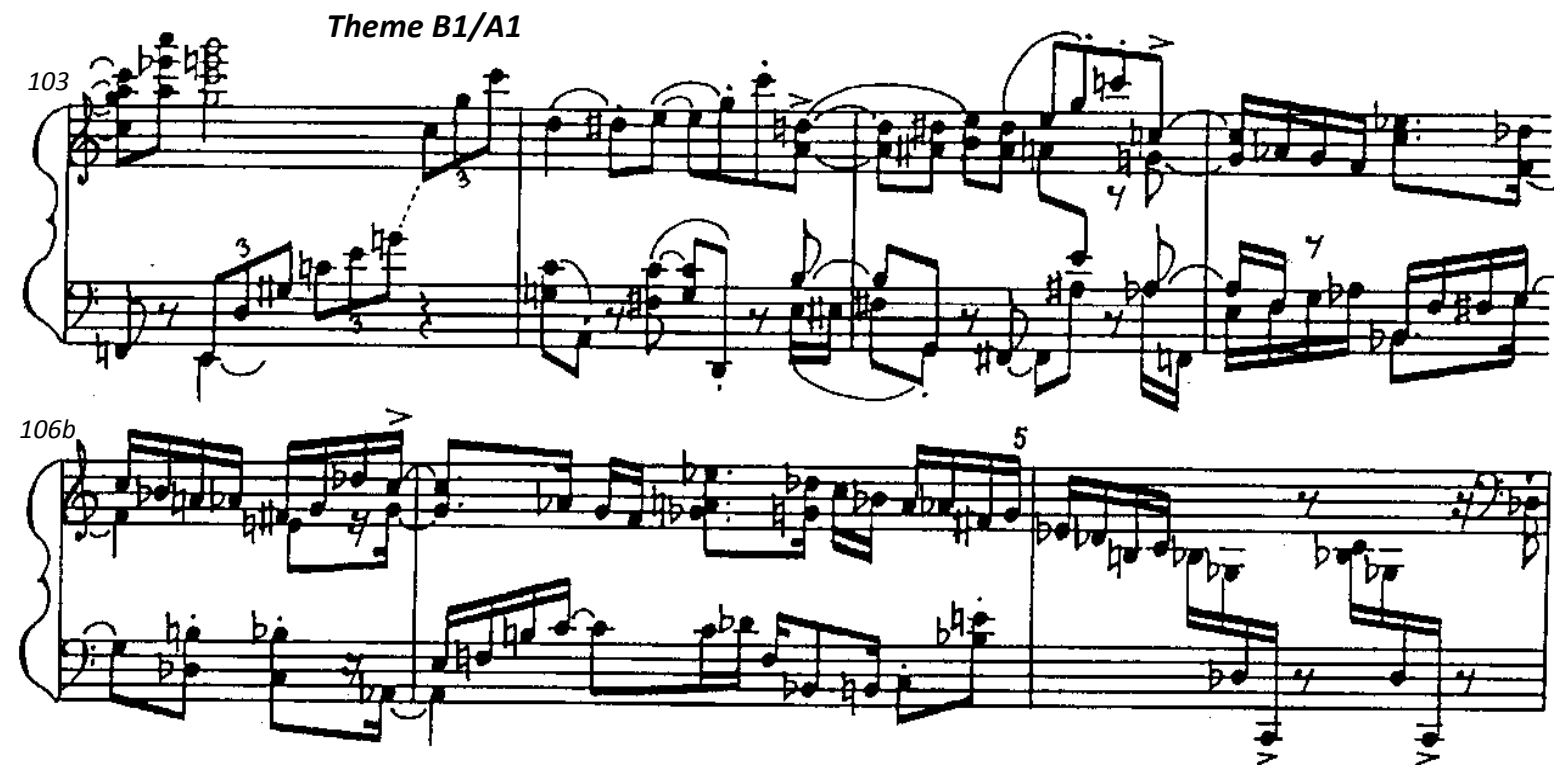

Example 14.2: Allegro Assai, Development Theme B1/A1, mm. 103-108

Due to the weight of the Development, Kapustin chose to place the Golden section of

this movement just before the arrival of the Recapitulation at measure 135. Beginning at

measure 116, Theme B1 is presented as a call-and-response style between the right and left hands. Any discernable key area is obscurred by the amount of chromaticism present during this section. After a short build-up, the Golden section begins immediately at measure 121, just 
after the downbeat. The whole section is based directly upon Theme B1's opening motive ("Together"). Kapustin places the motive in both hands, of which the right hand plays chordal harmonizations of the melody while the left hand plays the motive in octaves. Intensifying the use of call-and-response, the motives are now presented in stretto (mm 121-124).

The Golden Section continues to swell as the Development draws to a close. Theme B1 continues, now in full fortissimo, as the tenor voice in the left hand. Harmonized by stacked $4^{\text {th }} S$ under an augmented melody (both perfect and augmented), an intense chromatic solo erupts in the right hand. Finally, Theme B1 enters in the bass voice during measures 129 and 130 as the upper voices lessen in intensity. By measure 131, the piece approaches the Recapitulation using a series of blues-style chords, presented in triplets (Example 15). This offers a sense of harmonic clarity following a harsh textural and harmonic background (mm. 130-134). 

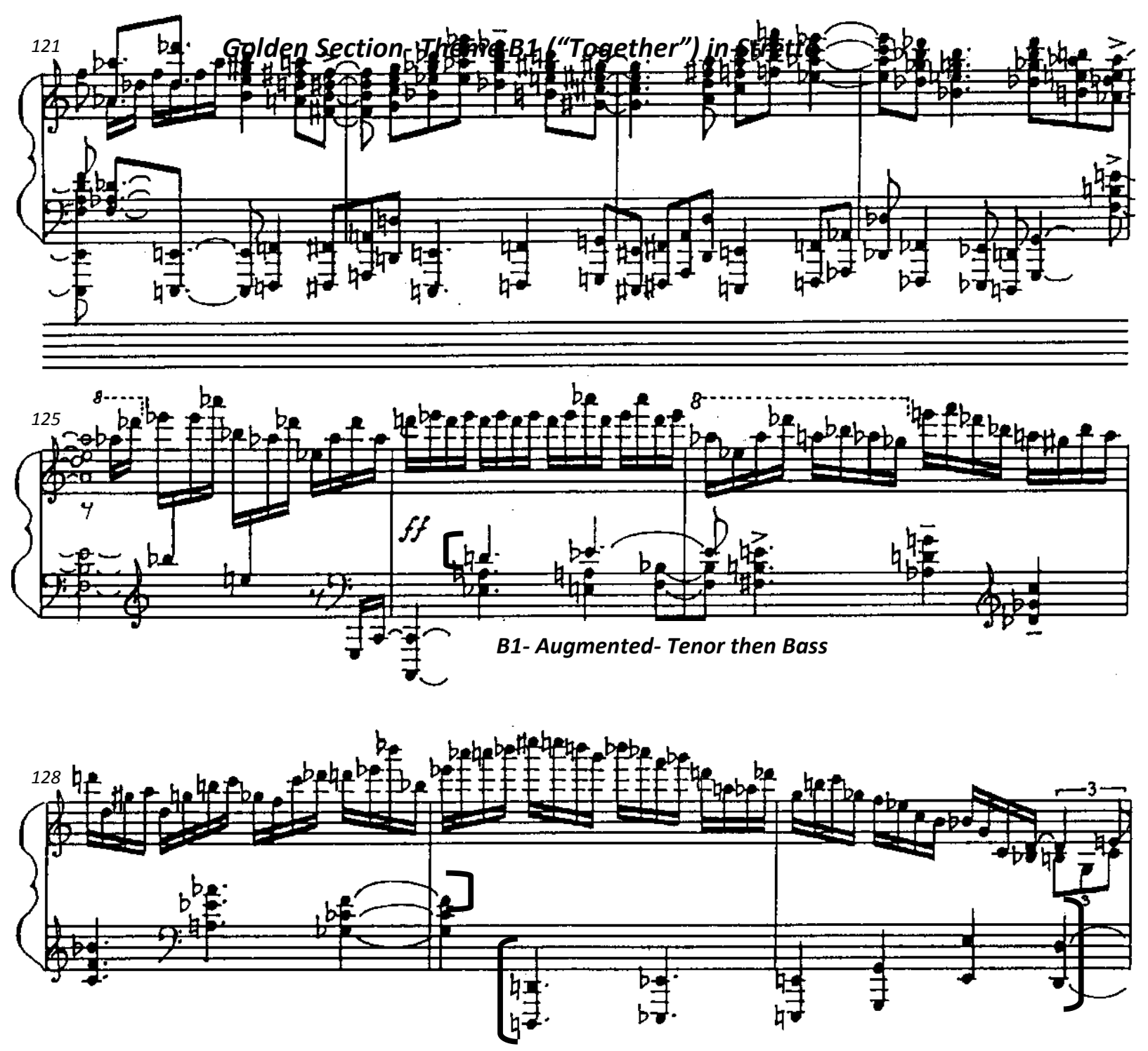

Example 15: Allegro Assai, Development - Golden section from Theme B1 (“Together”), mm. 121-130

The energy of the Golden section mirrors the first movement by driving the movement toward the conclusion of the piece. Theme A1 begins again with a $\mathrm{G}$ in the bass voice, while the right-hand motive from measure five appears to enter early (without the open $5^{\text {th's }}$ bass from the Exposition). Though the tonality also resembles the opening, the stability of a $\mathrm{C}$ root will prove quite brief. The first four measures of the Recapitulation end in a half cadence in the key of $C$ (D-minor flat 5/F). Kapustin uses this cadence to travel to an $E$ in the bass, which can then 
be interpreted as the dominant tone of A-minor, the overall tonic of the piece. Theme A1 ( $\mathrm{mm}$.

139-144) is then restated in the tonic of $A$, though the harmony and melody are much more chromatic and syncopated than that of the Exposition. The theme takes a slight motivic and harmonic detour from its original, yet the increasingly syncopated rhythms resemble the opening almost identically (Example 16).

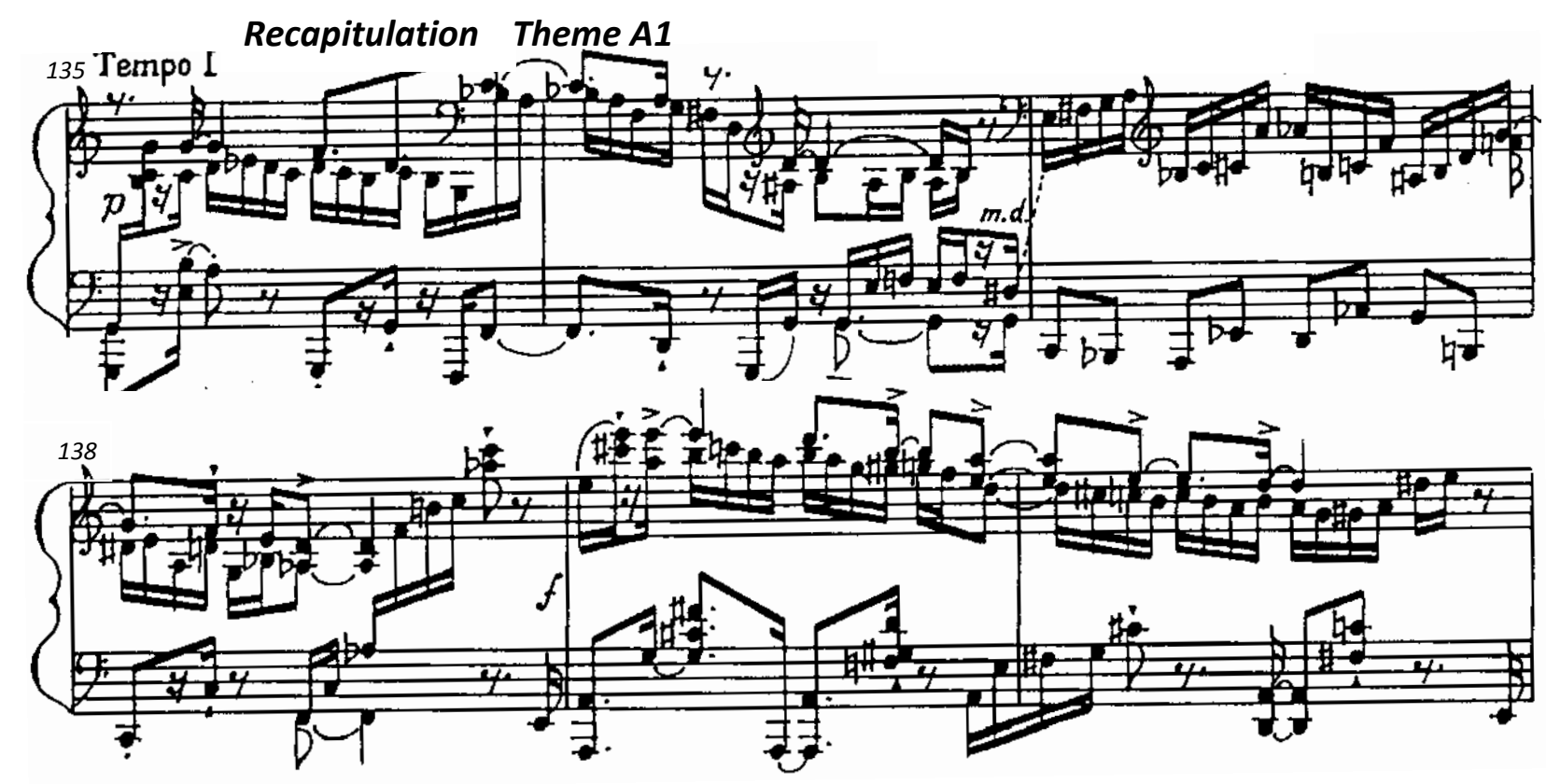

Example 16: Allegro Assai, Recapitulation - Theme A, mm. 135-140

The second half of the theme group (Theme A2) enters promptly at measure 153,

though this time with ' $A$ ' as the root note. Again, the entirety of Theme $A 2$ serves as a medium to shift texturally from the toccata style to the more lyrical rhythms from Theme Group B (mm. 153-164). The double bar line at the end of 164 marks the beginning of Theme Group B, officially; however, Kapustin foreshadows Theme B1's opening motive for nearly four measures before finally stating an uninterrupted version in measure 165.

As with the Exposition, Theme B1 centers around the use of the eighth note and the syncopations are far less extreme. The tonality at measure 165 proves much more spacious 
than its Theme Group A counterpart, as is apparent with the longer roots and much more melodic right-hand motives. The pivotal harmony that begins this entire section lies at the end of measure 165, an accented B-flat Major $7^{\text {th }}$ chord with C in the bass (Example 17). Mirroring the Exposition, this produces the same progressive harmonic motion as discussed above during the first appearance of Theme B1. Structurally, C as the root of a Thematic Group B during a sonata in A Minor is ideal. An accelerando at the beginning of measure 171 moves the tempo from the initial tempo back to the tempo from Theme B2 in the Exposition (Half-note=108). The accelerando this time is quite subtle, without the clever use of metric modulation, Kapustin instead simply beams the eighth notes in sets of three and increases the tempo. Throughout much of Theme B2, barring the eighths in sets of three adds to a sense of rhythmic progression, especially when an actual triplet finally occurs in measures 178 and 181 . Motivically, this section only resembles some of the contours of Theme B2, but rather functions as a break from the rigidity of Theme Group A and as a transition toward the sweeping cadenza that soon follows. 

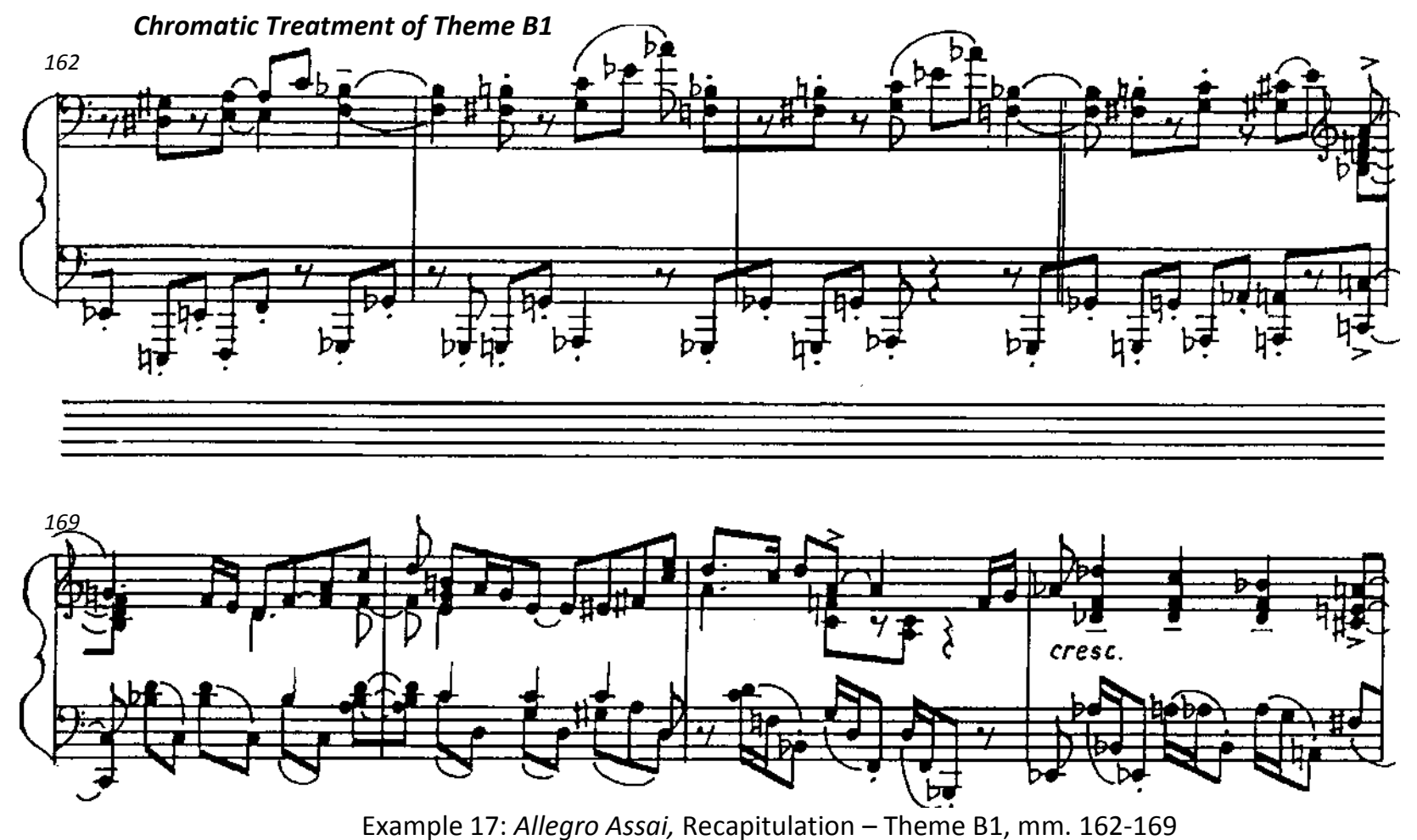

Kapustin ends Theme Group B on a harsh F-Minor chord with added thirteenth (Dnatural), over an E-natural root that is blurred multiple times via a trill that resolves up to F. Additionally, the right hand provides the upper extensions resulting in an overall harmonic feeling of an F Melodic Minor chord, with the major $7^{\text {th }}$ root of E-natural. The melodic minor scale proves quite exotic at this point in the work and thus serves as a crucial transition away from more lyrical nature of Theme Group B. This F-Minor harmony provides the basis for the cadenza that appears next (m. 195), driving the work towards a dramatic Closing Theme (m. 196-205). The texture of the cadenza develops very rapidly as Kapustin indicates not only crescendo and accelerando, but also the phrase tornado al Tempo I. Finally, at the end of the cadenza, the final two patterns are labeled as martellato, which Kapustin uses to help draw attention to an important low 'E.' This 'E' will serve as a dominant function, setting the harmonic stage for the return of tonic (mm. 195-196). 
The Closing Theme returns in the home key of 'A,' though the blues left-hand pattern appears inverted, descending after the octave rather than ascending. The right hand continues the expected syncopated rhythms and chromatic melodic movement (Example 18). Harmonic movement begins in the tonic and moves to the sub-dominant as it had in the Exposition, though Kapustin will again depart from any typical blues or boogie forms beginning in measure 202 by introducing a $\mathrm{G}$ in the bass voice. The Closing Theme from the Recapitulation ends abruptly as the Coda enters in measure 206.
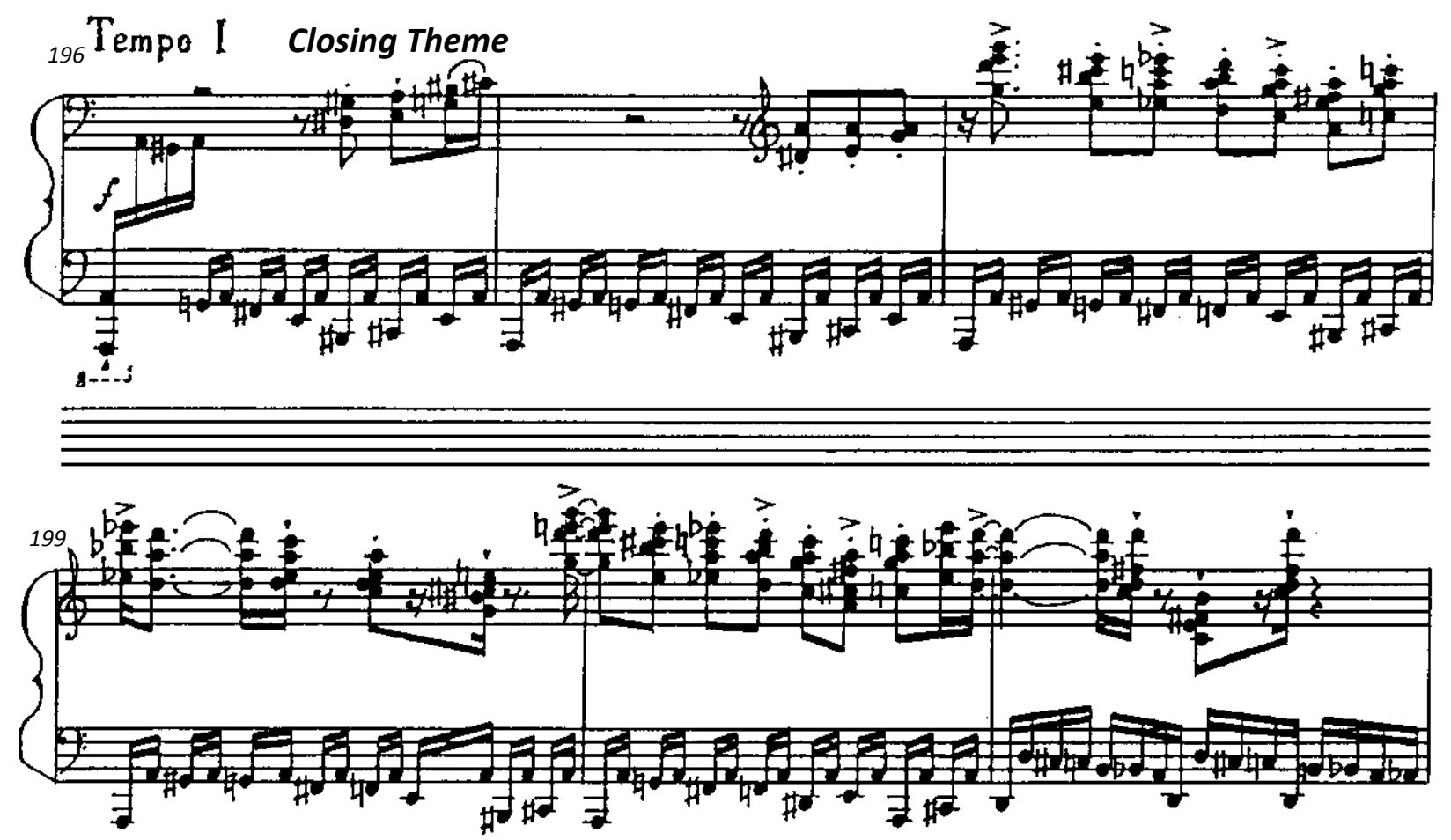

Example 18: Allegro Assai, Recapitulation - Closing Theme, mm. 196-201

The Coda (mm. 206-228) introduces a new motive, beginning on the lowest ' $A$ ' on the piano. The motive's relation to previous material is rooted in both syncopation as well as chromatic movement. Though a new idea is present, the texture and energy from the Closing Theme remain (Example 19.1). By measure 213, Theme A1 returns in a different order from the Exposition (Example 19.2). Immediately following Theme A1, Theme B enters for only two 
measures (mm. 219-220) as the piece approaches the final burst of energy. Although this section is not harmonically functional in a traditional manner, the overall effect of the harmonic structure of the Coda often returns to the tonic of A.

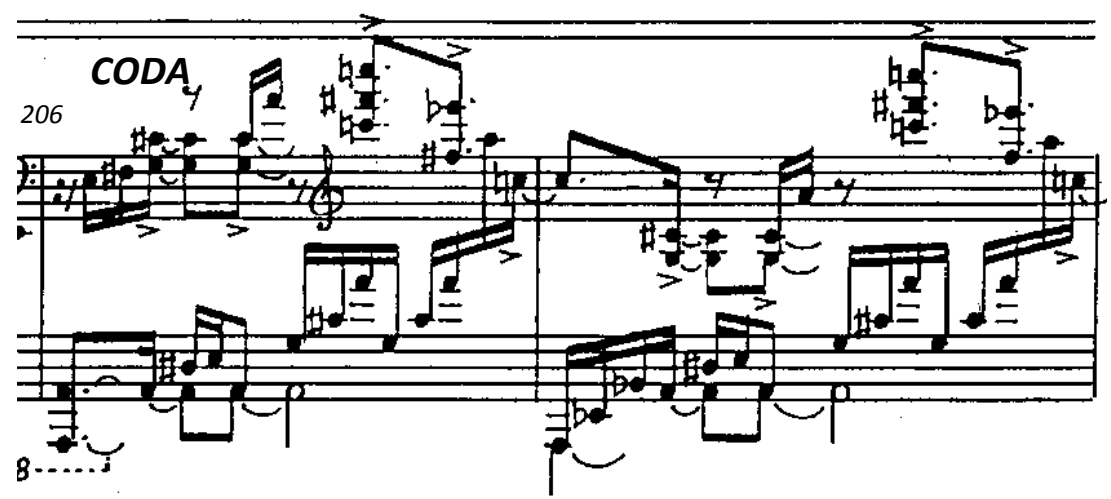

Example 19.1: Allegro Assai, Coda - new thematic component, mm. 206-207

Theme A1

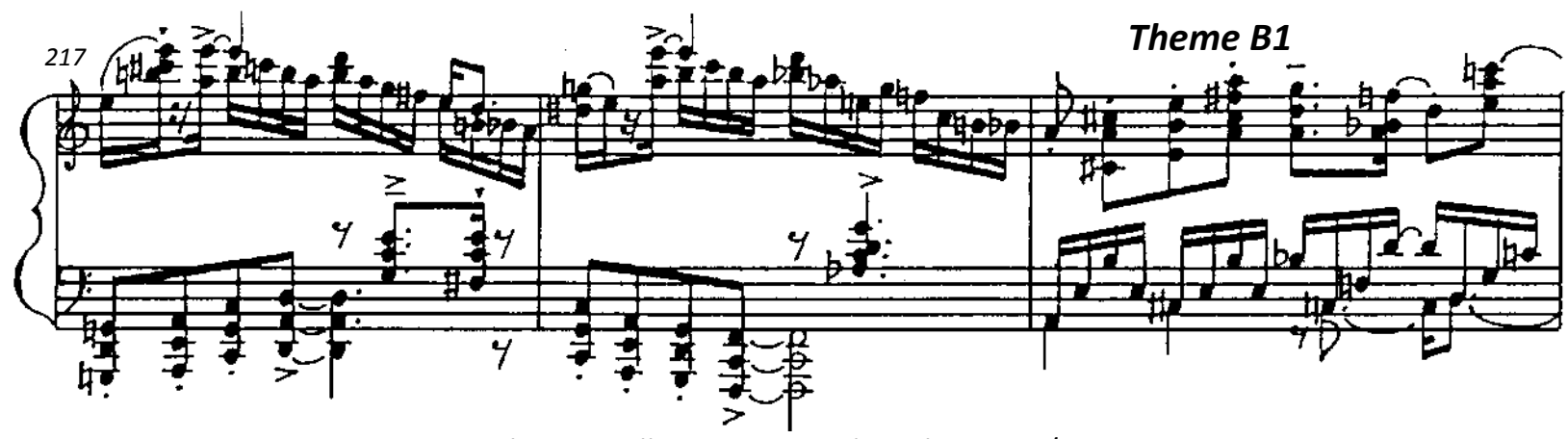

Example 19.2: Allegro Assai, Coda - Theme A1/B1, mm. 217-219

The last eight measures of the piece (mm. 221-228) build intensity to help conclude the work. Hemiola patterns continue in the form of sets of three sixteenth notes per grouping, while the open $5^{\text {th }}$ s of the Exposition return in the bass. Measures 223 and 224 revisit the open harmonies of Theme B2 followed by the new thematic component of the Coda in measures 225 and 226. Finally, the blues bass motive returns as the final two measures crescendo from $\mathbf{m p}$ to ff. Presented in contrary motion, the two hands ultimately finish at both extremes of the piano. 

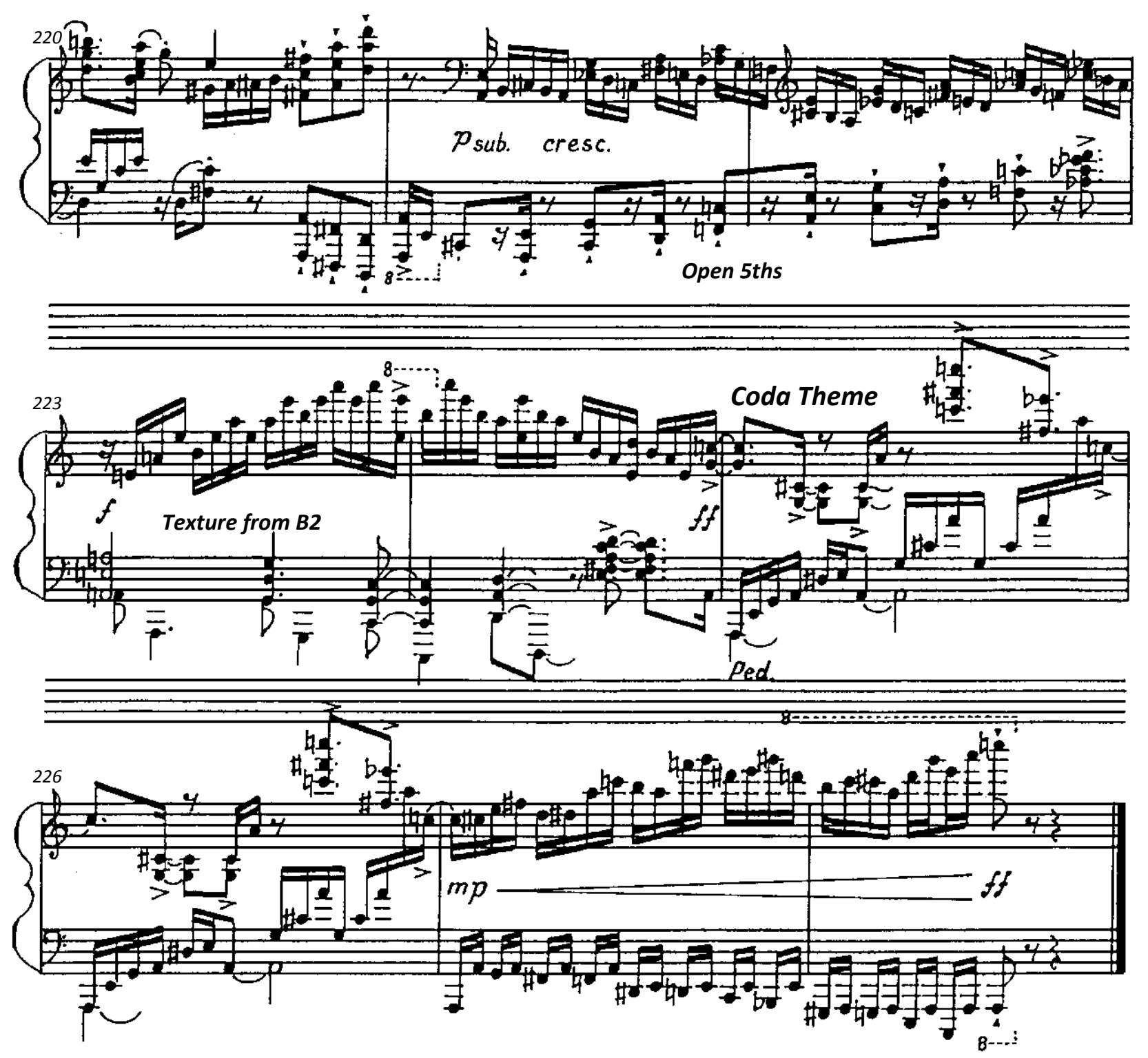

Example 19.3: Allegro Assai, Coda - mm. 220-228

Op. 102 exhibits considerable synergy not only between both movements but throughout the thematic relationships within each movement as well. While the thematic groups display a myriad of stylistic jazz and classical components, the presentation of sonata form remains clear. The requirement depicted by the above quote of Charles Rosen is ultimately attained as each movement contains the standard thematic elements of sonata form: two polarized themes (or groups) presented with a distinct harmonic relationship, 
allowing for a return to the tonic during the Recapitulation that brings a sense of perspective to the listener (isolated events no longer appear isolated). Through use of standard compositional manipulations such as augmentation, diminution, and inversion, Kapustin acheives a work that not only exemplifies the sonata form, but maintains fresh and innovate thematic content. After an in-depth analysis of these thematic components, we can see clearly why Kapustin has a particular fondness for Opus 102. 


\section{Chapter Four}

\section{Stylistic and Pedagogical Observations}

When approaching a work of this level of difficulty and complexity, it can be quite helpful to have a basic understanding of different styles associated with jazz. Though classically trained pianists can play this piece with no jazz background, one certainly benefits greatly by identifying the stylistic components found within each movement of Opus 102. Typical jazz harmonic voicing, rhythm, as well as motives or patterns all contribute to the overall effectiveness of the work. Developing a mental database of jazz styles as one learns the music of Nikolai Kapustin will only continue to aid the performer as they learn more works of this nature. Pedagogically, focusing on identifying styles (most typically located in rhythmic patterns in left-hand figures) will assist the performer to make informed interpretive choices regarding the use of pedal as well as whether the use of 'swing' is appropriate. Though fingering is specific to the individual, some fingering options will be provided throughout the chapter. Finally, a section identifying misprinted notes in the published Moscow score of Opus 102 will conclude the chapter.

The opening of the first movement, as analyzed previously, is lyrical in quality, with the melodic motives dancing the line between a swing style and straight eighth-notes. To the classical pianist first experiencing swing, the style revolves around the concept that the second eighth-note of each pairing occurs late. In more technical terms, imagine eighth notes to be rewritten as triplets, where the first eighth note of the pair becomes a quarter note within a triplet of eighths and the second then fills out the beat with the remaining eighth-note triplet (Example 20). 

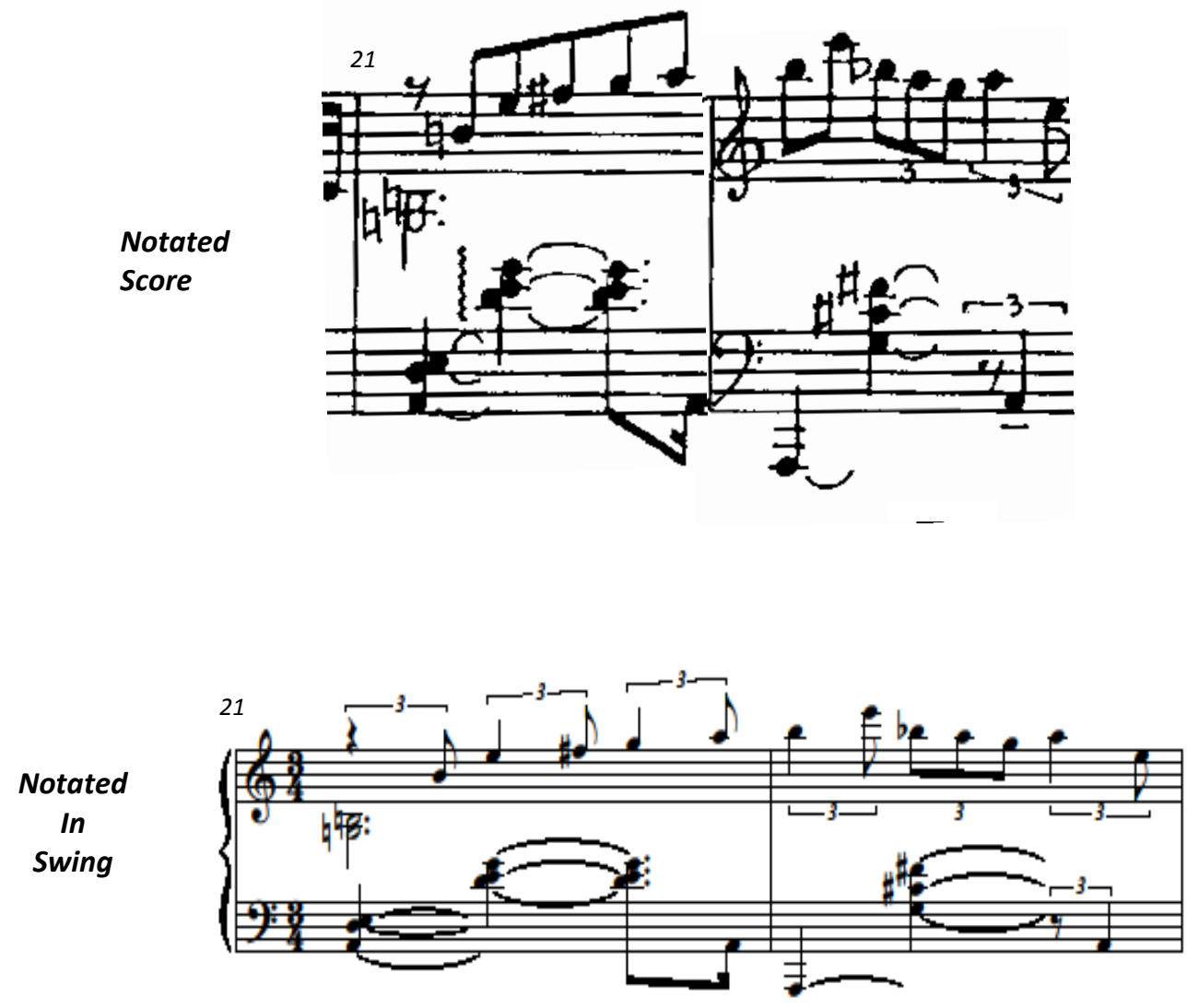

Example 20: Allegretto, Exposition- Theme A1 - 'blues motive' as written (above); swing style (below), mm. 21-22

The above example represents the only time the writer of this document attempts to change Kapustin's rhythm in his own performance. It occurs during Theme A1 in the Exposition of the first movement of Opus 102, and provides a nice variance upon Theme A1 while remaining stylistically tasteful. As noted, every second eighth-note per couplet should be placed on the last triplet of the beat. Since Theme A1 is derived from a simple pentatonic scale that varies swing with straight rhythms, to swing the 'blues motive' makes absolute sense. This exact 
deviation from the score is something that Kapustin himself utilizes during his Last Recording (2004) album. ${ }^{44}$

With the exception of Theme A1 during the Allegretto, there are not a lot of opportunities to swing notes outside the realm of what is notated in the score. The notated rhythm is often highly complex with a great deal of swing placed directly next to awkward syncopated sections, as is the case with Theme B1 of the same movement. In this situation, it often helps to practice the rhythm separately from actually playing the notes. Learning to count the rhythm with metronome at a moderate tempo will help develop a strong sense of the style for each theme (Example 21.1/21.2). This tactic can be applied to the entire piece; however, it proves most beneficial when the style shifts between straight and swung eighth notes as during the Introduction and Theme B of the opening movement.

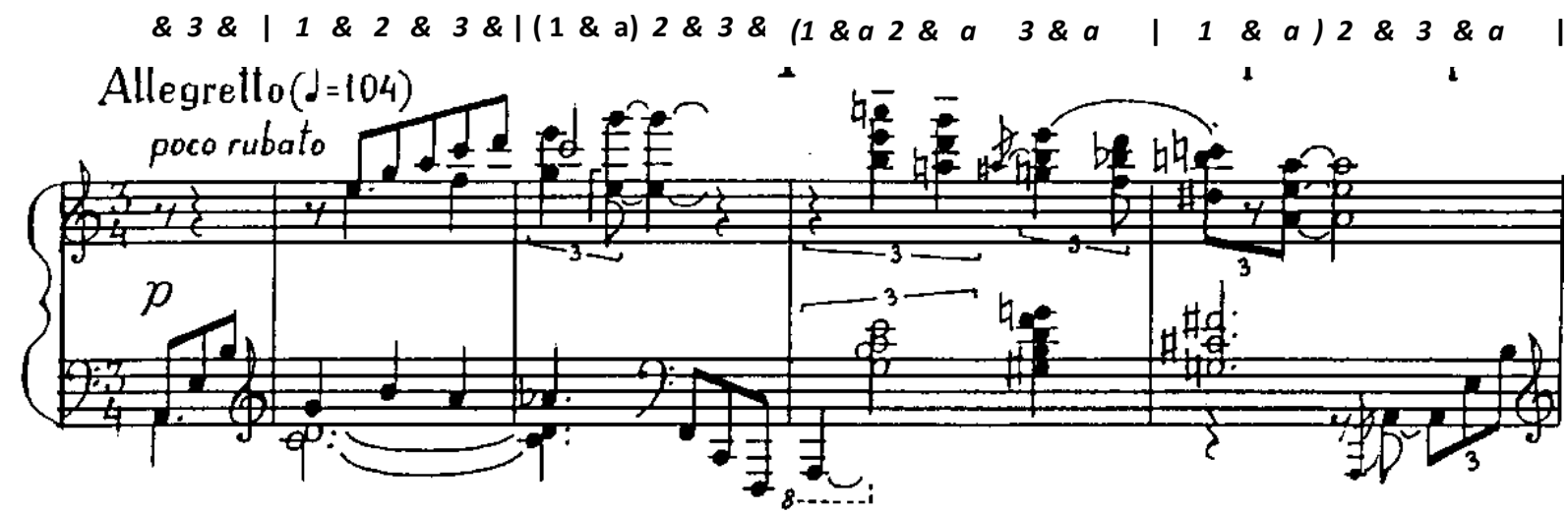

Example 21.1: Allegretto, Introduction - Practice counting the shifting styles with metronome, mm. 1-4 *swing style notated with parantheses

\footnotetext{
${ }^{44}$ Nikolai Kapustin, Last Recording, Triton OVCT-00017, 2004.
} 


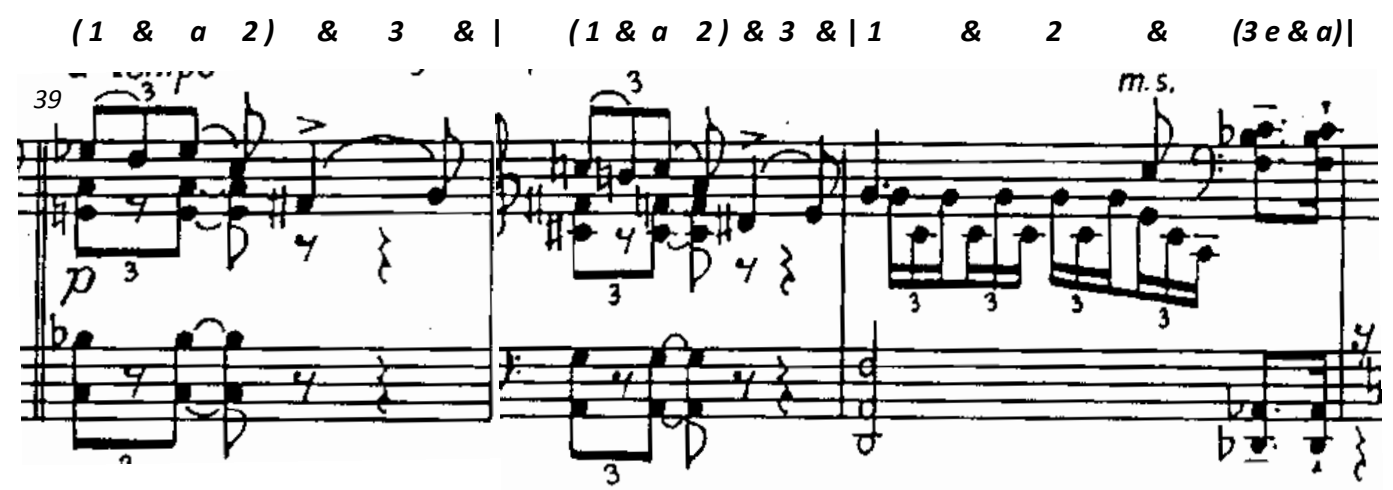

Example 21.2: Allegretto, Exposition - Theme B, mm. 39-41

*swing style notated with parantheses

Rhythmically, the entire second movement of Opus 102 presents a considerable

challenge. Due to complex syncopations, the performer should learn these rhythms in short

motives, often the length of only a single measure, half-measure, or beat. Most of the figures

occur in two-measure pairings, so the largest interval of practice, until the notes and rhythms

are learned, can be limited to just two measures. The difficulty with rhythm during the second

movement emerges from excessive use of syncopations, hemiolas, and ties. The fascination

with groups of three sixteenth-notes produces a pattern of notes that is one sixteenth note

shorter than a full beat which makes feeling the pulse incredibly difficult. The most difficult

syncopations occur during Theme Group A (Example 21.3). Tracking the eighth-note pulse is

critical to effective syncopation throughout these passages.

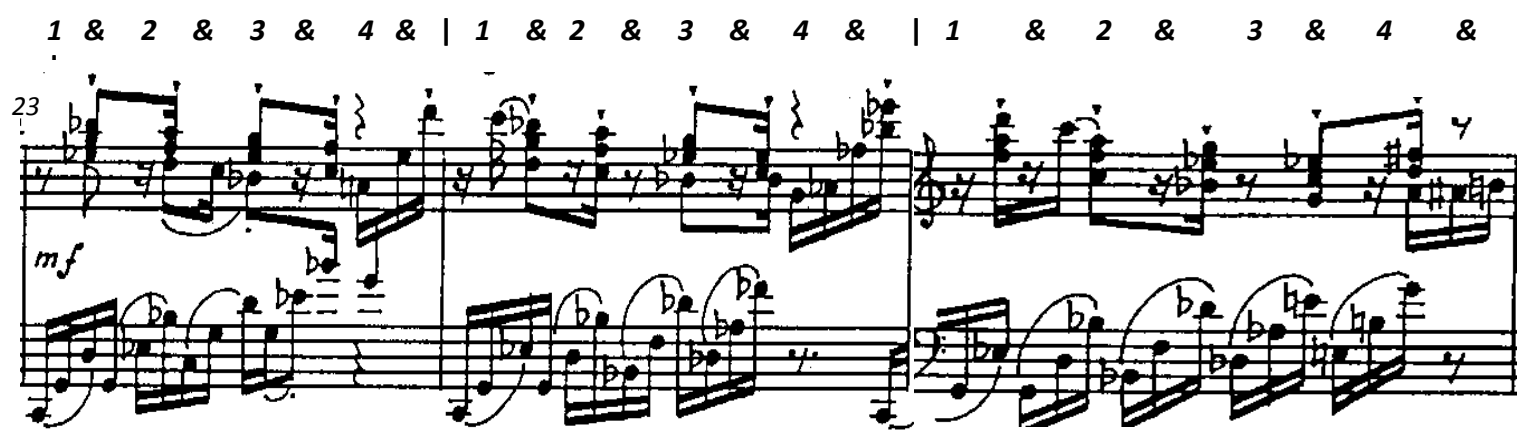

Example 21.3: Allegro Assai, Exposition - Theme A2, mm. 23-25 
The most challenging rhythmic figure in the entire piece occurs at the beginning of the Recapitulation of the second movement (Example 21.4). Complex usage of tied notes in conjunction with left-hand patterns harshly obscure the performers sense of pulse. The lefthand part proves particularly confusing due to the absence of downbeats.

\section{Hemiola with Ties, downbeat occurs every other measure}
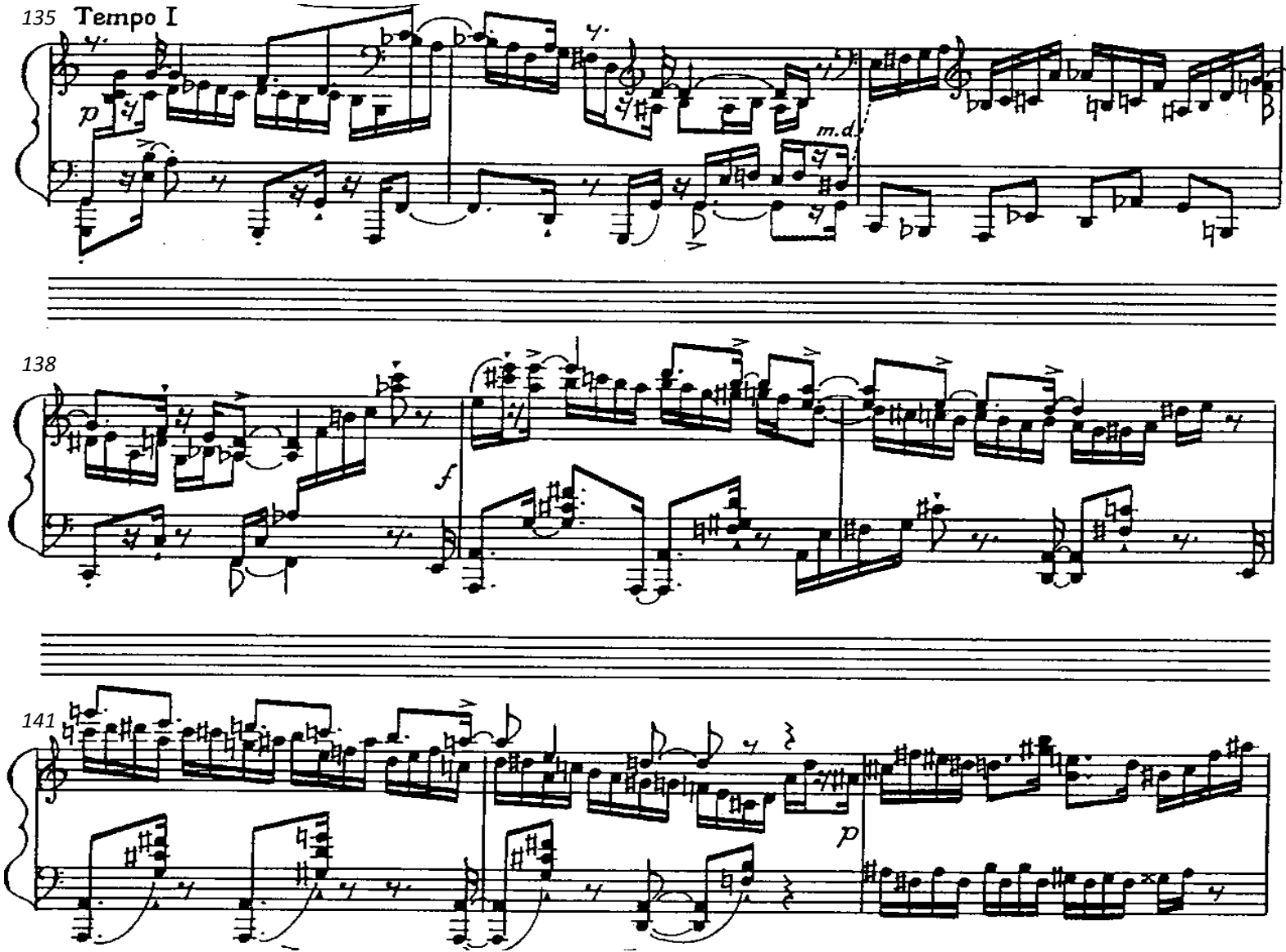

Example 21.4: Allegro Assai, Recapitulation - Theme A1, mm. 135-142

The best method to attain accurate memory and pulse is practicing very slowly, either counting aloud or with a metronome, while focusing on which notes fall on the eighth-note or quarter-note pulse. There are two schools of thought concerning hemiola-some feel it is 
important to maintain the quarter-note pulse, while others feel the pattern exists separate from pulse. The noticeable difference between the two methods, in most cases throughout this piece, is minimal due to the style of piece and its specific articulation. The most important factor is to be able to re-center oneself around the pulse as soon as the pattern ends, in order to maintain the overall flow of the piece.

Mastering the different styles of Opus 102 absolutely relies on the strength of the pianist's control of the harmonic flow of the work. In order to achieve the accurate style, Kapustin provides clues to the performer concerning how to pedal the sonata. Pianists pedal around harmonic movement in order to provide clarity; however, Kapustin often writes pedaling within the articulation as well. The most common occurrence of such articulation can be seen as a tie which has no target note. Correctly realizing such a notation simply means that the note is held with pedal until the harmony changes. This first appears during the Introduction (m. 3) of the Allegretto. In this case, the pedal will be held until the third beat where the E dominant $7^{\text {th }}$ chord occurs (Example 22.1/22.2). These types of ties occur in the right-hand part as well, though coinciding with a tie in the left-hand part (mm. 17-18).

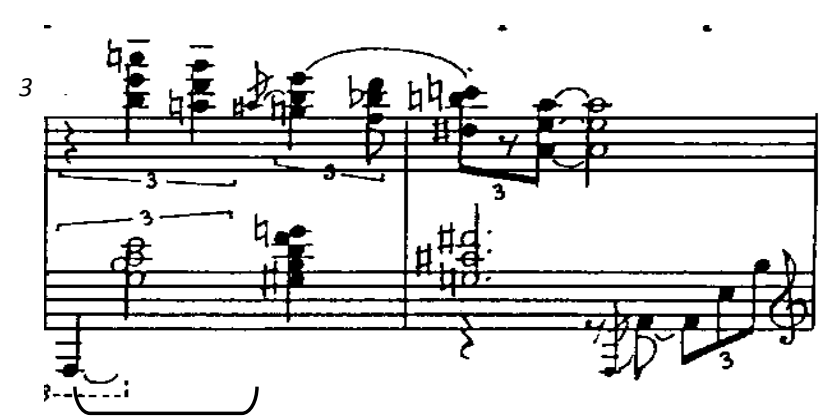

Example 22.1: Allegretto, Introduction - long pedal expressed as an indefinite tie, mm. 3-4 


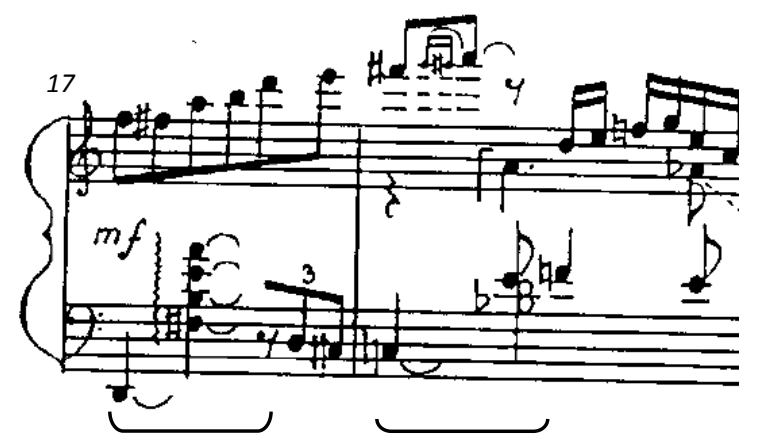

Example 22.2: Allegretto, Introduction - pedal as a tie in both hands, mm. 17-18

Another important aspect to proper pedaling is the ability to pedal with musical

motives. Theme B from the Allegretto movement is presented as an awkwardly articulated triplet figure ending in two syncopated upbeats. Pedaling the first note of the slur while lifting during the latter will assist the performer in clarity of both rhythm and melody. By the third measure of the theme, another long pedal occurs, though no indefinite tie exists. The harmony of the first two beats moves chromatically from D-Minor to D-flat Major. In this case, pedaling for the first two beats fits very nicely. On beat three, a tenuto mark followed by a staccatissimo should be pedaled and abruptly cut off during the final sixteenth note (Example 22.3).

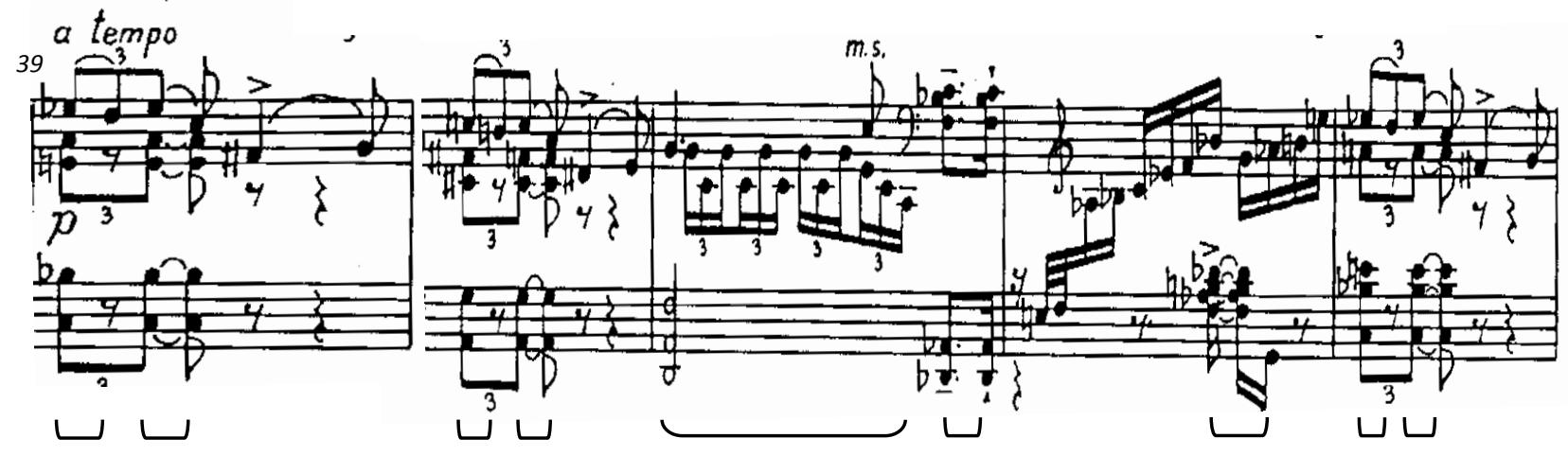

Example 22.3: Allegretto, Exposition - stylistic pedaling, mm. 39-43 
In general, more lyrical themes will have more pedal, such as the Introduction, Theme Group A, and the Development of the Allegretto, as well as Theme Group B from the Allegro Assai. However, more aggressive themes such as Theme Group A and the Closing Theme of the second movement require more intricate pedaling. This type of pedaling requires observation of both harmonic and melodic patterns (Example 22.4). In this example, the pedal changes nearly every half beat. Also, the actual use of the term Ped occurs to help guide the pianist. This is one of the few times Kapustin actually uses this term throughout Opus 102.

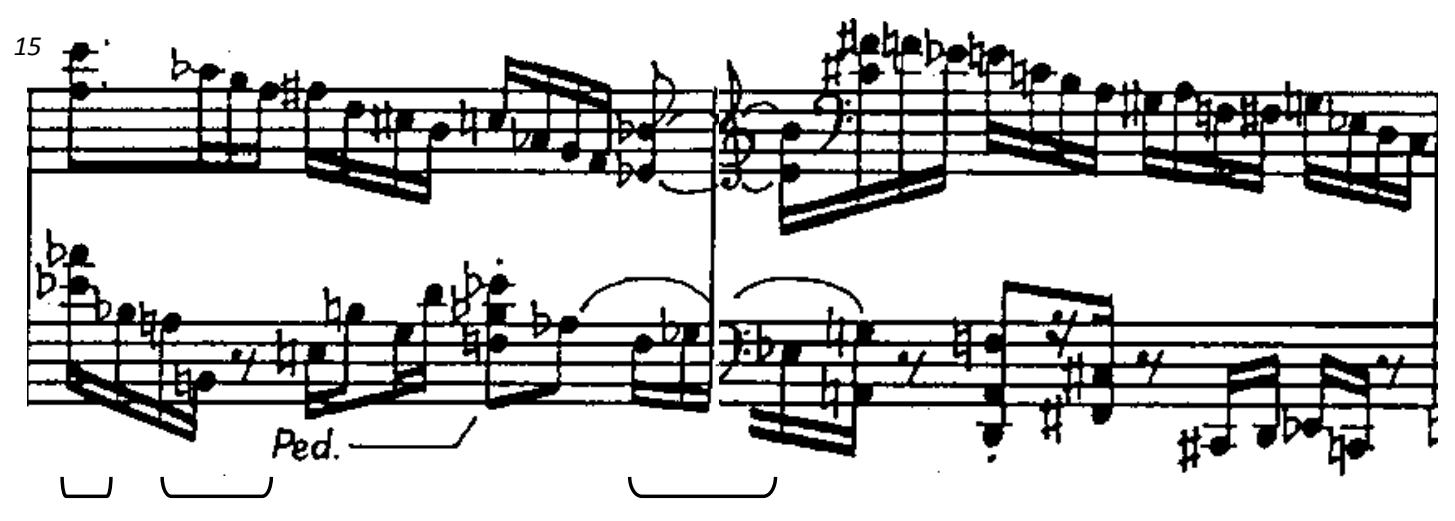

Example 22.4: Allegro Assai, Exposition - Theme A1, mm. 15-16

During the Closing Theme of the second movement, pedaling is best reserved as a method of voicing the melody more smoothly. It can be quite effective to simply pedal with the accented or tied notes briefly providing extra resonance (Example 22.5). If one pedaled each entire harmony during this passage, the abundance of left hand notes would simply overpower the melody. Often when the left hand has a repeated pattern, it requires little or no pedal. Additionally, the chromatic nature of the melodic line is best heard with conservative pedaling. 


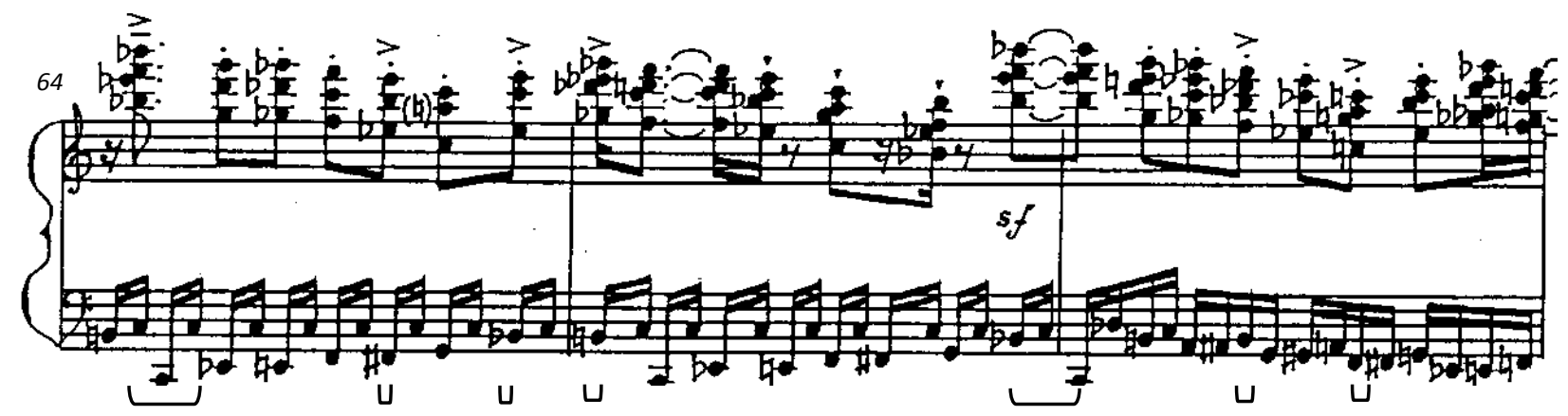

Example 22.5: Allegro Assai, Exposition - Closing Theme, mm. 64-66

Another aspect of jazz music that can be difficult to internalize is the use of extended harmonies, often stacked in $4^{\text {th }} \mathrm{s}$. Of particular importance is the order of the $4^{\text {th }} \mathrm{s}$, with the perfect $4^{\text {th }}$ being stacked upon the augmented $4^{\text {th }}$. This voicing appears commonly in jazz since the harmony is derived from the dominant $7^{\text {th }}$ chord, with the $3^{\text {rd }}$ and $7^{\text {th }}$ of the chord being represented by the augmented $4^{\text {th }}$ (or tritone) interval. A common substitution, called tritone substitution, is possible because dominant chords with roots separated by a tritone share similar chord tones (most notably the $3^{\text {rd }}$ and $7^{\text {th }}$ are inversions of each other). The top interval (perfect $4^{\text {th }}$ ) implies a different chord tone depending on the root (\#9 or 13), but the lower interval will nearly always be either the $3^{\text {rd }}$ or $7^{\text {th }}$ of the chord. To the pianist new to these harmonies, learning this shape in a variety of keys will prove substantially beneficial. Practicing the chords in sets of two, resolving the entire shape down by half-step, will aid the performer to quickly develop a broader harmonic vocabulary. Kapustin often utilizes harmonic movement in this manner as it is consistent with harmonies and voicings often seen in jazz and blues (Example 23). 

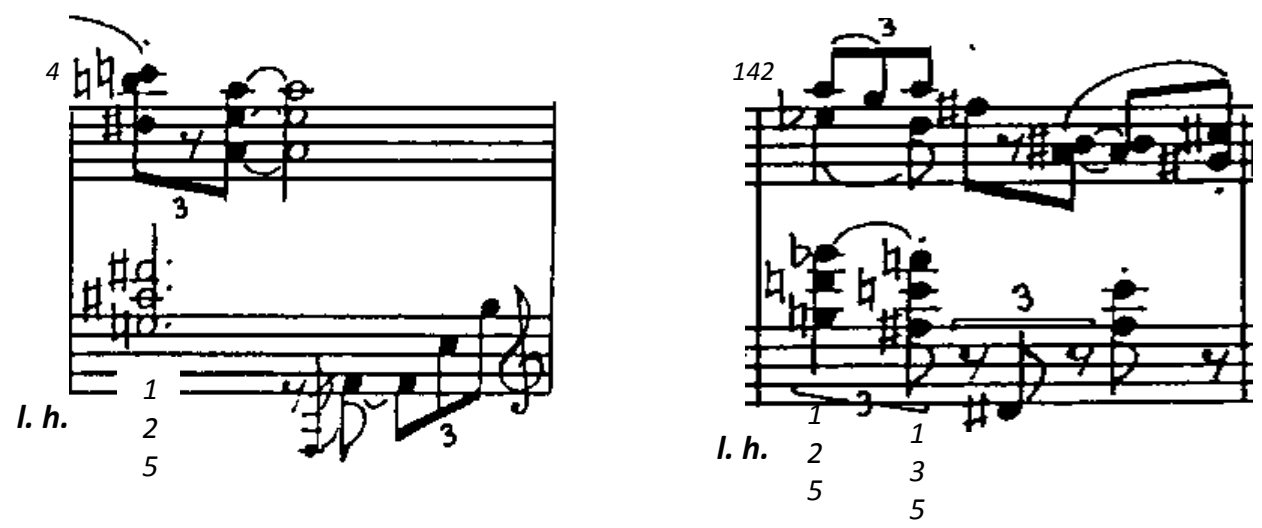

Example 23: Allegretto, Introduction/Recapitulation - chord voicings, mm. 4 (left), 142 (right)

Jazz pianists often use root-less voicings simply because they have to avoid clashing with the bass player. The classical pianist, however, very often plays strong bass lines. Without prior knowledge, the harmony can prove challenging. The most important aspect about these voicings is that they are arranged in $4^{\text {th }} \mathrm{s}$, with the $3^{\text {rd }}$ and $7^{\text {th }}$ of each chord as the base structure of the chord. The $3^{\text {rd }}$ chord tone is located a $4^{\text {th }}$ above this base structure and will always be an alteration or extension $\left(\# 9^{\text {th }}, 13^{\text {th }}\right)$. Below is a chart that displays chord tones for each pitch using this voicing (Chart 3). Note the overlap between harmonies with roots an augmented $4^{\text {th }}$ apart. 
Root-less Dominant Chord Voicings in $4^{\text {th }} \mathrm{S}$

\begin{tabular}{|c|c|c|c|c|}
\hline $3^{\text {rd }}$ & $7^{\text {th }}$ & $\# 9^{\text {th }}$ & $13^{\text {th }}$ & IMPLIED ROOT \\
\hline$E$ & B Flat & E Flat & $A$ & C \\
\hline B Flat & F Flat (E) & A Natural & E Flat & G Flat \\
\hline F Sharp & C & E Sharp (F) & $A$ & $D$ \\
\hline C & G Flat (F Sharp) & B Natural & $\mathrm{F}$ & A Flat \\
\hline G Sharp & $\mathrm{D}$ & F Double Sharp (G) & C Sharp & $E$ \\
\hline $\mathrm{D}$ & A Flat (G Sharp) & C Sharp & G & B Flat \\
\hline$A$ & E Flat & G Sharp & $\mathrm{D}$ & $\boldsymbol{F}$ \\
\hline D Sharp (E Flat) & $A$ & C Double Sharp & G Sharp & B \\
\hline B & $\mathrm{F}$ & A Sharp & $E$ & $\boldsymbol{G}$ \\
\hline $\mathrm{F}$ & C Flat (B) & E Natural & B Flat & D Flat \\
\hline C Sharp & G & B Sharp (C) & F Sharp & $A$ \\
\hline G & D Flat (C Sharp) & F Sharp & C & E Flat \\
\hline
\end{tabular}

Chart 3: Dominant harmonies voiced in $4^{\text {th }} s$ - Note the chords are listed in pairs to showcase that dominant chords with roots a tritone (aug. $4^{\text {th }}$ ) apart contain inverted $3^{\text {rd }} / 7^{\text {th }}$ as well as $\# 9 / 13^{\text {th }}$ chord tones. Voicings only include three out of four of the above listed tones: either $3^{\text {rd }}, 7^{\text {th }}, \# 9^{\text {th }}$ or $7^{\text {th }}, 3^{\text {rd }}, 13$.

The rhythm section often determines the style of a song before the melody or soloist enters. If applied to a solo jazz piano piece, this translates into the left hand often dictating the style of a given section. Pianists such as Art Tatum and Oscar Peterson possessed a mastery of 
jazz techniques and styles of the left hand. Many of these left-hand techniques exist in Opus 102 as well. Since the first movement is mostly representative of either a lyrical or swing style, many of these devices are located during the second movement.

Stride bass helped pianists like Tatum imitate the depth of harmonic color from the jazz combo while still providing a strong bass line (playing the entire rhythm section with just one hand). In this technique, the bass note is played low while the chord follows immediately in the middle register of the keyboard, often with no pedal support. The rhythm is predominantly constant eighth notes in order to drive a steady pulse. The pattern repeats every beat for several beats, requiring absolute control of the left hand. At high speeds, stride proves incredibly challenging. The first time Kapustin uses stride in the Allegro Assai movement occurs in measures 10 and 12 (Example 24.1). Different forms of simplification are often the most efficient manner to learn sections that exhibit stride. Learning the upper chord progression first often allows the pianist to understand the harmonic movement before compounding the difficulty with the bass line. After the bass and chords are memorized, practice slowly while aligning the hand with the following eighth note as quickly as possible. Think: Arrive early, play later. Eventually the coordination of the two hands develops and the passage becomes performable. As with any split pattern, the eyes should hover toward the middle of the keyboard, using peripheral vision only to locate bass notes. Ideally, one can use their first and second finger to cover both upper notes in the following example. 


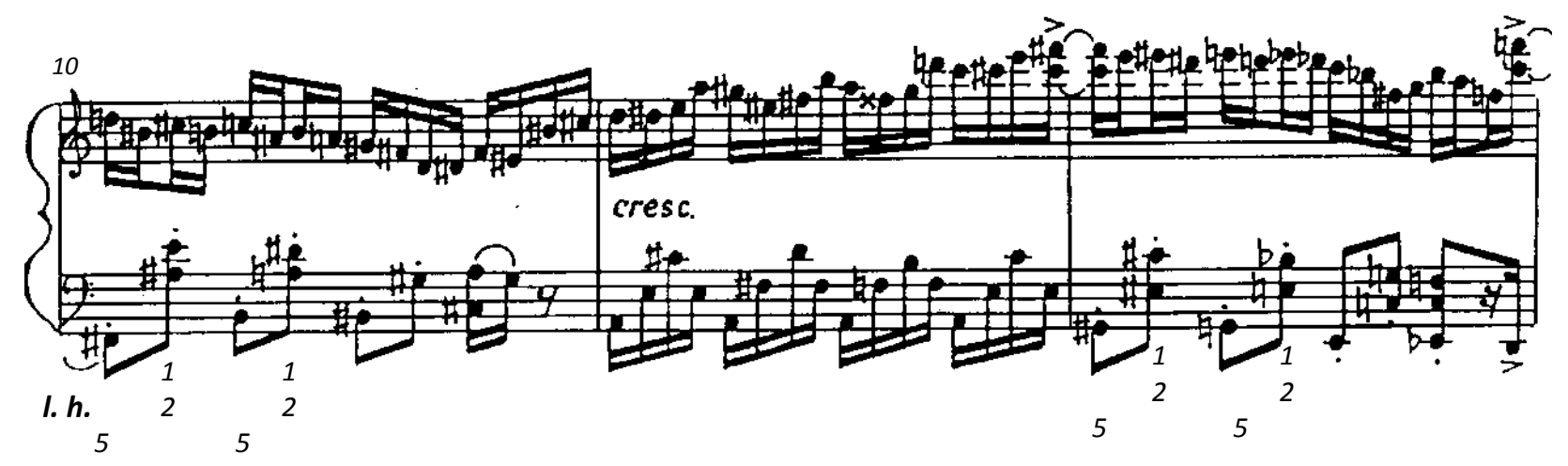

Example 24.1: Allegro Assai, Exposition - Theme 1A, stride bass fingering, mm. 10-12

The blues bass line from the Closing Theme to the Allegro Assai can be cumbersome at higher speeds. The pattern outlines the blues scale of each chord to begin the section. The reoccurrence during the Recapitulation is slightly more complex but the technique is identical. For smaller hands especially, fingering and rotation are critical aspects in playing this section at full tempo. The fingering suggestion in the example below is preferable for smaller hands as any interval larger than $5^{\text {th }}$ or $6^{\text {th }}$ can be hard to sustain (Example 24.2). After the fifth finger moves up to F natural, the rest of the hand can complete the figure with just arm rotation. This entire section will benefit from memorizing and practicing the left hand separately from the right hand until movement between notes feels natural. Additionally, learning and memorizing the left-hand intervals in blocked pairs using the correct fingering will help provide a strong foundation for this figure. 


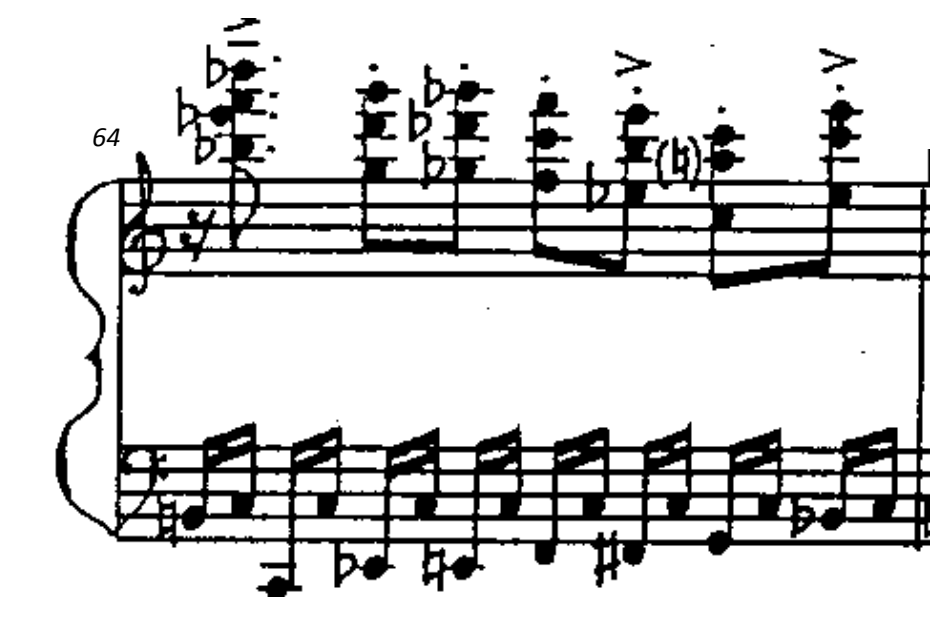

l. h. $\quad \begin{array}{lllllllllllllllll}2 & 1 & 5 & 1 & 4 & 1 & 5 & 1 & 5 & 1 & 4 & 1 & 3 & 1 & 2 & 1\end{array}$

Example 24.2: Allegro Assai, Exposition - Closing Theme - blues bass line fingering, mm. 64

The walking bass line represents another highly prevalent left-hand style for jazz

pianists. An impressive, highly chromatic walking bass line exists during the Development of the second movement of Opus 102. To further complicate the passage, the right hand exhibits a strong improvisatory feel. The section lasts eight measures with consistent eighth-note pulse. Nearly every downbeat is the root of the chord while the second eighth of each pair is almost always a passing tone. These eight measures benefit from practicing in varied rhythms, as the focus of such practice is to learn the coordination between the hands while memorizing the section in micro motives. The process of this technique simply involves practicing each beat at near tempo with large pauses between each beat. The first sixteenth receives a fermata and the following three sixteenth-notes become a triplet-type rhythm leading to the next beat. The fermata is not necessarily held; it simply signifies a pause of indefinite length, while the triplets should be played cleanly and as fast as possible (Example 24.3). This same process can be repeated moving the fermata to any sixteenth note of the beat, using quicker notes to navigate 
the notes between each pause. The two most beneficial rhythms are often the first or last sixteenth of each beat. Keeping relaxed between each beat is paramount in producing a controlled sensation. An additional benefit of this method is that muscle-memory tends to develop quite rapidly. This technique can be applied to much of the more difficult passage-work in Opus 102, such as the Closing Theme from this movement.

r. $h$.

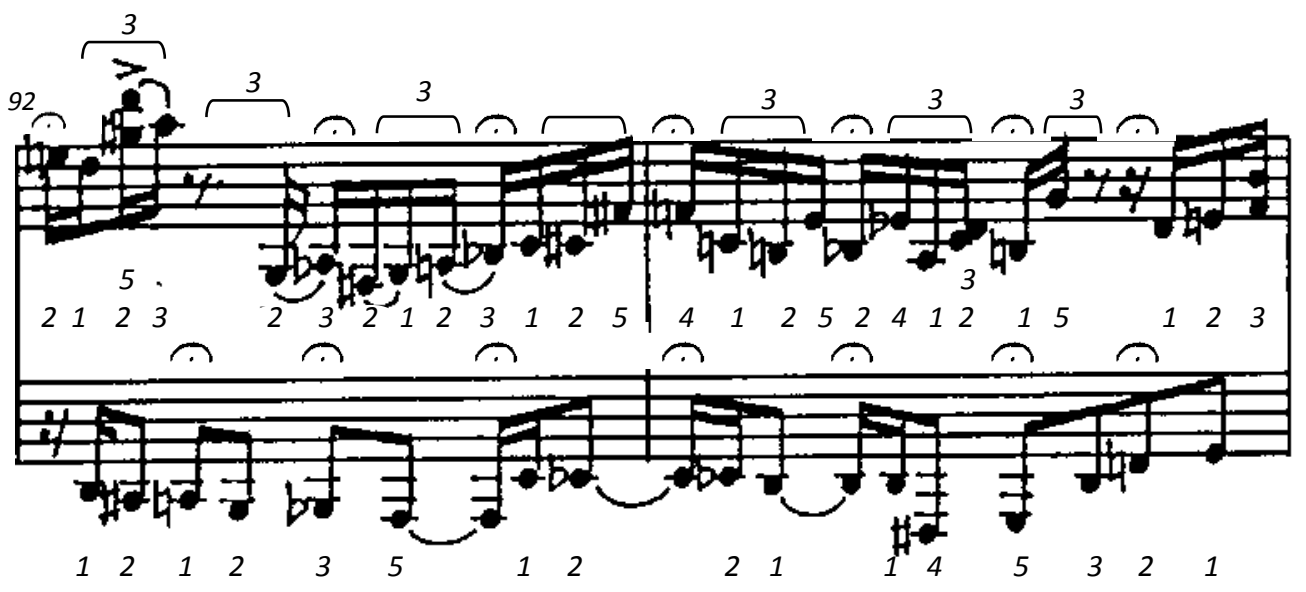

I. $\boldsymbol{h}$.

Example 24.3: Allegro Assai, Development - Walking bass line, mm. 92-93

Since Nikolai Kapustin is a virtuoso pianist himself, his piano music often has strong idiomatic writing. Aside from a few instances, mostly due to smaller hand size, hand distribution between the voices can be followed directly as it has been scored. The voice leading, though more complex than traditional Classical or Romantic sonatas, has clearly been indicated throughout the piece. Generally, the performer should attempt to finger similar motives identically. The most important factors in strong fingering are consistency and ease, both physically and mentally. If a fingering is too difficult to play physically or awkward to memorize mentally, the passage will suffer in terms of clarity until the fingering is simplified. The 'blues motive' from the first movement can be fingered in nearly the exact same manner 
throughout the work, providing a consistent tactile feel for the performer. The only exception to this fingering occurs in measure 49 , due to a slight variation in the motive (Example 25).

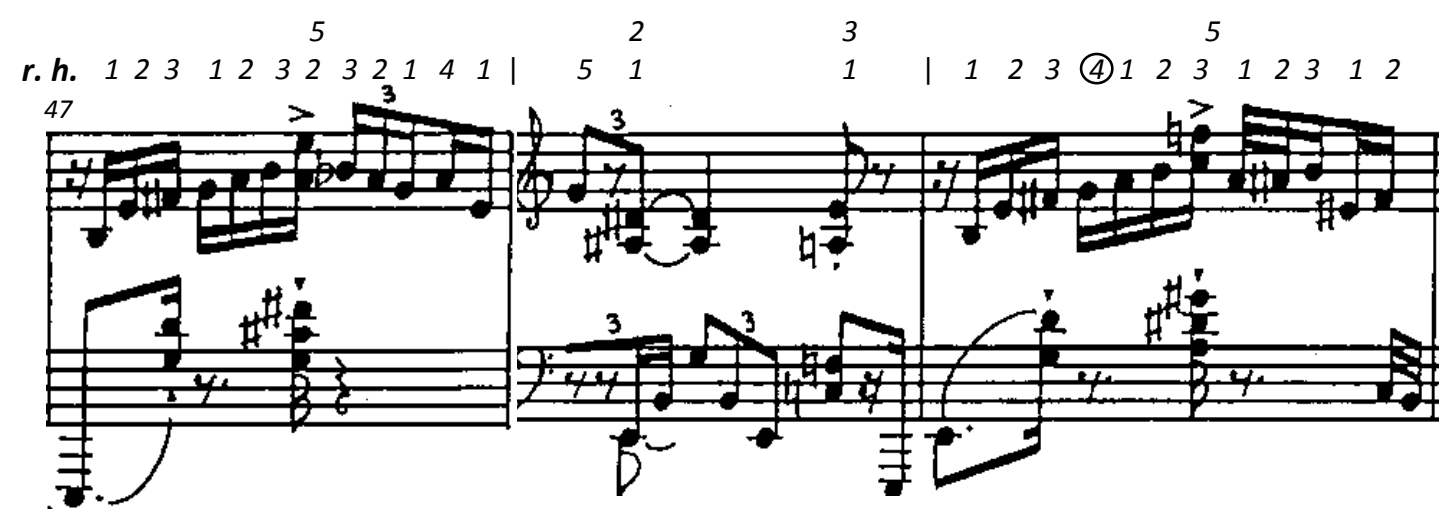

Example 25: Allegretto, Exposition - Theme B, 'blues motive' fingering followed by variation, mm. 47-49

Comparing editions can yield crucial observations for any piece of music. Though this can be a great idea for any work, older pieces of music tend to have more variance between editions. For the purpose of learning a piece, published editions are often clearer and easier to read. Unfortunately for performers, misprinting still exists in modern editions. However, due to the internet and easier access to scores and manuscripts, correcting these errors merely requires an observant musician to make score comparisons. While comparing the manuscript of Opus 102 with the published A-RAM Moscow edition, only three discrepancies were present, each located in the second movement. In measure 117 of the published score, the bass line has an E-natural followed by an F-natural, occurring on beat two in the left hand. In order to preserve the integrity of the Theme B1 motive, the E-natural should be followed by a G-natural (Example 26). 

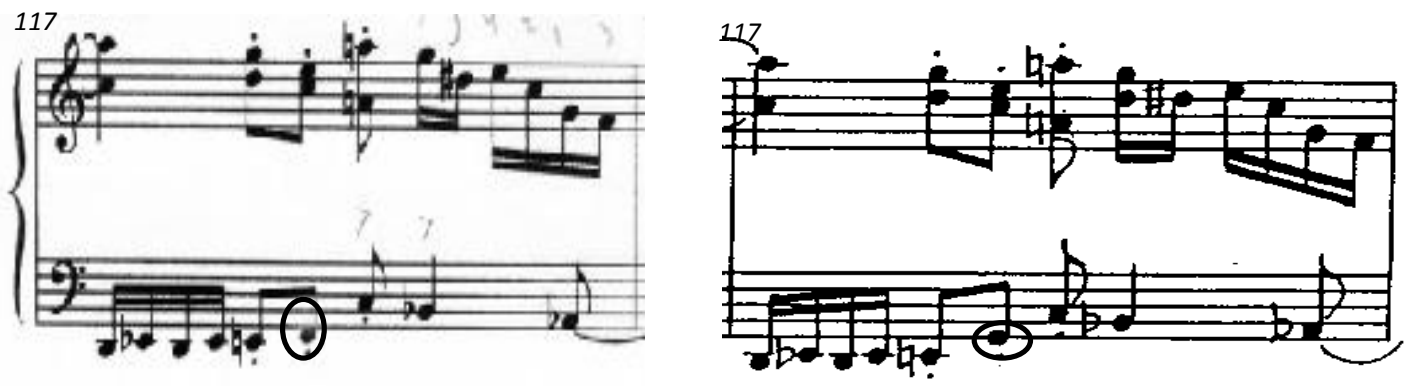

Example 26.1: Allegro Assai, Development - error in published A-RAM Moscow (left) ${ }^{45}$; manuscript (right), m. 117

The second error is located during the third beat of measure 156. In the published edition, an E-flat followed by an additional E-flat in successive sixteenth notes is present and clearly does not fit the melodic contour of the musical line. The manuscript version contains the correct notes, an E-natural followed by an E-flat (Example 26.2).
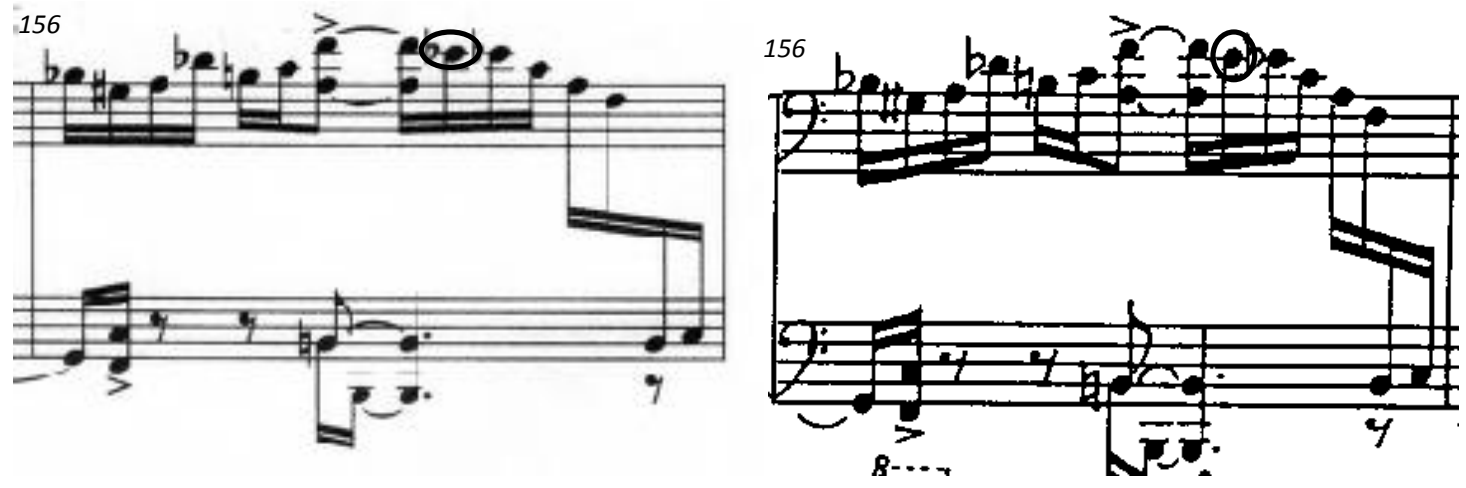

Example 26.2: Allegro Assai, Recapitulation - error in A-RAM Moscow(left); manuscript (right), m. 156

The final error occurs in the left hand during the Closing Theme of the second movement (Example 26.3). In this instance, the left hand is much easier when played with the manuscript version. The tonality is a B dominant $7^{\text {th }}$, with the C-Sharp representing the $9^{\text {th }}$ of the chord, however the right hand already has a $9^{\text {th }}$ occurring just a half-beat later.

\footnotetext{
${ }^{45}$ Score Examples on left side of this page and the following page are from Piano Sonata No. 12 Opus 102 A-RAM Moscow Edition and are intended for educational purposes only.
} 

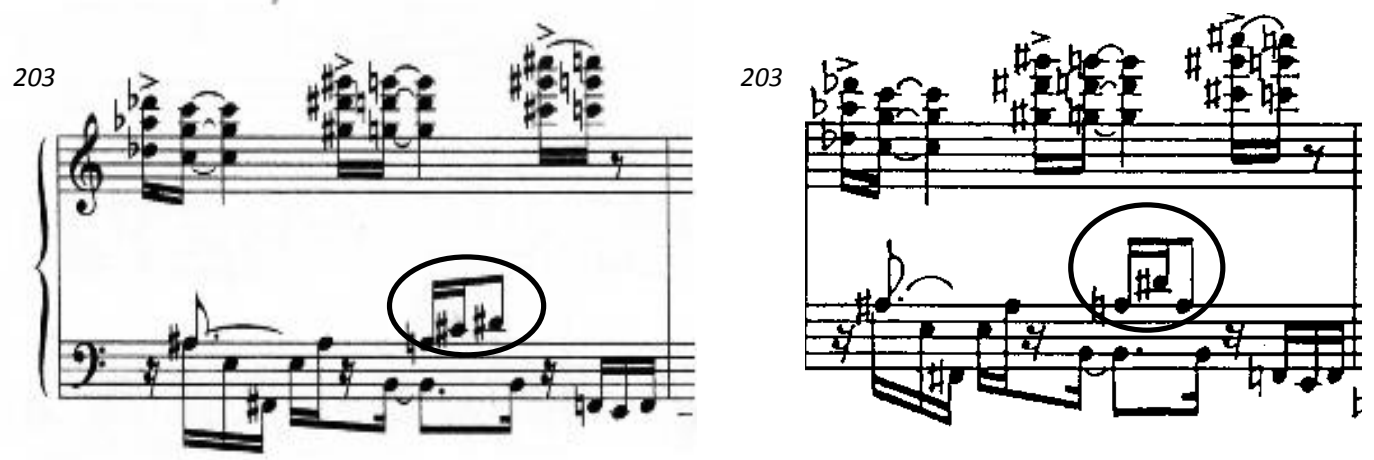

Example 26.2: Allegro Assai, Recapitulation - error in A-RAM Moscow (left); manuscript (right), m. 203

Nikolai Kapustin's Sonata No. 12, Opus 102 presents a considerable challenge for the experienced pianist. Kapustin's mastery of jazz harmonies and styles is equally matched by his ability to craft and develop meaningful musical motives. Possessing a basic understanding of the most common jazz concepts will not only aid the performer's interpretation of Opus 102, but provides a strong foundation for the proper styles required to play this piece effectively. These concepts include ideas such as swing, stride bass, and walking bass. Kapustin's use of articulation is both unique and immensely helpful to pianists learning his music. The proper use of pedal depends on keen observation of both articulation and harmony. Following Kapustin's detailed articulation implicitly is a major component of mastering of this work. 


\section{Chapter Five}

\section{Conclusion}

Nikolai Kapustin's style presents an exquisite union of classical forms with jazz musical elements. Kapustin's music combines traditional classical musical genres with exotic jazz harmonies and complex jazz rhythms. Born in the Ukraine in 1937, Kapustin had limited access to jazz music due to restrictions by the Russian government. Astoundingly, he was able to transcribe American jazz radio shows while he finished his traditional education at the Moscow Conservatory. At this point, he knew his life goal would be to fuse classical and jazz music. While transcribing parts for Oleg Lundström's Big Band for over a decade, Kapustin wrote and performed a number of his early works. By the 1970's, his style had matured greatly as he became more familiar with composition. Thirty years later, the West was introduced to Kapustin in London during Marc-André Hamelin's premiere of Sonata No. 2, Op. 54.

The sonata genre represents a critical genre for the classical pianist. Nearly every great composer of piano works has written in this genre. From Ludwig van Beethoven and Franz Liszt to Alexander Scriabin and Sergei Prokofiev, the sonata has evolved greatly but the principle concept remains the same. Themes, or groups of themes, will share a key relationship and are often polarized stylistically from one another. The themes are then developed in some manner during the Development and return in the tonic key during the Recapitulation. As a genre, sonatas have typically had three movements, the first of which must be cast in sonata form. Though Kapustin's Sonata No. 12, Op. 102 is only two movements, both movements are composed in fairly strict sonata form. 
Kapustin's Sonata No. 12 presents a considerable challenge for pianists. The incredibly complex rhythm and harmony are exacerbated by fast tempi and rapid style changes. Listening to recordings of Kapustin's music will accelerate the learning process immensely. The swing style of the Allegretto can be difficult to sense as the duple pulse often interrupts any successive swing beats. Dividing and counting measures without playing any notes is one method for internalizing the rhythmic and stylistic feel of the first movement. Learning to pedal effectively can make awkward rhythms feel more secure.

The Allegro Assai movement contains a number of adversities that must be overcome to perform the movement effectively. The coarse syncopated textures from the opening theme only become more rhythmically ambiguous during the Recapitulation. Kapustin's use of chromaticism increases as the movement proceeds, with moments of harmonic clarity to provide textural relief. The second theme's lyricism feels somewhat brief as the movement quickly progresses toward an energetic Closing Theme. Elaborate left-hand figures, often utilizing standard jazz techniques such as stride and walking bass, also provide considerable challenge. The harmonic language throughout the entire work can feel foreign to pianists unfamiliar with jazz. Learning some basic jazz voicings as provided in this document can help aid in this progression.

Kapustin's Sonata No. 12, Op. 102 is an exemplary model of the modern-day sonata. The cohesiveness of the thematic material throughout both movements is astonishing. The organic evolution of the theme groups gently flows from one section of music to the next. The stylist challenges posed by this sonata are rather demanding; however, the score contains 
extensive details to assist pianists to achieve proper style. It is my hope that this study will inspire more pianists to analyze and perform the works of Nikolai Kapustin! 


\section{Bibliography}

Encyclopedias

Grigoryeva, Alla Vladimirovna. "Kapustin, Nikolay Girshevich." In Grove Music Online. Oxford Music Online.

Sandra Mangsen, et al. "Sonata." In Grove Music Online. Oxford Music Online.

Schuller, Gunther. "Third Stream." In Grove Music Online. Oxford Music Online.

Internet/Database

Breemer, Chris. "Nikolai Kapustin.” Accessed March 10, 2017.

www.pianosociety.com/cms/index.php?section=1454.

en.wikipedia.org/wiki/Nikolai_Kapustin. Accessed March 10, 2017.

www.nikolai-kapustin.info/. Accessed March 10, 2017.

Books

Rosen, Charles. Sonata Forms. New York: W.W. Norton, 1980.

Dissertations

Choi, Jiwon. An Eclectic Combination of Classical and Jazz Idioms: Nikolai Kapustin's Piano Works. D.M.A. Diss. University of Kansas, 2015. Web. 10 Mar. 2017.

Mann, Jonathan Edward. Red, White, and Blue Notes: The Symbiotic Music of Nikolai Kapustin. D.M.A. Diss. University of Cincinnati, 2007. Web. 10 Mar. 2017.

Roberts, Jonathan E. Classical Jazz: The Life and Musical Innovations of Nikolai Kapustin. University of Alabama, Ann Arbor, 2013. Web. 10 Mar. 2017.

Tyulkova, Yana. Classical and Jazz Influences in the Music of Nikolai Kapustin: Piano Sonata No. 3, Op. 55. West Virginia University, Morgantown, 2015. Web. 10 Mar. 2017.

Periodicals

Anderson, Colin. "Steven Osborne, Seeking Music Where "There's Something Deep Being Said." Fanfare: The Magazine for Serious Record Collectors 31, no. 2 (November/December 2007): 18-26.

Anderson, Martin. "Nikolai Kapustin, Russian Composer of Classical Jazz." Fanfare: The Magazine for Serious Record Collectors 24 (September 2000): 93-98. 
Bayley, Lynn René. "FUSION: Music for a New Age." Fanfare: The Magazine for Serious Record Collectors 39, no. 3 (January/February 2016): 527-528.

Becker, Alan. "24 Preludes in Jazz Style." American Record Guide 74, no. 1, (January/February 2011): 147.

Bellman, Jonathan. "Guide to Records: KAPUSTIN." American Record Guide 64, no. 2 (March/April 2001): 116.

Smith, Harriet. "Bridging the Divide: The Russian Composer Nikolai Kapustin." International Piano Quarterly 4, no.13 (Autumn 2000): 54-55.

Musical Scores

Kapustin, Nikolai. Piano Sonata No. 12, Op 102. Manuscript edition. www.nikolai-kapustin.info/sheetmusic_piano_sonatas.html Piano Sonata No. 12, Op. 102. Moscow: A-RAM, 2006.

Recordings

Kapustin, Nikolai. Last Recording. Triton OVCT-00017, 2004. 
Appendix A

Chart 1: Sonata Form within Opus 102, I. Allegretto

\begin{tabular}{|c|c|c|c|}
\hline Section & Measures & $\begin{array}{c}\text { Number of } \\
\text { Measures }\end{array}$ & Key Area/Root \\
\hline Exposition & $1-72$ & 72 & \\
\hline Introduction & $1-8$ & 8 & A-Minor \\
\hline Theme A1 & $9-24$ & 16 & A-Minor \\
\hline Theme $A 2$ & $25-38$ & 14 & C-Major/G \\
\hline Theme B & $39-72$ & 34 & C-Major/Dominant \\
\hline Development & $73-110$ & 38 & \\
\hline Recapitulation & $111-168$ & 58 & \\
\hline Theme A1 & $111-123$ & 11 & A-Major \\
\hline Theme $A 2$ & $124-136$ & 13 & G-Major/D \\
\hline Theme B & $137-168$ & 32 & A-Minor \\
\hline Coda (Theme A1) & $169-180$ & 12 & A-Minor \\
\hline
\end{tabular}


Chart 2: Sonata Form within Opus 102, II. Allegro Assai

\begin{tabular}{|c|c|c|c|}
\hline Section & Measures & \# of Measures & Harmony \\
\hline Exposition & $1-85$ & 85 & \\
\hline Theme A1 & $1-18$ & 18 & A Aeolian \\
\hline Theme A2 & $19-26$ & 8 & B Dorian \\
\hline Theme B1 & $27-40$ & 14 & E flat $>$ A flat Dominant, sus $4 / 2$ \\
\hline Theme B2 & $41-55$ & 15 & A minor sus 4 (no $3^{\text {rd }}$ ) \\
\hline Transition & $56-61$ & 6 & \\
\hline Closing Theme & $62-85$ & 24 & $\mathrm{C}$ blues \\
\hline Development & $86-134$ & 49 & \\
\hline Recapitulation & $135-205$ & 71 & \\
\hline Theme A1 & $135-152$ & 18 & $\begin{array}{c}\text { A (Both Major/Minor by } m . \\
139)\end{array}$ \\
\hline Theme A2 & $153-164$ & 12 & A Dorian \\
\hline Theme B1 & $165-172$ & 8 & C Dominant $7^{\text {th }}$ sus $4 / 2$ \\
\hline Theme B2 & $173-194$ & 22 & F Major \\
\hline Cadenza/Transition & 195 & 1 & F Minor \\
\hline Closing Theme & $196-205$ & 10 & A Blues \\
\hline Coda & $206-228$ & 23 & A \\
\hline
\end{tabular}


Chart 3: Root-less Dominant Chord Voicings in $4^{\text {th }} \mathrm{S}$

\begin{tabular}{|c|c|c|c|c|}
\hline $3^{\text {rd }}$ & $7^{\text {th }}$ & $\# 9^{\text {th }}$ & $13^{\text {th }}$ & IMPLIED ROOT \\
\hline $\mathrm{E}$ & B Flat & E Flat & A & $C$ \\
\hline B Flat & F Flat (E) & A Natural & E Flat & G Flat \\
\hline F Sharp & $\mathrm{C}$ & E Sharp (F) & A & $D$ \\
\hline C & G Flat (F Sharp) & B Natural & $\mathrm{F}$ & A Flat \\
\hline G Sharp & D & F Double Sharp (G) & C Sharp & $\boldsymbol{E}$ \\
\hline $\mathrm{D}$ & A Flat (G Sharp) & C Sharp & G & B Flat \\
\hline A & E Flat & G Sharp & $\mathrm{D}$ & $\boldsymbol{F}$ \\
\hline D Sharp (E Flat) & A & C Double Sharp & G Sharp & $B$ \\
\hline B & $\mathrm{F}$ & A Sharp & $E$ & $\boldsymbol{G}$ \\
\hline $\mathrm{F}$ & C Flat (B) & E Natural & B Flat & D Flat \\
\hline C Sharp & G & B Sharp (C) & F Sharp & $A$ \\
\hline G & D Flat (C Sharp) & F Sharp & C & E Flat \\
\hline
\end{tabular}


Appendix B

\section{List of Works}

Op. 1: Concertino for Piano and Orchestra (1957)

Op. 2: Concerto for Piano and Orchestra No. 1 (1961)

Op. 3: Variations for Piano and Big Band (1962)

Op. 4: Chorale and Fugue for Orchestra (1962)

Op. 5: Piece for Trumpet and Band (1962)

Op. 6: "Rose-Marie" Fantasia for Orchestra (1963)

Op. 7: Fantasia on Three Children's Songs for Orchestra (1963)

Op. 8: Toccata for Piano and Orchestra (1964)

Op. 9: The Trial for Orchestra (1966)

Op. 10: Big Band Sounds for Orchestra (1966)

Op. 11: Estacade for Big Band (1966)

Op. 12: Aquarium Blues for Big Band (1967)

Op. 13: Intermezzo for Piano and Orchestra (1968)

Op. 14: Concerto for Piano and Orchestra No. 2 (1974)

Op. 15: The Forest Story for Orchestra (1972)

Op. 16: Nocturne for Piano and Orchestra (1972)

Op. 17: Three Pieces for Orchestra (1972)

Op. 18: Four Pieces for Instrumental Ensemble (1973)

Op. 19: Etude for Piano and Orchestra (1974)

Op. 20: Nocturne for Piano and Orchestra (1974)

Op. 21: Minuet for Big Band (1974)

Op. 22: Piece for Five Saxophones and Orchestra (1975)

Op. 23: Enigma for Big Band (1975)

Op. 24: March for Orchestra (1975)

Op. 25: Concert Rhapsody for Piano and Orchestra (1976)

Op. 26: Daybreak (Sunrise) for Piano (1976)

Op. 26a: Daybreak (Sunrise) for Orchestra (1976)

Op. 27: Fantasia for Jazz Quartet (1976)

Op. 28: Suite in the Old Style for Piano (1977)

Op. 29: Scherzo for Piano and Orchestra (1978)

Op. 30: Two-movement Concerto for Orchestra (1980)

Op. 31: Elegy for Orchestra (1980)

Op. 32: The Wind from the North for Orchestra (1981)

Op. 33: Piece for Two Pianos and Orchestra (1982)

Op. 34: Meridian for Orchestra (1982)

Op. 35: Closed Curve for Orchestra (1982)

Op. 36: Toccatina for Piano (1983)

Op. 37: The Pleasant Meeting for Orchestra (1983)

Op. 38: Presentiment for Orchestra (1983)

Op. 39: Piano Sonata No. 1 “Quasi una Fantasia” for Piano (1984) 
Op. 40: Eight Concert Studies for Piano (1984)

Op. 41: Variations for Piano (1984)

Op. 42: Rush Hour for Ensemble (1985)

Op. 43: An April Day for Ensemble (1985)

Op. 44: The Morning for Ensemble (1985)

Op. 45: Motive Force for Piano (1985)

Op. 46: Big Band Sounds for Piano (1986)

Op. 47: Contemplation for Piano (1987)

Op. 48: Concerto for Piano and Orchestra No. 3 (1985)

Op. 49: Sinfonietta for Orchestra (1987)

Op. 50: Concerto for Alto Saxophone and Orchestra (1987)

Op. 51: Overture for Big Band (1987)

Op. 52: Intrada for Big Band (1988)

Op. 53: Twenty-Four Preludes for Piano (1988)

Op. 54: Piano Sonata No. 2 (1989)

Op. 55: Piano Sonata No. 3 (1990)

Op. 56: Concerto for Piano and Orchestra No. 4 (1989)

Op. 57: Chamber Symphony for Chamber Orchestra (1990)

Op. 58: Andante for Piano (1990)

Op. 59: Ten Bagatelles for Piano (1991)

Op. 60: Piano Sonata No. 4 (1991)

Op. 61: Piano Sonata No. 5 (1991)

Op. 62: Piano Sonata No. 6 (1991)

Op. 63: Sonata for Cello and Piano No. 1 (1991)

Op. 64: Piano Sonata No.7 (1991)

Op. 65: Berceuse for Piano (1991)

Op. 66: Three Impromptus for Piano (1991)

Op. 67: Three Etudes for Piano (1992)

Op. 68: Five Etudes in Different Intervals for Piano (1992)

Op. 69: Sonata for Viola and Piano (1992)

Op. 70: Sonata for Violin and Piano (1992)

Op. 71: Capriccio for Piano (1992)

Op. 72: Concerto for Piano and Orchestra No. 5 (1993)

Op. 73: Ten Inventions for Piano (1993)

Op. 74: Concerto for Piano and Orchestra No. 6 (1993)

Op. 75: Humoresque for Piano (1994)

Op. 76: Concerto for Double Bass and Symphony Orchestra (1994)

Op. 77: Piano Sonata No. 8 (1995)

Op. 78: Piano Sonata No. 9 (1995)

Op. 79: Piece for Sextet (1995)

Op. 80: Theme and Variations for Piano (1996)

Op. 81: Piano Sonata No. 10 (1996)

Op. 82: Twenty-four Preludes and Fugues for Piano (1997)

Op. 83: Impromptu for piano (1997) 
Op. 84: Sonata for Cello and Piano No. 2 (1997)

Op. 85: Cello Concerto No. 1 (1997)

Op. 86: Trio for Flute, Cello and Piano (1998)

Op. 87: Seven Polyphonic Pieces for Piano Left Hand (1998)

Op. 88: String Quartet No. 1 (1998)

Op. 89: Piano Quintet (1998)

Op. 90: Concerto for Eleven Instruments (1998)

Op. 91: Divertissement for Two Flutes, Cello and Piano (1998)

Op. 92: Suite for Piano (1999)

Op. 93: Introduction and Scherzino for Cello Solo (1999)

Op. 94: Ballad for Piano (1999)

Op. 95: Scherzo for Piano (1999)

Op. 96: Elegy for Cello and Piano (1999)

Op. 97: Burlesque for Cello and Piano (1999)

Op. 98: Nearly Waltz for Cello and Piano (1999)

Op. 99: Duet for Alto Saxophone and Cello (1999)

Op. 100: Sonatina for Piano (2000)

Op. 101: Piano Sonata No. 11 "Twickenham" (2000)

Op. 102: Piano Sonata No. 12 (2001)

Op. 103: Concerto No. 2 for Cello and String Orchestra (2002)

Op. 104: Concert for Two Pianos and Percussion (2002)

Op. 105: Concert for Violin, Piano and String Orchestra (2002)

Op. 106: Suite for Viola, Alto Saxophone, Piano and Bass (2002)

Op. 107: Variations on "Sweet Georgia Brown" for Viola, Alto Saxophone, Piano and Bass (2002)

Op. 108: Paraphrase on a Theme of Paul Dvoyrin for Piano (2003)

Op. 109: There is Something Behind That for Piano (2003)

Op. 110: Piano Sonata No. 13 (2003)

Op. 111: Gingerbread Man for Piano (2003)

Op. 112: End of the Rainbow for Piano (2003)

Op. 113: Wheel of Fortune for Piano (2003)

Op. 114: No Stop Signs for Piano (2003)

Op. 115: Fantasia for Piano (2003)

Op. 116: Rondoletto for Piano (2003)

Op. 117: Spice Island for Piano (2003)

Op. 118: Paraphrase on "Aquarela do Brasil" by Ary Barroso for Piano (2003)

Op. 119: Nothing to Lose for Piano (2004)

Op. 120: Piano Sonata No. 14 (2004)

Op. 121: Vanity of Vanities for Piano (2004)

Op. 122: Two Etude-like Trinkets for Piano (2004)

Op. 123: Paraphrase on "Blue Bossa" by Kenny Dorham for Piano (2004)

Op. 124: Suite for Cello Solo (2004)

Op. 125: Sonata for Flute and Piano (2004)

Op. 126: Divertissement in Four Movements for Violin, Cello and Piano (2005)

Op. 127: Piano Sonata No. 15 (Fantasia quasi Sonata) (2005) 
Op. 128: Introduction and Rondo for Piano (2006)

Op. 129: Paraphrase on Dizzy Gillespie's "Manteca" for Two Pianos, Four Hands (2006)

Op. 130: Countermove for Piano (2006)

Op. 131: Piano Sonata No. 16 (2006)

Op. 132: String Quartet No. 2 (2007)

Op. 133: Six Little Preludes for Piano (2007)

Op. 134: Piano Sonata No. 17 (2008)

Op. 135: Piano Sonata No. 18 (2008)

Op. 136: Piano Trio No. 1 for Violin, Cello and Piano (2009)

Op. 137: Good Intention for Piano (2009)

Op. 138: Sleight of Hand for Piano (2009)

Op. 139: Holy Cow for Piano Solo (2009)

Op. 140: Freeway for Piano Solo (2009)

Op. 141: Violin Concerto (2009)

Op. 142: Piano Trio No. 2 for Violin, Cello and Piano (2010)

Op. 143: Piano Sonata No. 19 (2011)

Op. 144: Piano Sonata No. 20 (2011)

Op. 145: Triptych for Two Pianos, Four Hands (2012)

Op. 146: Capriccio for Piano, Four Hands (2012)

Op. 147: Concerto for Piano and orchestra No. 1 (2nd edition) (2012)

Op. 148: Dialogue for Solo Piano (2013)

Op. 149: Etude Courte mais Transcendante pour Piano (2013)

Op. 150: String Quartet "Rondo Frivole" pour quatuor à cordes (2013)

Op. 151: Nobody is Perfect for Piano (2013)

Op. 152: A Pianist in Jeopardy for Piano (2013)

Op. 153: Wandering for Piano (2013)

Op. 154: Piece for String Quartet "The Last Attempt" (2014)

Op. 155: Allegro for Piano Trio (2014)

Op. 156: A Little Duo for Flute \& Cello (2014)

Op. 157: Curiosity for Piano (2015)

Op. 158: Sonatina for Viola and Piano (2015)

Op. 159: Rainy Weather (2015)

Op. 160: Something Else for Piano (2015)

Op. 161: The Moon Rainbow for Piano (2016) 